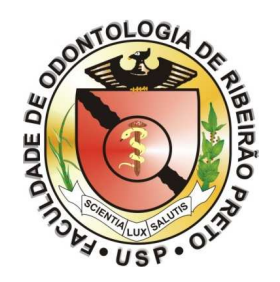

Tatiana Ramirez Cunha

MÉTODO SIMPLIFICADO VERSUS CONVENCIONAL DE CONFECÇÃO DE PRÓTESES TOTAIS PARA APLICAÇÃo NA SAÚdE PÚBLICA. PARTE III: AVALIAÇÃo DA FUNÇÃo MASTIGATÓRIA.

Ribeirão Preto 


\author{
Tatiana Ramirez Cunha
}

\title{
MÉTODO SIMPLIFICADO VERSUS CONVENCIONAL DE CONFECÇÃO DE PRÓTESES TOTAIS PARA APLICAÇÃo NA SAÚdE PÚBLICA. PARTE III: AVALIAÇÃo dA FUnÇÃo MASTigatória.
}

Dissertação apresentada à Faculdade de Odontologia de Ribeirão Preto da Universidade de São Paulo, para a obtenção do título de Mestre no Programa de Reabilitação Oral.

Área de Concentração: Reabilitação Oral

Orientador: Prof. Dr. Valdir Antônio Muglia

\author{
VERSÃO CORRIGIDA \\ A versão original se encontra disponível \\ na Faculdade de Odontologia de \\ Ribeirão Preto - USP
}

Ribeirão Preto 


\section{AUTORIZO A REPRODUÇÃO E DIVULGAÇÃO DO TEOR TOTAL OU PARCIAL DESTE TRABALHO, POR QUALQUER MEIO CONVENCIONAL OU ELETRÔNICO, PARA FINS DE ESTUDO E PESQUISA, DESDE QUE CITADA A FONTE.}

\section{FICHA CATALOGRÁFICA}

Elaborada pela Biblioteca Central do Campus USP - Ribeirão Preto

Cunha, Tatiana Ramirez

Método simplificado versus convencional de confecção de próteses totais para aplicação na saúde pública. Parte III: Avaliação da função mastigatória. Ribeirão Preto, 2011.

151 p. : il. ; $30 \mathrm{~cm}$

Dissertação de Mestrado, apresentada à Faculdade de Odontologia de Ribeirão Preto/USP. Área de concentração: Reabilitação Oral.

Orientador: Muglia, Valdir Antônio

1. Prótese total. 2. Mastigação. 3. Performance mastigatória.

4. Habilidade mastigatória. 5. Ensaio clínico controlado aleatório. 


\section{FOLHA DE APROVAÇÃO}

\section{Tatiana Ramirez Cunha}

MÉTODO SIMPLIFICADO VERSUS CONVENCIONAL DE CONFECÇÃO DE PRÓTESES TOTAIS PARA APLICAÇÃO NA SAÚDE PÚBLICA.

PARTE III: AVALIAÇÃO DA FUNÇÃO MASTIGATÓRIA.

Dissertação apresentada à Faculdade de Odontologia de Ribeirão Preto da Universidade de São Paulo, para a obtenção do título de Mestre.

Área de Concentração: Reabilitação Oral

Data da defesa:

\section{Banca Examinadora}

Prof.(a). Dr.(a).:

Instituição:

Julgamento: Assinatura:

Prof.(a). Dr.(a).:

Instituição:

Julgamento: Assinatura:

Prof.(a). Dr.(a).:

Instituição:

Julgamento: Assinatura: 



\section{Dedicatória}

"Tudo quanto fizerdes, fazei-o de todo o coração, como para o Senhor e não para os homens, cientes de que recebereis do Senhor a recompensa da herança." 

İ Deus, que me capacita e fortalece para a conquista dos meus sonhos.

Obrigada Senhor pela sua infinita misericórdia, pelas suas bênçãos, pela sua bondade e graça. Obrigada por ser meu melhor amigo, aquele que éfiel em toda sua palaura e cuja vontade é boa, perfeita e agradável. Graças a Ti sei que nunca estarei sozinha e que em Ti encontrarei toda vitória.

Zlos meus queridos e amados pais, Givandete Aparecida Xateus Ramirez Cunha e Geraldo Ramirez Cunha, pelo amor, segurança, apoio e compreensão. Dor tornarem meus sonhos também seus e não medirem esforços para investir na minha educação. Dor estarem ao meu lado, ainda que distantes e por serem pais perfeitos, ainda que tenham suas imperfeições. Obrigada, amo vocês!

Zlos meus imnãos, Diego Ramirez Cunha e Leonardo Dedro Ramirez Cunha, pelo amor, incentivo, cuidado, carinho e amizade. Amo vocês!

Alo meu namorado, Marco Aurélio Barbosa de Souza

Pardinho, pelo amor, companheirismo e paciência. Dor acreditar na minha capacidade e me ajudar a adequar nossas vidas à distância e aos nossos sonhos. Delos momentos de conforto, descanso, alegria e força. Zlmo vocề!

À vocês que torcem por mim e sem os quais eu não saberia o que éfelicidade e saudade, e dos quais me orgulho muito.

\section{Obrigada por tudo!}



Algradecimentos Especiais 



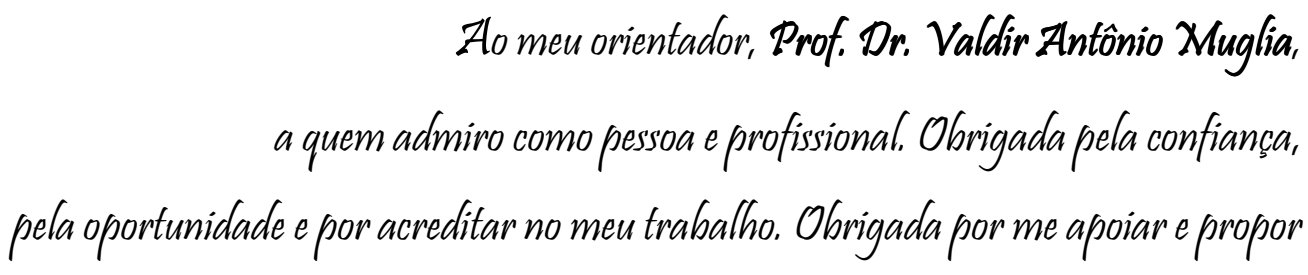
novos desafios que tornaram possivel a realização deste trabalho e engrandeceram a minha formação. Obrigada por ser um exemplo de coragem e dedicação, e pelo carisma e sinceridade que tornaram minha caminhada mais suave. De coração, obrigada por tudo!

\section{Zlo Prof. Dr. Raphael Freitas de Souza, exemplo de competência e amor}

a pesquisa e profissão. Obrigada pela paciência, compreensão, amizade, ensinamentos e pela honra e oportunidade de trabalhar ao seu lado desde a iniciação cientifica. Obrigada por me fazer enxergar novos horizontes e entender ciência com mais maturidade. Obrigada pelo encorajamento e orientação essenciais durante a elaboração, execução e escrita deste trabalho.

Zlos amigos, Xaria Paula Della Vecchia e Rômulo Rocha Regis, pela amizade, carinho, paciência e compreensão. Juntos trabalhamos muito por um objetivo em comum e apesar de toda dificuldade, do cansaço, da falta de tempo e das incertezas, nos mantivemos unidos e passamos por tudo juntos. Delas lágrimas compartilhadas, pelas risadas, pelos problemas e pelas conquistas. Obrigada pela certeza de que poderia contar com vocês, e eu contei, e sou muito grata pela ajuda. Tenho muito orgulho de vocês e torço pelo sucesso de cada um.

Deço que Deus abençõe a vida de todos, e aguardo ansiosa a oportunidade de novos trabalhos.

$$
\text { Muito obrigada! }
$$





\section{Agradecimentos}



Al Universidade de São Daulo, na pessoa do atual reitor, Prof. Dr. João Grandino Rodas, e do vice-reitor, Prof. Dr. Hélio Nogueira da Cruz.

Al Faculdade de Odontologia de Ribeirão Preto da Universidade de São Daulo, na pessoa do atual diretor, Prof. Dr. Osvaldo Luiz Bezzon, e do vice-diretor, Prof. Dr. Waldemar Xallet da Rocha Barros, pelas portas a bertas para meu crescimento profissional desde a graduação.

À Coordenação do Programa de Pós-Graduação em Reabilitação Oral da Faculdade de Odontologia de Ribeirão Preto da Universidade de São Daulo, na pessoa da coordenadora, Prof ". Dra'. Fernanda de Carvalho Danzeri Dires de Souza, e da vice-coordenadora, Prof ${ }^{a}$. Dr ${ }^{a}$. Helena de Freitas Oliveira Paranhos. Obrigada pela confiança, oportunidade de crescimento e participação em um programa tão conceituado, bem direcionado e organizado.

À CADES (Coordenação de Aperfeiçoamento de Pessoal de Nivel Superior), pela bolsa de mestrado concedida.

Zlo Prof. Dr. Wilson Mestriner Junior, pela contribuição na realização desse trabalho, bem como do conhecimento somado. Dela disponibilização do alimento teste utilizado no teste de performance mastigatória do estudo. Dela simpatia e por ser um profissional admirável.

\section{À Profa. Dra. Cláudia Helena Lovato da Silua e Prof ". Dra. Helena de Freitas Oliveira} Paranhos, por toda orientação desde a graduação, pelos ensinamentos na área de prótese total e da vida, pelo encorajamento e pelo carinho.

À Prof'. Dra'. Valéria Oliveira Pagnano de Souza, pela contribuição na minha formação profissional desde a graduação, e pelo carinho e confiança durante a orientação no Programa de Aperfeiçoamento de Ensino. 
Zlos professores do Departamento de Materiais Dentários e Prótese, da Faculdade de Odontologia de Ribeirão Preto da Universidade de São Paulo, por toda contribuição para minha formação como cirurgiã-dentista e Xestre.

Às funcionárias da Secretaria do Programa de Dós-Graduação em Reabilitação Oral da Faculdade de Odontologia de Ribeirão Preto da Universidade de São Paulo, Regiane de C. Tirado Damasceno, Ana Paula Xavier e Fernanda Talita de Freitas, pela ajuda na realização de procedimentos burocráticos. Obrigada pela paciência, simpatia, orientações e torcida de sempre.

Zlos funcionários da Seção de Dós-Graduação da Faculdade de Odontologia de Ribeirão Preto da Universidade de São Paulo, Isabel Cristina Galino Sola, Regiane Cristina Moi Sacilloto e Leandro Marin Silva, pela atenção e disponibilidade.

Zlos funcionários da Clinica I e 99 da Faculdade de Odontologia de Ribeirão Preto da Universidade de São Paulo, José Aparecido Neves do Nascimento, Cleber Barbosa Rita, Vera do Nascimento Scandelai, Silvia Helena Fabris F. Campos, Roberta da Silva, Daniela Steter Martins e Dona Laura, pelo carinho e ajuda durante os atendimentos clinicos desse trabalho.

À funcionária da Seção de Apoio Aldministrativo, Marta Aparecida de Andrade Oliveira, pela ajuda e paciência na organização de triagens, abertura de pastas, arquivamento e orientação em procedimentos burocráticos.

Zlo técnico em prótese dentária e funcionário do Laboratório de Zlpoio Clinico do Departamento de Xateriais Dentários e Prótese, da Faculdade de Odontologia de Ribeirão Preto da Universidade de São Paulo, Júlio Cesar Souza da Xatta, pelo carinho, ajuda, compreensão, orientação e dedicação para a realização dos trabalhos laboratoriais desse estudo. Algradeço pela honra de conhecido-lo e conhecer seu trabalho. Obrigada por tudo. 
Zlos funcionários do Laboratório de Zlpoio Clinico do Departamento de Materiais Dentários e Prótese, da Faculdade de Odontologia de Ribeirão Preto da Universidade de São Paulo, Eduardo Destito e José Zlenrique Loureiro, pela ajuda e alegria nos momentos de trabalhos Laboratoriais.

Zlo técnico do Departamento de Clinica Infantil e Odontologia Preventiva e Social, da Faculdade de Odontologia de Ribeirão Dreto da Universidade de São Daulo, Dorival Gaaspar, pela paciência, simpatia e disposição na análise colorimétrica das biocápsulas e ajuda no entendimento dessa metodologia.

Its amigas e irmãs, Vanessa Xaria Fagundes Leite, Xaressa Xorais de Oliveira e Xayra Dorigan de Xacedo, pela convivência diária, por transformar nossa casa em um lar, por sermos uma familia, ainda que longe das nossas, pela saudade compartilhada, pelas alegrias e tristezas, pela paciência, carinho e união. Dor nunca estar sozinha e sempre ter palauras de aconchego e direçãa. Almo vocês!

À amiga, Viviane de Cássia Ofiveira, técnica do laboratório de Reabilitação Oral, da Faculdade de Odontologia de Ribeirão Preto da Universidade de São Paulo, que em pouco tempo de convivência conquistou minha amizade e admiração pela pessoa maravilhosa, competente e dedicada que é. Obrigada pelas palauras nos momentos dificies, por viver comigo os momentos de alegria, e por fazer acontecer o que fosse preciso. Obrigada pela ajuda e pela amizade.

Zlos meus colegas e amigos da pós-graduação, Carla, Juliana, Milena, Lurdes, Nathália, Isabela, Karina, Brahim, Danilo, Marcelo, Rafael, Lourenço, e Camilo. Obrigada pela convivência maravilhosa, pelos momentos inesquecíveis, por todo apoio, companheirismo e amizade. Torço por cada um de vocês. 
Its queridas amigas Cristiane Bataglion, Daula Dariana, Glauce Crivelaro do Nascimento, Cintia Piccolo, Rayana Bighetti, Xichelle Yamamoto, Xaria Beatriz, Amanda Peracini e Ingrid Xachado de Andrade, pelos bons momentos, amizade, força e companheirismo.

À minha tia Elizabeth e minha prima Daniele pelas orações, amor, carinho e amizade. Almo vocês e toda nossa familia. Sinto a falta de vocềs sempre.

Zlos meus familiares, pela torcida e carinho.

Á toda familia do meu namorado, pelo apoio, incentivo e carinho. Dor terem somado momentos inesquecíveis à minha vida e me "adotado" para sua familia. Obrigada pela torcida. Almo vocês.

À Rosangela Paiva Spagnole Xarcos André Spagnol, pelas orações, orientações, paciência, carinho, alegria, e toda história que temos vivido na vida da igreja. Obrigada tio Xarcos pela confiança e por ter me dado a oportunidade do primeiro emprego como cirurgiá-dentista. Obrigada tia Rồ pelo amor incondicional. Almo vocês e sua familia.

Zlos irmãos e irmãs da Igreja em Barretos, por tantos anos de caminhada juntos, pelas orações que me fortaleceram e pelos desejos de sucesso. Almo vocês! Que continuemos juntos e sempre fazendo a vontade do nosso Senhor Jesus.

À Jéssica Curi Ferreira e Sara Xurra, amigas e irmãs fiés, e à familia de cada uma, obrigada pelo carinho e pela torcida. Sinto saudades. Almo vocês!

Zlos pacientes que participaram dessa pesquisa, agradeço pela paciência e pelo bom convívio. Obrigada pela boa vontade, aprendizado e presentes. Obrigada pela compreensão e colaboração. Foi muito gratificante o tempo que convivemos. 
Resumo 

CUNHA, T. R. Método simplificado versus convencional de confecção de próteses totais para aplicação na saúde pública. Parte III: Avaliação da função mastigatória. Ribeirão Preto, 2011. 151p. Dissertação (Mestrado em Reabilitação Oral). Faculdade de Odontologia de Ribeirão Preto, Universidade de São Paulo.

\section{RESUMO}

Métodos convencionais para a confecção de próteses totais envolvem uma série de procedimentos técnicos complexos. No entanto, métodos simplificados podem ser tão efetivos quanto os convencionais, porém é importante que a mastigação não sofra influências deletérias. Assim, o objetivo deste estudo foi comparar um método simplificado de confecção de próteses totais a outro convencional, tendo como variáveis a performance e a habilidade mastigatórias. A amostra foi formada por pacientes desdentados solicitando tratamento com próteses totais duplas. Os participantes foram divididos aleatoriamente em dois grupos: Grupo $S(\mathrm{n}=17)$, que recebeu próteses confeccionadas por um método simplificado, e Grupo $C$ $(\mathrm{n}=18)$, que recebeu próteses confeccionadas de forma convencional. Após 3 meses da instalação das próteses, a performance mastigatória foi avaliada por um método colorimétrico, utilizando duas "biocápsulas" como alimento teste, após 20 e 40 ciclos mastigatórios, e a habilidade mastigatória dos participantes foi avaliada por meio de questionário (Questionário HM) e escala visual analógica (EVA). Foi feita referência dos resultados a um grupo de participantes dentados, Grupo $D N(\mathrm{n}=17)$. Os três grupos foram comparados por meio de testes adequados à distribuição dos dados $(\alpha=5 \%)$. A performance mastigatória foi similar nos grupos $C$ e $S$ e representou $31 \%$ daquela encontrada no grupo $D N$. A habilidade mastigatória foi semelhante para $S$ e $C$ independente do método de análise, sendo que algumas questões do questionário HM, analisadas isoladamente, tiveram maior ocorrência de respostas favoráveis para o primeiro. Conclui-se que métodos simplificados de confecção de próteses totais são capazes de reabilitar a mastigação de maneira comparável ao método convencional, tanto fisiologicamente como segundo as percepções do paciente.

Palavras-chave: Prótese total; mastigação; performance mastigatória; habilidade mastigatória; ensaio clínico controlado aleatório. 

Abstract 

CUNHA, T. R. Simplified versus conventional method for complete denture fabrication for application in public health. Part III: Assessment of masticatory function. Ribeirão Preto, 2011. 151p. Dissertação (Mestrado em Reabilitação Oral). Faculdade de Odontologia de Ribeirão Preto, Universidade de São Paulo.

\begin{abstract}
Complete denture fabrication involves a series of complex technical procedures. Nevertheless, simplified methods may be as effective as conventional ones and mastication should not be further impaired. Therefore, this study aimed to compare a simplified method and a conventional protocol for complete denture fabrication, in terms of masticatory performance and ability. A sample was formed by edentulous patients requesting treatment with maxillary and mandibular complete dentures. Participants were randomly allocated into two groups: Group $S(\mathrm{n}=17)$, which received dentures fabricated by a simplified method, and Group $C$ $(n=18)$, which received conventionally fabricated dentures. After 3 months following insertion, masticatory performance was evaluated by means of a colorimetric assay based on chewing two capsules as test food during 20 and 40 cycles. Masticatory ability was assessed by means of a questionnaire (HM) with dichotomous answers and a single question answered by means of a visual analogue scale (VAS). A third group $(D N, \mathrm{n}=17)$ formed by dentate volunteers served as an external comparator. Results for the three groups were compared by means of statistical tests suitable for the distribution of data $(\alpha=5 \%)$. Groups $C$ and $S$ presented similar masticatory performance which corresponded to $31 \%$ of group $D N$. Results for masticatory ability showed similarity between $S$ and $C$, regardless of the assessment method, though some isolate items of the HM questionnaire showed more favorable results for the first group. It can be concluded that simplified methods for complete denture fabrication are able to restore masticatory function to a level comparable to the conventional protocol, physiologically and according to patient perceptions.
\end{abstract}

Keywords: Complete denture; mastication; masticatory performance; masticatory ability; randomized controlled trial. 

Sumário 



\section{Resumo}

\section{Abstract}

1. Introdução.

1.1. Edentulismo total

1.2. Tratamento com próteses totais

1.3. Técnicas simplificadas para a confecção das próteses totais _ 35

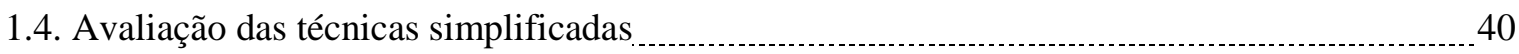

1.4.1. Função mastigatória

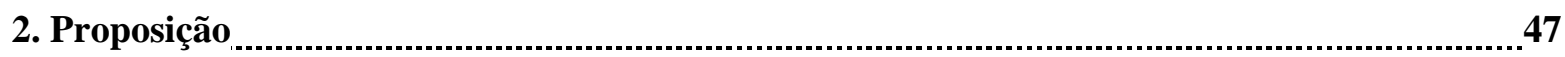

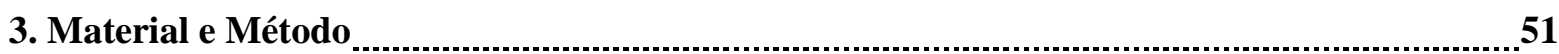

3.1. Material 53

3.1.1. Material de consumo

3.1.2. Material permanente $\ldots$

3.2. Método

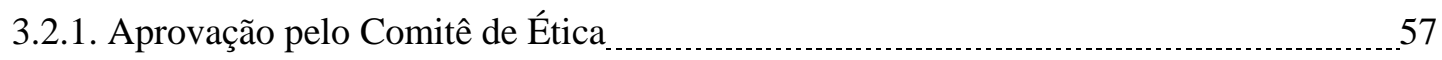

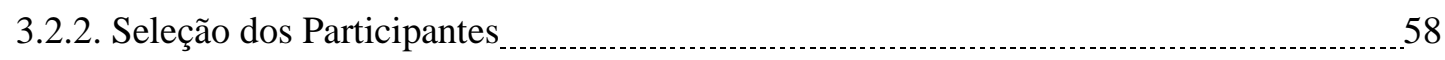

3.2.3. Tratamentos 60

3.2.3.1. Técnica Convencional

3.2.3.2. Técnica Simplificada 72

3.2.4. Alocação dos participantes nos grupos

3.2.5. Variáveis de desfecho 74

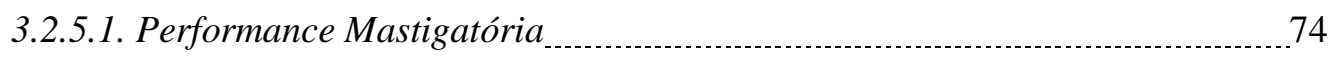

3.2.5.2. Habilidade Mastigatória 79

3.2.6. Análise dos resultados

3.2.6.1. Performance mastigatória 80

3.2.6.2. Habilidade mastigatória

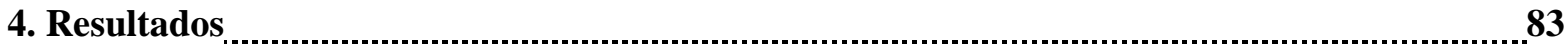

4.1. Amostra 85

4.2. Performance mastigatória $\quad 88$

4.3. Habilidade mastigatória

5. Discussão

5.1. Desenho do estudo

5.2. Protocolo clínico 102

5.3. Avaliação da função mastigatória

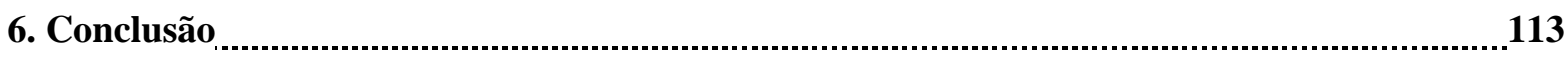

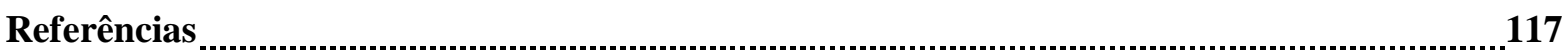

Anexos

Apêndice 

1. Introdução 



\subsection{Edentulismo total}

O edentulismo total é um problema importante de saúde pública, particularmente entre os idosos (Cooper, 2009; Felton, 2009), o qual, segundo a Organização Mundial de Saúde (OMS) é resultado de um sistema de saúde pobre e afeta consideravelmente o padrão de saúde oral e geral. Embora a literatura relate o declínio na prevalência dessa condição em países que possuem dados epidemiológicos confiáveis, o número de indivíduos desdentados necessitando de tratamento reabilitador é grande, e essa necessidade permanecerá considerável por muitas décadas (Anastassiadou et al., 2002; Douglass, 2002; Kawai et al., 2005; Müller et al., 2007; Carlsson e Omar, 2010).

Apesar da expectativa de vida no Brasil ter aumentado, sendo atualmente de 73,1 anos (IBGE, 2010), 63,1\% e 37,5\% da população entre 65 e 74 anos de idade utiliza próteses totais nos arcos maxilar e mandibular, respectivamente, e a porcentagem dessa população que necessita de próteses totais em um ou dois arcos é estimada em 38,3\%, respectivamente (Ministério da Saúde, 2011). Além disso, estudos têm demonstrado que o edentulismo acomete mais ostensivamente aqueles indivíduos com piores condições socio-econômicas, sendo a renda fortemente associada com essa condição (U.S. Department of Health and Human Services, 2000; Petersen et al., 2005). Assim, o aspecto epidemiológico demonstra a necessidade da utilização de métodos com boa relação custo-efetividade para o controle da alta demanda pelo tratamento protético.

\subsection{Tratamento com próteses totais}

A forma mais comum de reabilitação dos pacientes desdentados totais é a confecção de próteses totais removíveis, as quais substituem os dentes bem como os tecidos perdidos 
pelo processo de reabsorção alveolar contínua. Entretanto, não é incomum ouvirmos relatos por parte dos usuários desse tipo de prótese, da dificuldade em mastigar certos alimentos mais duros e resistentes (Wayler e Chauncey, 1983; Brodeur et al., 1993; Andrade e Seixas, 2006), bem como da falta de segurança com este tipo de reabilitação, principalmente quando se trata do aparelho mandibular.

Como possível alternativa ao tratamento do edentulismo, a literatura descreve amplamente a aplicação dos implantes osseointegráveis. O sucesso da osseointegração nos últimos 30 anos permitiu que pacientes desdentados totais pudessem ser reabilitados com próteses suportadas e/ou retidas por implantes, as quais promovem melhoria considerável das suas funções orais, da satisfação e da qualidade de vida associada à saúde bucal (Feine et al., 2002; Thomasson et al., 2003; Carlsson, 2006; Cooper, 2009). Entretanto, nem todos os pacientes aceitam ou podem ser submetidos a procedimentos cirúrgicos de instalação dos implantes e o alto custo associado restringe o acesso a esse tipo de tratamento, tornando, assim, as próteses totais convencionais a única possibilidade para a grande maioria desses indivíduos (MacEntee e Walton, 1998; Owen, 2004; Takanashi et al., 2004; Heydecke et al., 2005; Carlsson, 2006; Heydecke et al., 2008; Cooper, 2009; Carlsson e Omar, 2010).

Os métodos tradicionais para confecção de próteses totais, os quais exigem uma ampla seqüência de procedimentos clínicos e laboratoriais (Rahn e Heartwell, 1993; The British Society for the Study of Prosthetic Dentistry, 1996; Zarb et al., 2006a), têm sido aceitos e ensinados pela maioria das faculdades de Odontologia no Brasil (Souza et al., 2002) e na América do Norte (Petropoulos e Rashedi, 2003; Petrie et al., 2005), sendo enfatizada a necessidade da qualidade técnica na realização desses procedimentos para que este seja bem sucedido (Carlsson, 2006, 2009). Uma seqüência típica de procedimentos clínicos empregados na confecção de um par de próteses totais compreende: 
a. moldagens iniciais dos rebordos desdentados visando à obtenção de um par de modelos e posterior confecção de moldeiras individuais;

b. moldagens funcionais com as referidas moldeiras individuais, empregando pressão seletiva e resultando na obtenção de modelos de trabalho e, posteriormente, placas articulares;

c. montagem do modelo maxilar em articulador conforme o uso de um arco facial;

d. modificação das placas articulares e posterior montagem do modelo mandibular em articulador, de acordo com planos de orientação e registro das relações intermaxilares;

e. uma ou mais provas clínicas das placas com dentes artificiais montados;

f. instalação e ajuste das próteses. A remontagem das próteses em articulador é recomendada antes ou depois da instalação, a fim de se corrigir discrepâncias oclusais. Entretanto, a literatura levanta questionamentos sobre a real necessidade desses procedimentos, apontando a sua não utilização pela maioria dos clínicos, em alguns países investigados, da forma como são ensinados, os quais selecionam métodos mais simples para a obtenção desse tipo de prótese (Silversin et al.,1978; Gauthier et al., 1992; Hyde e McCord, 1999; Clarck et al., 2001; Wang et al., 2008; Carlsson, 2009). Também, não há evidência que próteses totais construídas por técnicas complexas são mais utilizadas e apreciadas pelos pacientes em comparação com as construídas por técnicas mais simples (Critchlowa e Ellis, 2010).

\subsection{Técnicas simplificadas para a confecção das próteses totais}

Algumas abordagens têm sido descritas no intuito de simplificar, modificar ou eliminar etapas clínicas e laboratoriais para a fabricação de próteses totais, buscando avaliar a qualidade das mesmas bem como os relatos dos participantes. É dedutível que protocolos 
simplificados permitiriam um maior número de procedimentos com o mesmo recurso disponível. Owen (2004) discute a necessidade do estabelecimento de protocolos mínimos que estejam em conformidade com princípios protéticos e biofuncionais, os quais levariam à obtenção de próteses capazes de restabelecer efetivamente a função mastigatória, estética e qualidade de vida. De acordo com o autor, isso aconteceria por meio de tecnologias apropriadas, baseadas em materiais e métodos de baixo custo e boa efetividade, com adequado controle de qualidade para que os pacientes não precisem se adaptar a próteses insatisfatórias.

A literatura relata a confecção de bases de prova diretamente sobre modelos de estudo obtidos a partir de moldes de alginato feito com moldeiras de estoque, ou seja, sem uma segunda moldagem e nem utilizando moldeiras individuais e materiais de moldagem de maior precisão (Duncan e Taylor, 2001, 2004). Outras abordagens simplificadas incluem a montagem dos modelos em articulador sem o uso do arco facial (Nascimento et al., 2004; Heydecke et al., 2007), transferência direta do molde funcional para o articulador semiajustável (Giannotti et al., 2007), realização de moldagem funcional e registro das relações intermaxilares em uma única sessão, onde a moldeira individual e a placa articular consistem de um dispositivo único (Ansari, 1997), substituição de materiais tradicionais para simplificação da moldagem funcional (Ulbrich e Franco, 2004), esquemas oclusais alternativos como a oclusão lingualizada (Sutton et al., 2005), e as técnicas baseadas na duplicação de próteses em uso (Davis e Watson, 1993; Clarck et al., 2004; Ellis et al., 2007; Rodrigues e Morgano, 2007). Entretanto, os trabalhos acima se basearam em relatos de caso ou estudos retrospectivos, tornando a avaliação científica desses procedimentos empírica, e não baseada em evidência (McCord, 2009). 
As abordagens baseadas em evidência têm tido um impacto emergente na prática clínica, sendo os ensaios clínicos controlados aleatorizados e as revisões sistemáticas da literatura os tipos de estudo mais indicados para responder questões controversas e estabelecer conclusões confiáveis sobre a efetividade de alternativas terapêuticas (Anderson, 2000; Sutherland, 2001; Carlsson, 2009). Assim, em outubro de 2011, foi realizada uma busca sistemática na base de dados PubMed por relatos dessa natureza, que fornecessem informações de alto nível de evidência referentes à eficácia de métodos simplificados para a confecção de próteses totais. Foi utilizada a seguinte estratégia de busca:

(overdenture or ((removable or complete) and denture)) and ((techni* or fabricat* or simpl $^{*}$ or tradition*) or (impression* or occlus* or (facebow or face-bow) or remount* or adjust*)) and $((($ randomized controlled trial $[\mathrm{pt}])$ or (controlled clinical trial $[\mathrm{pt}])$ or (randomized [tiab]) or (placebo [tiab]) or (drug theraas py [sh]) or (randomly [tiab]) or (trial [tiab]) or (groups [tiab])) and (humans [mh])).

Dentre os 490 títulos e resumos apresentados, apenas três relatos do tipo ensaios clínicos prospectivos randomizados controlados (Kawai et al., 2005; Heydecke et al., 2008; Kawai et al., 2010) e um estudo cruzado (Nascimento et al., 2004) tentaram avaliar métodos simplificados para a confecção de próteses totais e compará-los aos métodos tradicionais. É possível também citar um estudo mais antigo, cujo primeiro relato foi publicado em 1969, que comparou duas sequiências técnicas com diferente complexidade com acompanhamentos de até 20 anos (Hickey et al., 1969).

Hickey, et al. (1969) propuseram uma técnica alternativa de confecção de prótese total onde os modelos de trabalho eram montados em articulador de forma arbitrária, ou seja, sem utilização de arco facial ou registros oclusais excursivos, oclusão estabelecida sem seguir o esquema balanceado bilateral e com ajustes oclusais feitos somente na boca. Foram reabilitados 64 pacientes, 32 em cada grupo, e avaliações feitas anualmente, por um período 
de 5 anos. Por meio de cefalometria, foi investigado o padrão de reabsorção óssea mandibular e maxilar, diminuição da altura facial, rotação mandibular e migração das bases das protéticas, não sendo encontrada diferença significante entre as técnicas, revelando um padrão de reabsorção óssea semelhante nos dois grupos (Nicol et al., 1979). No intuito de investigar se a técnica pela qual as próteses foram confeccionadas teve efeito na performance das mesmas e que pudesse ser determinado clinicamente, foi realizada uma avaliação da satisfação do paciente, onde não foi encontrada diferenças significantes entre os dois grupos (Ellinger et al., 1979). Foi realizada uma análise microscópica baseada nas características citológicas do tecido da mucosa bucal por meio de esfregaço em 4 diferentes regiões da zona de suporte da prótese, e nenhuma diferença foi encontrada entre os grupos (Sabes et al., 1981). Também foi investigada a habilidade mastigatória entre os grupos, sendo encontrada diferença na habilidade ao longo dos anos, mas não entre os grupos (Wesley et al., 1984). Após 10 anos, foi avaliada a topografia do rebordo alveolar nos dois grupos por meio da análise dos modelos de estudo e não foram encontradas diferenças significantes para as variáveis contorno e largura do arco (Brehm e Abadi, 1980). Passados 20 anos da instalação das próteses, os participantes foram novamente recrutados para avaliação, dos quais 26 ainda utilizavam suas próteses. As mesmas foram classificadas por 5 diferentes dentistas e relatadas por 26 pacientes como clinicamente aceitáveis em termos de adaptação, ajuste e saúde dos tecidos (Ellinger et al., 1989).

Nascimento, et al. (2004), por meio de um ensaio clínico cruzado, compararam duas técnicas de confecção de próteses totais, com e sem o uso do arco facial, e concluíram que a técnica que evitou o uso do arco facial apresentou melhores resultados em relação a estética, conforto e estabilidade das próteses segundo a aceitação dos participantes e que uma oclusão balanceada foi conseguida com o uso de ambas as técnicas, podendo a técnica sem o uso do arco facial ser uma alternativa para obter próteses totais adequadas. 
Kawai, et al. (2005), por meio de um ensaio clínico de grupos paralelos, compararam um método simplificado a um convencional para a confecção de próteses totais. Os participantes tratados pela técnica convencional receberam moldagem funcional com moldeira individual, registro com arco-facial, montagem e remontagem em articulador semi-ajustável. Uma única moldagem com moldeiras de estoque foi realizada nos participantes do grupo tratado pela técnica simplificada, os quais não receberam registro com arco facial e a montagem dos modelos de trabalho foi realizada em articulador não ajustável, sem procedimento posterior de remontagem. Os autores não observaram diferença significante entre os grupos quanto à satisfação dos pacientes em relação às próteses e a qualidade das mesmas, e apontam o considerável potencial educacional e implicações econômicas desses resultados. Já em 2010, esses autores publicaram os resultados relativos ao ensaio clínico citado anteriormente, onde investigaram os custos diretos envolvidos na fabricação das próteses por meio de cada uma das técnicas, e foi observado que o custo médio para as próteses fabricadas pelo método convencional foi significativamente maior, bem como o tempo clínico gasto nesse tratamento.

Por sua vez, Heydecke, et al. (2008) estudaram a eficácia relativa de próteses totais confeccionadas de acordo com dois conceitos oclusais, seguindo um estudo cruzado (crossover). O método mais complexo baseou-se no conceito de Gerber, que indica o uso do arco facial com registros da inclinação condilar, traçado do arco gótico e oclusão balanceada bilateral. A técnica simplificada obedeceu ao conceito de Gysi - sem o arco facial, técnica guiada para o registro da oclusão central e desoclusão pelos caninos. Assim como no estudo anterior, a satisfação dos pacientes foi semelhante para ambas as técnicas de confecção.

Com base nos aspectos levantados acima, observa-se que a evidência atual levanta dúvida quanto à relevância de alguns procedimentos envolvidos na confecção de próteses totais (Carlsson, 2006, 2009, 2010). Apesar dos estudos iniciados por Hickey, et al. (1969) e 
dos estudos mais recentes previamente citados (Kawai et al., 2005; Heydecke et al., 2008; Kawai et al., 2010), os quais compararam técnica mais simples às tradicionalmente utilizadas, a evidência em relação aos melhores métodos para a confecção de próteses totais é limitada (Harwood, 2008). Assim, dados de estudos adicionais poderiam ser combinados por meio de revisão sistemática e meta-análise, aumentando o nível de evidência e possibilidade de extrapolação dos resultados. Além disso, abordagens mais pragmáticas poderiam ser utilizadas, como o uso de pacientes do sistema de saúde pública como participantes de pesquisa e operadores mais parecidos com aqueles que tratam esses pacientes, nem sempre um dentista sênior como nos estudos anteriores. Assim, os resultados poderiam dar evidência à utilização de técnicas que melhorem o acesso dos pacientes desdentados ao tratamento com próteses totais, já que este poderia ser feito com menor custo e complexidade, bem como influenciar o currículo atual de ensino da prótese total nos cursos de graduação e pósgraduação ou, por outro lado, podem reforçar a importância dos procedimentos técnicos convencionalmente propostos para a confecção dessa modalidade protética.

\subsection{Avaliação das técnicas simplificadas}

A avaliação da efetividade de técnicas simplificadas pode ser realizada por meio da abordagem clínico/objetiva de fatores relacionados diretamente à qualidade do aparelho protético como espaço funcional de pronúncia, oclusão, articulação, retenção e estabilidade (Anastassiadou et al., 2002; De Lucena et al., 2011), e seu relacionamento com as estruturas da cavidade bucal dos usuários. Dentre os fatores pertinentes ao sucesso da reabilitação com próteses totais, deve-se considerar a avaliação da função mastigatória (Awad e Feine, 1998; Celebić e Knezović-Zlatarić, 2003; Prado et al., 2006), visto que o tratamento odontológico tem como principal objetivo preservar e/ou restabelecer a função oral, especialmente a 
mastigação (Carlsson, 1984; Wesley et al., 1984; Budtz-Jorgensen et al., 2000; Ikebe et al., 2006; Prado et al., 2006; Ikebe et al., 2007; Mendonça et al., 2009; De Lucena et al., 2011), que é considerada uma das funções mais importantes do sistema estomatognático (Santos et al., 2006; Borges, 2007; Goiato et al., 2008).

\subsubsection{Função mastigatória}

A mastigação é definida como um grupo de fenômenos estomatognáticos projetados para o processamento mecânico de alimentos, que inclui moagem e quebra do alimento em partículas menores para serem deglutidas (Douglas, 2004a). É, portanto, o início do fenômeno físico-químico da digestão, cujos passos seguintes serão tanto mais eficazes quanto mais completa for a mastigação (Borges, 2007).

A função mastigatória envolve um processo complexo e dinâmico, controlado pelo sistema nervoso central e periférico (Helkimo et al., 1978; Hirano et al., 2004; De Lucena et al., 2011). Apesar de a mastigação obedecer a um padrão básico de movimentos rítmicos, esse padrão é modificado por um feedback sensorial iniciado por aferências periféricas, originadas em uma variedade de receptores intraorais, articulares e musculares, e que o adaptam às características dos alimentos. Também há uma importante influência das aferências centrais, que controlam os músculos inseridos na mandíbula nas fases da mastigação (Lund, 1991; Douglas, 2004b). Quando os dentes são perdidos ocorre um prejuízo sensorial e motor como consequiência da perda dos receptores periodontais (Hirano et al., 2004; Van Der Bilt, 2011). Em outras palavras, perdem-se importantes aferências periféricas envolvidas no controle da motricidade mandibular, bem como na mastigação, manipulação e apreensão de alimentos entre os dentes (Trulsson, 2006, 2007).

A função mastigatória está diretamente relacionada às condições da dentição (Prado et al., 2006), sendo que o número de dentes presentes na cavidade oral (Ikebe et al., 2011) e 
principalmente a quantidade de pares de dentes naturais em oclusão (Helkimo et al., 1978; Wayler e Chauncey, 1983) são relacionados à sua manutenção (Carlsson, 1984; BudtzJorgensen et al., 2000; Ikebe et al., 2006; Ikebe et al., 2011). Entretanto, a função mastigatória é dependente de muitos fatores e não pode ser predita apenas pelo estado da dentição (Akeel et al., 1992). Pacientes desdentados totais, além das dificuldades relacionadas à fonética, deglutição, estética, convívio social e conforto psicológico, apresentam ainda uma condição de quase incapacitação total da mastigação, podendo ser considerados inválidos orais (Carlsson, 1984; Van Der Bilt, 2011). Próteses totais removíveis, mesmo com retenção e estabilidade adequadas, não devolvem aos indivíduos uma mastigação satisfatória quando comparados a pessoas com dentição natural (Manly e Braley, 1950; Kapur e Soman, 1964; Bates et al., 1976; Helkimo et al., 1978; Wayler e Chauncey, 1983; Carlsson, 1984), o que muitas vezes leva a uma alteração da dieta pela eliminação de alimentos ricos em fibras, frutas e verduras cruas, e opção por alimentos mais macios e fáceis de serem mastigados, o que pode levar ao aparecimento de desordens gastrintestinais (Brodeur et al., 1993) e afetar diretamente a saúde geral e qualidade de vida desses indivíduos (BudtzJorgensen et al., 2000). Assim, a manutenção da função mastigatória tem importância especial em pacientes portadores de prótese total devido às limitações inerentes a esse tipo de tratamento (Boretti et al., 1995; Farias Neto et al., 2010).

A função mastigatória pode ser avaliada por meio de testes de eficiência e/ou performance mastigatórias, que medem a capacidade dos indivíduos em reduzir os alimentos a pequenas partículas, e por meio de testes de habilidade mastigatória, relacionados à percepção do próprio individuo (Bates et al., 1976). Desse modo, é importante a definição dos termos que serão utilizados nesta pesquisa, visto que termos como habilidade mastigatória, eficiência mastigatória e performance mastigatória são utilizados de maneira intercambiável e como se fossem sinônimos para designar função mastigatória (Kapur e Soman, 1964; Carlsson, 1984; Boretti et al., 1995). A fim de padronizar os termos utilizados, este estudo considerará a 
performance mastigatória como sendo a concentração de corante liberado após mastigação e fragmentação das partículas do alimento teste (Käyser e van der Hoeven, 1977; Gunne, 1983; Nakasima et al., 1989), diferentemente da definição clássica de performance mastigatória como sendo a distribuição do tamanho das partículas de alimento mastigadas após um dado número de ciclos mastigatórios, e a eficiência mastigatória como sendo o número de ciclos mastigatórios requeridos para reduzir o alimento a um determinado tamanho de partícula (Bates et al., 1976). Por fim, a habilidade mastigatória foi definida como a própria avaliação do indivíduo de sua função mastigatória (Carlsson, 1984).

Para a realização dos testes de performance e eficiência mastigatória, não existe um consenso a respeito das metodologias para análise dos fragmentos dos alimentos - naturais ou artificiais - utilizadas. O método mais utilizado e ainda considerado viável é o das peneiras (tamises) (Santos et al., 2006). De maneira geral este método requer que o paciente mastigue uma quantidade estipulada do alimento teste, por um número determinado de ciclos mastigatórios, de tempo, ou até sentir que está pronto para deglutir. As partículas do alimento são então recolhidas e passam através de uma ou uma série de peneiras de tamanho de malhas decrescentes. Essencialmente, uma mastigação mais eficiente será aquela que produzir maior quantidade de fragmentação do alimento que irá passar pela malha mais fina, e o material coletado poderá ser quantificado por volume, peso e no caso de múltiplas peneiras, pela utilização de fórmulas para o cálculo do tamanho médio das partículas mastigadas e sua distribuição. No entanto, há divergências quanto à validade deste método devido à complexidade dos procedimentos, variações dos materiais-teste utilizados e à imprecisão das metodologias empregadas, pelo fato de ser associado à perda de parte do alimento, seja durante o processamento ou deglutição de pequenos pedaços, como também pela dissolução na saliva ou água (Santos et al., 2006).

Outros métodos, como a análise digital das imagens do alimento fragmentado (Wilding, 1993) ou o escaneamento óptico do material triturado (van der Bilt et al., 1993), são métodos 
mais simples, precisos, permitem maior rapidez da análise, têm melhor reprodutibilidade e são mais higiênicos (Boretti et al., 1995), entretanto, são mais onerosos e de aquisição mais difícil.

Existe uma variedade de alimentos naturais e artificiais que podem ser utilizados, embora também não exista um consenso sobre o material ideal para a realização dos referidos testes. Dentre os alimentos naturais mais utilizados estão a cenoura (Wayler e Chauncey, 1983), o amendoim (Manly e Braley, 1950), e as amêndoas (Brodeur et al., 1993). Assim como os alimentos naturais, muitos alimentos artificiais têm sido descritos, porém os mais utilizados são o Optocal (Silveira, 2005; Prado et al., 2006; Borges, 2007) e o Optosil (Edlund e Lamm, 1980; Olthoff et al., 1984). Os alimentos artificiais como estes tem sido relacionados à melhor reprodução quanto à forma e textura, ao passo que os alimentos naturais, embora possuam a grande vantagem de serem consumidos no dia-a-dia, de modo que as pessoas possam estar habituadas a eles, podem ter sua consistência alterada devido às variações sazonais e geográficas (Olthoff et al., 1984). No Brasil, materiais que não envolvem perda de parte do alimento por ingestão ou que correspondem a variações típicas de alimentos naturais têm sido desenvolvidos, como cápsulas contendo grânulos de violeta de fucsina (Santos et al., 2006) e esferas (Moreschi, 2006). O grau de fragmentação destes materiais é determinado em função da liberação de fucsina e esta é analisada posteriormente por meio de colorimetria (Mestriner Junior et al., 2005; Farias Neto et al., 2010; Borges, 2011).

A vantagem dessa cápsula é que, após a realização dos ciclos mastigatórios pelo paciente, as mesmas não são rasgadas e o material é totalmente removido da boca, sem risco de deglutição ou dissolução pela saliva, e seu processamento laboratorial é rápido e eficaz, permitindo, assim, uma análise da eficiência e performance mastigatórias do paciente, sendo este método considerado confiável, sensível e reprodutível (Santos et al., 2006).

Por sua vez, os testes para avaliação da habilidade mastigatória são realizados geralmente por meio de questionários, contendo questões gerais relacionadas com a função mastigatória, questões específicas relacionadas aos tipos de alimentos que são difíceis para 
mastigar, e questões relacionadas ao grau de dificuldade de mastigação de certos alimentos (Slagter et al., 1992a; Geertman et al., 1999; Awad et al., 2003).

Tendo em vista que é comum na prática clínica haver desacordo em relação à opinião do cirurgião-dentista e a auto-percepção do paciente portador de próteses dentárias (De Lucena et al., 2011), a associação de testes baseados nos dois pontos de vista, avaliação pelo clínico/pesquisador e pelo indivíduo, tem sido considerada de extrema importância para avaliação da função mastigatória (Boretti et al., 1995), embora nem sempre sejam encontradas correlações entre ambos (Gunne et al., 1982; Silveira, 2005; Prado et al., 2006).

Devido à relevância dos parâmetros relacionados à mastigação, é de grande importância que eles não sofram influências deletérias de métodos simplificados para a confecção de próteses totais. O único trabalho clínico controlado realizado com o objetivo de comparar a função mastigatória de usuários de próteses totais confeccionadas por meio de métodos simplificados em comparação a outro mais sofisticado não encontrou diferença significante entre os dois grupos (Wesley et al., 1984). Porém, o método simplificado daquele estudo apresenta relativa complexidade e pode ser comparado àqueles preconizados pela maioria das faculdades de odontologia de nosso país e dos EUA (Souza et al., 2002; Petropoulos e Rashedi, 2003; Petrie et al. 2005). Esse tipo de método fica mais extenso que aqueles considerados pelo estudo de Kawai, et al. $(2005,2010)$ e utilizados por diversos dentistas (Silversin et al.,1978; Hyde e McCord, 1999; Wang et al., 2008; Carlsson, 2009). Portanto, a literatura aponta a necessidade de mais evidências científicas em relação a essa variável nesse contexto, a fim de determinar se protocolos com número mínimo de sessões podem reabilitar a função mastigatória dos pacientes desdentados totais de maneira similar aos padrões academicamente aceitos. Esse tipo de informação poderá trazer grande impacto à forma com que esses pacientes são tratados. 
Ainda, segundo Cooper (2009), o edentulismo permanecerá prevalente e o seu manejo é benéfico para a população afetada. Por outro lado, tem sido afirmado há muitos anos que a promoção de cuidados efetivos sem se considerar os custos envolvidos pode levar a um uso ineficiente de fundos públicos ou privados destinados à saúde, e que esse tipo de gerenciamento pode ser prejudicial à sociedade (Williams, 1987; Drummond et al., 2005). Um exemplo de prejuízo para a realidade brasileira seria uma menor capacidade das clínicas odontológicas vinculadas ao Sistema Único de Saúde (SUS) em atender à demanda da população por próteses totais. Portanto, existe uma necessidade de se estudar novos materiais, técnicas e modelos clínicos para a confecção de aparelhos protéticos de qualidade, com boa relação custo-benefício (Cooper, 2009). Ainda, acreditamos que o potencial benefício desse tipo de pesquisa não seja somente regional, já que seria válido para outros países, tanto desenvolvidos quanto em desenvolvimento.

Sendo assim, nos propomos a investigar uma técnica simplificada para a obtenção de próteses totais, em comparação a métodos convencionais, onde avaliamos a performance e habilidade mastigatórias de usuários de próteses totais, por meio de um ensaio clínico controlado aleatorizado. Este estudo foi realizado como a $3^{\text {a }}$ parte de uma proposta maior (CAAE 0061.0.138.000-10, identificador NCT01230320 - clinicaltrials.gov), na qual avaliamos outras variáveis de desfecho, como custos diretos e indiretos envolvidos na confecção das próteses, padrão de ajustes necessários após instalação, qualidade dos aparelhos protéticos confeccionados, satisfação dos usuários com suas próteses, bem como a qualidade de vida relacionada à saúde bucal. Exclusivamente nessa parte do estudo, um grupo de voluntários dentados foi empregado para comparações com os indivíduos tratados por próteses totais, e não foi considerado para as demais. 
2. Proposição 

O objetivo desde trabalho foi comparar um método simplificado de confecção de próteses totais a outro convencional, por meio de um ensaio clínico controlado aleatorizado, tendo como variáveis de desfecho:

- Avaliação da performance mastigatória (PM) por meio de um método colorimétrico, utilizando uma "biocápsula" como simulador de alimento teste;

- Avaliação da habilidade mastigatória (HM) dos participantes, por meio da aplicação de questionário (Questionário HM) e escala visual analógica (EVA).

As avaliações foram analisadas comparativamente a indivíduos com dentição natural completa. 




\section{Xateriale Método}





\subsection{Material}

Os materiais de consumo e permanentes utilizados no estudo durante os trabalhos clínicos e laboratoriais estão listados a seguir:

\subsubsection{Material de consumo}

$\checkmark$ Abaixador de língua, Estilo, Estilo Artefatos de Madeira Ltda., Guarapuava, PR, Brasil.

$\checkmark$ Alginato, Jeltrate Dustless, Dentsply Indústria e Comércio Ltda., Petrópolis, RJ, Brasil.

$\checkmark$ Algodão, Nathalya, Euro Med Indústria e Comércio Ltda., Abreu e Lima, PE, Brasil.

$\checkmark$ Avental descartável gramatura 20, azul, manga longa, Use Útil, Use Útil Produtos Descartáveis Ltda., Batatais, SP, Brasil.

$\checkmark$ Biocápsula, Faculdade de Ciências Farmacêuticas de Ribeirão Preto - FCFRP, USP, SP, Brasil.

$\checkmark$ Cera $n^{\circ} 7$, Wilson, Polidental Indústria e Comércio Ltda., Cotia, SP, Brasil.

$\checkmark$ Cera $n^{\circ}$ 9, Wilson, Polidental Indústria e Comércio Ltda., Cotia, SP, Brasil.

$\checkmark$ Cera utilidade, Wilson, Polidental Indústria e Comércio Ltda., Cotia, SP, Brasil.

$\checkmark$ Gaze, Cremer, Cremer S.A., Blumenau, SC, Brasil.

$\checkmark$ Godiva de baixa fusão em bastão, Kerr, Kerr Corporation USA, Orange, CA, Estados Unidos.

$\checkmark$ Haste flexível, Aponete, Flexicotton Indústria e Comércio de Produtos de Higiene Pessoal S.A., Santo Amaro da Imperatriz, SC, Brasil.

$\checkmark$ Hiperbolóide, Hiperbolóide, Santa Bárbara d’Oeste, SP, Brasil. 
Luva de látex para procedimento, Satari, Siam Sempermed Corp. Ltd., Hat Yai, Songkhla, Tailândia. Importado por: Sempermed Brasil Comércio Exterior Ltda., Piracicaba, SP, Brasil.

Máscara com elástico descartável, Embramac, Embramac Empresa Brasileira de Materiais Cirúrgicos, Indústria, Comércio, Importação e Exportação Ltda., Itapira, SP, Brasil.

$\checkmark$ Óxido de zinco, Quimidrol, K-Dent, Joinville, SC, Brasil.

$\checkmark$ Papel de articulação, Accu Film II, Parkell in, Farmingdale, NY, Estados Unidos.

$\checkmark$ Pasta zincoenólica, Lysanda, Lysanda Produtos Odontológicos Ltda., São Paulo, SP, Brasil.

$\checkmark$ Resina acrílica autopolimerizável, JET Clássico, Clássico Indústria Brasileira, Campo Limpo Paulista, SP, Brasil.

Touca sanfonada descartável, Protdesc, Desc Life Indústria e Comércio de Descartáveis Ltda., Santa Bárbara d'Oeste, SP, Brasil.

Vaselina sólida, Rioquímica, Rioquímica Indústria Farmacêutica, São José do Rio Preto, SP, Brasil.

\subsubsection{Material permanente}

Arco facial Standard, BIO-ART Equipamentos Odontológicos Ltda., São Carlos, SP, Brasil.

Articulador 4000, BIO-ART Equipamentos Odontológicos Ltda., São Carlos, SP, Brasil.

$\checkmark$ Becker de vidro, Vitrex do Brasil Indústria e Comércio de Vidro Ltda., Mogi das Cruzes, São Paulo, Brasil. 
$\checkmark$ Broca de Tungstenio Maxicut, EDENTA AG, Au, Suíça.

$\checkmark$ Broca de Tungstenio Minicut, EDENTA AG, Au, Suíça.

$\checkmark$ Compasso de Willis Inox, JON Comércio de Produtos Odontológicos, São Paulo, SP, Brasil.

$\checkmark$ Cubeta Média 350 ml, OGP Produtos Odontológicos Ltda., São Paulo, SP, Brasil.

$\checkmark$ Esculpidor Le Cron 5, SS White Duflex Instumentos Dentários, Juiz de Fora, MG, Brasil.

$\checkmark$ Espátula Dupla 7, 80 mm, SS White Duflex Instumentos Dentários, Juiz de Fora, MG, Brasil.

$\checkmark$ Espátula Inox para Gesso Cabo de Plástico, JON Comércio de Produtos Odontológicos, São Paulo, SP, Brasil.

$\checkmark$ Espátula Simples 24F, SS White Duflex Instumentos Dentários, Juiz de Fora, MG, Brasil.

$\checkmark$ Espátula Simples 36, SS White Duflex Instumentos Dentários, Juiz de Fora, MG, Brasil.

$\checkmark$ Espelho Odontológico $\mathrm{n}^{\circ}$ 5, SS White Duflex Instumentos Dentários, Juiz de Fora, MG, Brasil.

$\checkmark$ Espelho de mão, RICCA Fashion style, Origem: China. Importado por: Belliz Indústria, Comércio, Importação e Exportação Ltda., São Paulo, SP, Brasil.

$\checkmark$ Espectrofotômetro, Beckman DU-640 UV Visível, Beckman Inc., Palo Alto, CA, EUA.

$\checkmark$ Estante para tubo de ensaio, Plena Lab, Plena Lab, São Paulo, SP, Brasil.

$\checkmark$ Funil de vidro, Vitrex do Brasil Indústria e Comércio de Vidro Ltda., Mogi das Cruzes, SP, Brasil.

$\checkmark$ Isqueiro MAXI - J6/J26, Bic Brasil S.A., Cajamar,SP, Brasil. 
Lamparina Inox Universitária 40 ml, Können Indústria e Comércio Ltda., São Paulo, SP, Brasil.

$\checkmark$ Lâmpada Hannau simples, Können Indústria e Comércio Ltda., São Paulo, SP, Brasil.

$\checkmark$ Medidor de Água para Alginato em Plástico, Technew Comércio e Indústria Ltda., Rio de Janeiro, RJ, Brasil.

$\checkmark$ Micro motor (peça reta), Dabi Atlante S.A. Indústrias Médico Odontológicas, Ribeirão Preto, SP, Brasil.

$\checkmark$ Moldeiras Totais Lisas em Inox (Desdentados), Tecnodent Indústia e Comércio Ltda., São Paulo, SP, Brasil.

$\checkmark$ Pinça Muller Serrilhada para articulação de carbono Inox, Golgran Indústria e Comércio de Instrumental Odontológico Ltda., São Paulo, SP, Brasil.

Pipetador de ajuste variável, HT, High Tech Lab S.A., Varsóvia, Polônia.

Placa de vidro grossa $15 \times 07 \times 20 \mathrm{~mm}$ polida, PR Indústria e Comércio de Produtos Odontológicos, Florianópolis, SC, Brasil.

Plano de fox de alumínio, JON Comércio de Produtos Odontológicos, São Paulo, SP, Brasil.

Pote Dappen de Vidro, Preven Indústria e Comércio de Produtos Odontológicos, Guapirama, PR, Brasil.

Régua Plástica Flexível 15 cm, JON Comércio de Produtos Odontológicos, São Paulo, SP, Brasil.

Tubo de ensaio de vidro, Vitrex do Brasil Indústria e Comércio de Vidro Ltda., Mogi das Cruzes, SP, Brasil. 


\subsection{Método}

Encontram-se neste trabalho os resultados de um ensaio clínico com dois grupos paralelos. Foi buscado o cegamento das partes envolvidas quando possível, ou seja, dos avaliadores e estatístico envolvidos. No referido ensaio clínico, foram avaliadas as seguintes variáveis de desfecho:

1. Qualidade de vida associada à saúde bucal;

2. Satisfação com a prótese, relatada pelo participante;

3. Qualidade da prótese, avaliada por um clínico;

4. Performance e habilidade mastigatórias;

5. Custos diretos e indiretos.

Esta dissertação apresenta detalhes sobre as variáveis no item $\mathrm{n}^{\circ} 4$, relativas à avaliação da performance e habilidade mastigatórias dos participantes envolvidos no estudo. As demais serão relatadas em outras oportunidades.

\subsubsection{Aprovação pelo Comitê de Ética}

Inicialmente, o projeto foi submetido ao Comitê de Ética em Pesquisa com seres humanos da Faculdade de Odontologia de Ribeirão Preto da Universidade de São Paulo (FORP-USP), sendo aprovado sob o número CAAE (Certificado de Apresentação para Apreciação Ética) 0061.0.138.000-10 (Anexo A). Após essa aprovação, o projeto foi registrado na base ClinicalTrials.gov (http://prsinfo.clinicaltrials.gov/) com o identificador NCT01230320 e título "Simplified vs. Conventional Methods for Complete Denture Fabrication" (Apêndice A). 


\subsubsection{Seleção dos Participantes}

O recrutamento dos participantes dentados (Grupo $D N$ ), considerado para esta parte do estudo, foi realizado a partir da divulgação da pesquisa e seleção de interessados após anamnese e exame clínico.

Os critérios de inclusão utilizados para a seleção desses participantes foram:

(a) 45 anos de idade ou mais,

(b) dentição natural completa, com presença de pelo menos até os segundos molares;

(c) sem tratamento ortodôntico prévio;

(d) não fazer uso de medicamentos que possam interferir na atividade muscular;

(e) boa compreensão do português.

Consideramos ainda os seguintes aspectos como critérios de exclusão:

(a) presença de sinais ou sintomas de disfunção temporomandibular;

(b) oclusão traumática;

(c) problemas periodontais.

O recrutamento dos participantes desdentados ocorreu a partir dos pacientes buscando tratamento nas clínicas localizadas na FORP-USP, encaminhados pela Secretaria Municipal de Saúde de Ribeirão Preto, bem como de novos pacientes encaminhados pelo mesmo órgão. Pacientes encaminhados dessa maneira recebem próteses totais convencionais custeadas pelo

Sistema Único de Saúde (SUS), sem que tenham que pagar pelas etapas clínicas ou laboratoriais do tratamento.

Os critérios de inclusão utilizados para a seleção desses participantes foram:

(a) 45 anos de idade ou mais; 
(b) edentulismo completo há pelo menos 1 ano;

(c) desejo por receber um par de próteses totais convencionais novas;

(d) boa receptividade;

(e) boa compreensão de português falado.

O recrutamento foi feito após conversa inicial e exame clínico, realizados pelos pesquisadores responsáveis pela fabricação das próteses totais. Após esses procedimentos, consideramos os seguintes aspectos como critérios de exclusão:

(a) desordens do sistema estomatognático;

(b) alterações patológicas dos rebordos alveolares;

(c) doenças sistêmicas debilitantes.

Os participantes desdentados em potencial foram informados sobre a natureza do estudo e todos os detalhes do mesmo foram explicados por meio da leitura do Termo de Consentimento Livre e Esclarecido (TCLE) (Apêndice B). O mesmo foi realizado para os participantes dentados, porém foi aplicado um TCLE adequado para este grupo que não recebeu nenhum tratamento odontológico (Apêndice B). Após a obtenção do consentimento por parte do participante, prosseguiu-se com as demais etapas.

$\mathrm{Na} 1^{\mathrm{a}}$ consulta, foram coletados dados referentes às características demográficas, utilizando-se um formulário específico preparado para essa avaliação inicial (Apêndice C), preenchido por um dos pesquisadores responsáveis pelo tratamento dos participantes. Nesse formulário foram anotados (a) idade, (b) gênero, (c) tempo de edentulismo e uso prévio de próteses totais, (d) emprego, (e) estado civil e (f) nível de escolaridade. O mesmo formulário foi utilizado para a coleta dos dados referentes às características demográficas dos participantes dentados, desconsiderando os dados sobre edentulismo e uso de prótese total. 
A avaliação inicial dos participantes desdentados também compreendeu uma anamnese para levantamento das condições sistêmicas e de saúde bucal, por meio da ficha clínica adotada pela disciplina de Prótese Total e Materiais Aplicados da FORP-USP (Anexo B).

Com o intuito de investigar a relação entre as condições anatômicas bucais dos participantes desdentados e as variáveis de desfecho estudadas, todos foram classificados de acordo com as 4 categorias do Índice Diagnóstico do American College of Prosthodontists (ACP) (McGarry et al., 1999), as quais agrupam os participantes quanto à dificuldade esperada para a resolução do caso clínico de I até IV - do caso mais simples ao mais complexo, respectivamente. Os critérios considerados nessa classificação compreendem a morfologia do rebordo alveolar maxilar, inserções da musculatura mandibular, relacionamento intermaxilar, necessidades de cirurgias pré-protéticas, espaço inter-arcos, e anatomia da língua, conforme vistos clinicamente, e a altura do osso mandibular aferida radiograficamente. Para essa classificação, uma ficha específica foi utilizada (Apêndice D).

A fim de investigar possíveis alterações patológicas dos rebordos alveolares e auxiliar na classificação dos participantes, a todos foram solicitadas radiografias panorâmicas.

\subsubsection{Tratamentos}

Os participantes edêntulos foram aleatoriamente divididos em dois grupos, de acordo com o tipo de técnica utilizada para a confecção das próteses totais convencionais. Um grupo foi tratado segundo uma técnica convencional de confecção desses aparelhos protéticos (Grupo $C$, controle) empregada na disciplina de Prótese Total e Materiais Aplicados da FORP-USP, e o outro tratado segundo uma técnica simplificada (Grupo $S$, experimental). 


\subsubsection{Técnica Convencional}

A técnica convencional consistiu dos seguintes passos clínicos e laboratoriais, similar aos usados em ensaios clínicos anteriores (Kawai et al., 2005; Heydecke et al., 2008; Kawai et al., 2010):

\section{$\underline{1^{a} \text { etapa clínica }}$}

Nesta etapa, realizou-se a moldagem dos arcos superior e inferior, por meio de moldeiras pré-fabricadas em aço inoxidável, utilizando-se como material de moldagem o hidrocolóide irreversível/alginato (Turano e Turano, 2004). Com o objetivo promover afastamento dos tecidos moles, dar conforto ao paciente, além de conferir retenção e espessura adequada ao material de moldagem na região das bordas, as moldeiras selecionadas foram previamente ajustadas em altura e espessura por meio de tiras de cera utilidade (Davis, 2006). Uma moldagem prévia do fundo de sulco vestibular e regiões sublinguais foi realizada por meio do aquecimento das lâminas de cera com o auxílio de uma lâmpada a álcool do tipo Hanau, e as moldeiras foram levadas à boca do paciente para que por meio de tracionamento dos lábios e bochecas feito pelo operador juntamente com movimentos funcionais de sucção e projeção lingual feitos pelo participante pudesse ser obtido uma cópia de detalhes anatômicos dessa região. Após, aplicou-se algodão seco sobre a cera utilidade para conferir retenção mecânica adicional ao material de moldagem. O molde foi considerado satisfatório quando apresentasse bordas arredondadas, reproduzindo todo o fundo de sulco, espessura uniforme do material de moldagem, superfície do material distribuída uniformemente na moldeira, correta centralização e reprodução detalhada dos tecidos moles que recobrem a área de assentamento da prótese, também chamada de área chapeável. Caso contrário, o mesmo era descartado e a repetição da moldagem realizada (Fig. 1). 


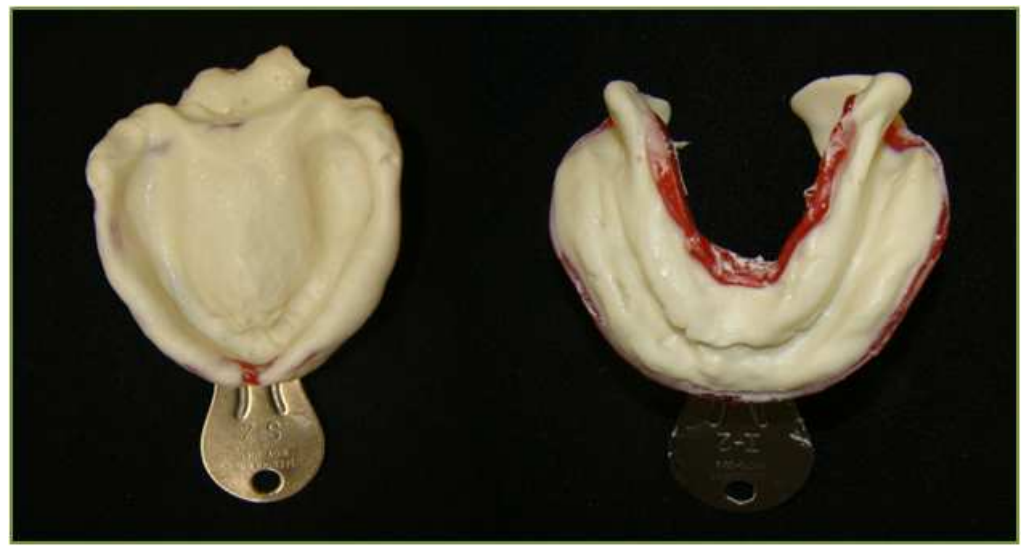

Figura 1 - Moldes dos arcos desdentados superior e inferior, imediatamente após sua obtenção.

\section{$\underline{1^{a} \text { etapa laboratorial }}$}

Após a moldagem dos arcos desdentados, foram obtidos os modelos de estudo em gesso pedra tipo III com posterior delimitação das estruturas a serem englobadas na área chapeável e contornadas pela borda da futura prótese (Davis, 2006). Para o modelo maxilar realizou-se a união dos sulcos hamulares posteriormente às fóveas palatinas, englobando tuberosidades e estendendo-se por todo o fundo de sulco, contornando freios laterais e labial. Para o modelo mandibular, o desenho englobou ambas as papilas retro-molares e se estendeu ao longo dos sulcos vestibulares e linguais contornando linhas oblíquas externas, freios laterais, labial e lingual. Em ambos os modelos, o desenho foi realizado a $2 \mathrm{~mm}$ do fundo de sulco no intuito de dar espaço ao material a ser utilizado na moldagem das bordas (Fig. 2A).

Em seguida, procedeu-se à confecção das moldeiras individuais em resina acrílica autopolimerizável por meio da técnica do lençol adaptado, associada à utilização de um cabo funcional longo confeccionado do mesmo material (Macedo et al., 2005; Malachias et al., 2005). Após realização dos alívios com lâmina de cera $n^{\circ} 7$ nas zonas de alívio - papila incisiva, rugosidades palatinas e regiões de tecidos flácidos e ósseos em lâmina de faca - e das regiões de retenção exagerada por meio de algodão, os modelos eram isolados em toda a sua extensão com isolante líquido por meio de um pincel, e um lençol de resina acrílica na 
espessura aproximada de $3 \mathrm{~mm}$ era acomodado e adaptado ao longo do rebordo alveolar. Os excessos eram recortados com espátula do tipo Le Cron e as bordas dobradas no nível do desenho existente da área chapeável com o auxílio de uma espátula $n^{0} 7$. Após completa a reação do material, a moldeira era removida do modelo, inspecionada, os recortes dos freios realizados e o acabamento e polimento dados com brocas de tungstênio acopladas em peça de mão e micro-motor. O cabo funcional em resina acrílica autopolimerizável era então posicionado na linha mediana da moldeira e fixado com o mesmo material. Para a moldeira inferior, pequenos suportes em resina acrílica eram posicionados na região dos pré-molares para auxiliar no manuseio da mesma durante a realização da moldagem (Fig. 2B).

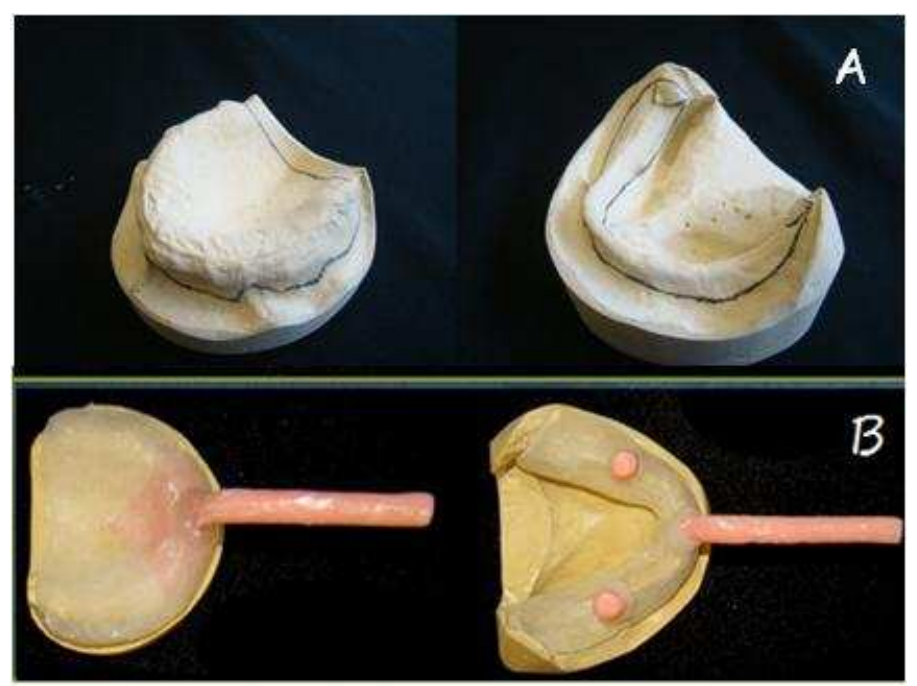

Figura 2 - (A) Modelos de estudo superior e inferior, após a delimitação da área chapeável; (B) Moldeiras individuais superior e inferior.

\section{$\underline{2^{a} \text { etapa clínica }}$}

As moldeiras individuais foram ajustadas por meio de desgastes das bordas com brocas de tungstênio acopladas a uma peça reta e micro-motor. Buscou-se a correta extensão, bem como alívios nas regiões de freios com discos de carborundum montados em mandril, com os mesmos critérios usados para a delimitação da área chapeável durante a $1^{\mathrm{a}}$ etapa 
laboratorial, exceto pelo limite posterior da moldeira individual maxilar, que clinicamente corresponde à linha vibratória (linha do "Ah”). Assim, as moldeiras apresentaram estabilidade quando assentadas nos rebordos alveolares dos participantes e proporcionaram desconforto mínimo durante a realização da moldagem funcional.

Na sequiência, realizou-se a moldagem funcional conforme Macedo, et al. (2005) e Malachias, et al. (2005). Para a impressão das bordas foi utilizada godiva de baixa fusão em bastão. Os flancos vestibulares de ambas as arcadas foram moldados pedindo-se que o participante realizasse sucção do cabo da moldeira, enquanto a mesma era mantida em posição no rebordo alveolar, por meio da correta empunhadura do cabo pelo operador. Para a impressão da borda posterior da moldeira superior, pressão era realizada na região central do palato duro e, para os flancos linguais mandibulares, o participante realizava movimentações da língua do tipo projeção para fora da boca, umedecendo os lábios de uma comissura a outra, elevação em direção ao palato e em ambas as bochechas, enquanto a moldeira era mantida em posição pelo operador por meio de pressão digital adequada nos suportes de resina acrílica presentes na região de pré-molares da moldeira individual inferior (Fig. 3A). Para a moldagem da zona de suporte de ambas as arcadas, foi utilizada pasta zincoenólica, com o participante realizando as mesmas movimentações descritas anteriormente durante a reação do material de moldagem. No caso da arcada superior, sobre a pasta zincoenólica, uma nova impressão era realizada na zona de selado posterior com cera rosa $n^{0} 7$ na espessura de aproximadamente $2 \mathrm{~mm}$, para melhoria do selado posterior da prótese final (Fig. 3B). 


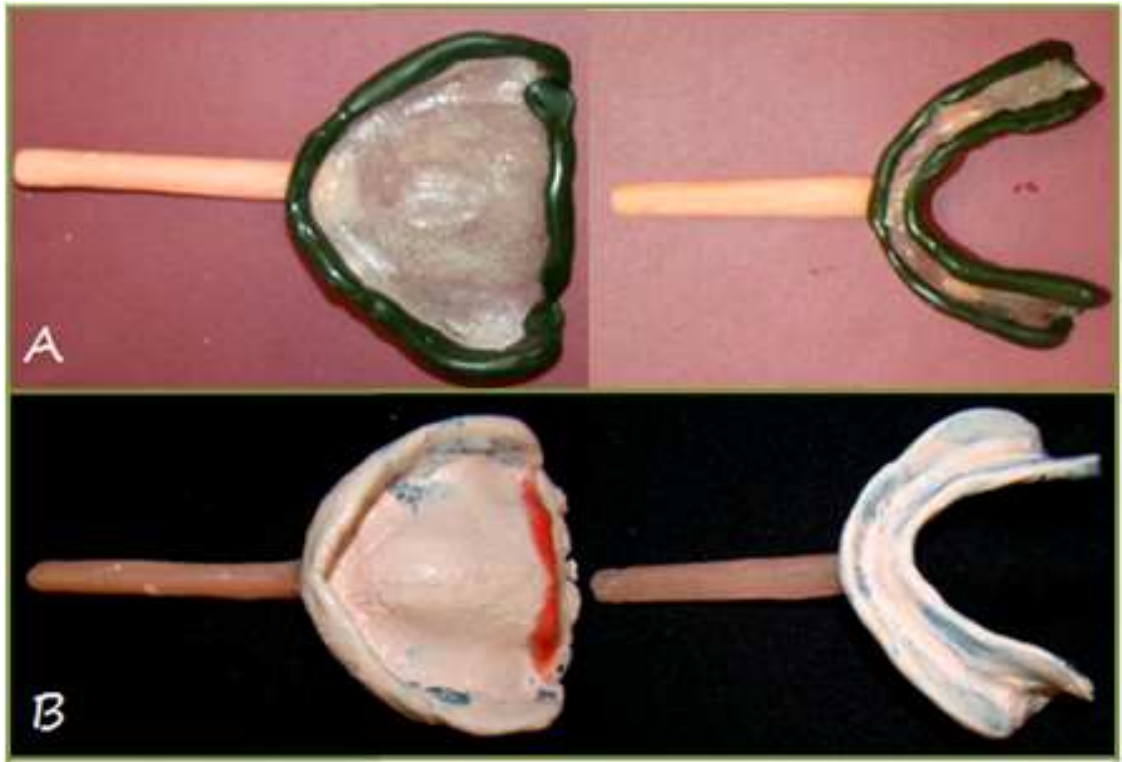

Figura 3 - (A) Molde do selado periférico superior e inferior; (B) Molde da zona de suporte superior e inferior.

\section{$\underline{2^{a} \text { etapa laboratorial }}$}

Após a moldagem funcional dos arcos, procedeu-se ao encaixamento dos moldes finais e obtenção dos modelos de trabalho em gesso pedra tipo III (Fig. 4A, B). Posteriormente, foram confeccionadas as placas articulares por meio de uma base em resina acrílica autopolimerizável, obtida de forma semelhante à descrita para as moldeiras individuais, exceto pela característica das bordas as quais preenchiam o fundo de sulco em toda sua extensão e largura. Sobre essa base, rodetes de cera foram posicionados ao longo da crista do rebordo alveolar (Fig. 4C). Foram utilizadas ceras de diferentes durezas, cera $\mathrm{n}^{\circ} 9$ para o superior e $\mathrm{n}^{\mathrm{o}} 7$ para o inferior, para facilitar o ajuste das mesmas em altura durante a determinação da Dimensão Vertical de Oclusão (DVO) a ser realizada na etapa clínica seguinte. 


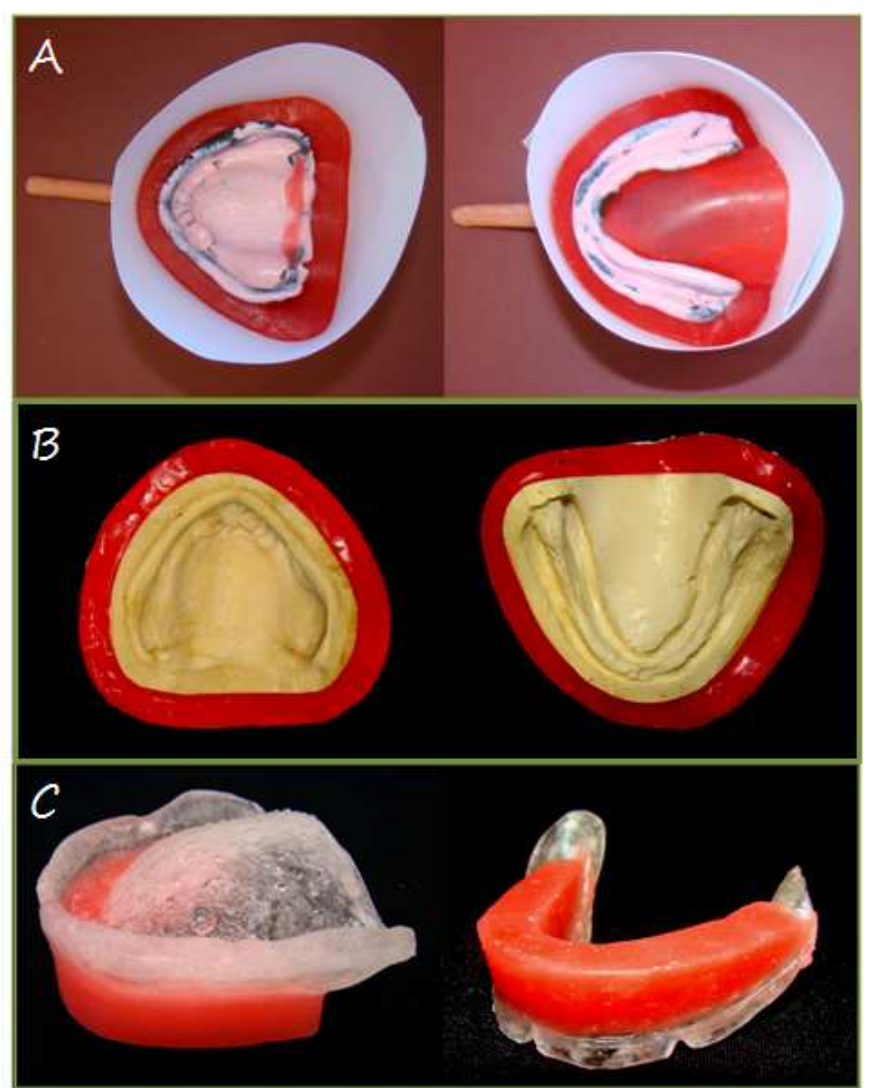

Figura 4 - (A) Encaixamento dos moldes funcionais superior e inferior; (B) Modelos de trabalho superior e inferior; (C) Placas articulares superior e inferior.

\section{$\underline{3^{a} \text { etapa clínica }}$}

As placas articulares receberam ajustes de sua extensão e volume, alívio das inserções musculares e verificação da adaptação, estabilidade, retenção e conforto. A seguir, o rodete de cera superior foi ajustado em volume, por meio de desgaste ou acréscimo de cera $\mathrm{n}^{\mathrm{o}} 9$ na porção vestibular, de forma a oferecer suporte labial e corredor bucal esteticamente adequados. Em seguida, o plano de orientação superior foi determinado, por meio de paralelismo entre a superfície articular do rodete de cera e os planos antropométricos de Camper e bipupilar com o auxílio de uma régua de Fox (Fig. 5A).

Foi então realizada uma determinação indireta da DVO do paciente por meio da tomada da Dimensão Vertical de Repouso (DVR). Os participantes foram instruídos a atingir a posição de repouso mandibular realizando limpeza dos lábios com a língua, deglutição e pronúncia da letra $/ \mathrm{m} / \mathrm{sem}$ as placas articulares na boca. Ao fim dos exercícios solicitados ao 
participante, aguardou-se uma estabilização da posição mandibular e a distância média da base do mento à base do nariz foi medida utilizando-se um compasso de Willis. Esse procedimento foi repetido 3 vezes, a média entre os valores obtidos escolhida como a DVR e a DVO estabelecida pela diminuição de $3 \mathrm{~mm}$ desse valor, correspondente ao Espaço Funcional Livre (EFL) (Anderson, 2006; Souza et al., 2007).

Foi realizada a modificação do rodete de cera inferior em altura de acordo com a DVO estabelecida e análise por meio de testes fonéticos para verificação de espaço adequado entre os rodetes durante a pronúncia de sons sibilantes (Silverman, 2001). A verificação do relato do paciente em relação ao conforto (Zarb et al., 2006a) e a observação da harmonia facial determinavam a finalização dos ajustes. Por fim, a relação Cêntrica (RC) foi registrada por meio da confecção de uma chave de posição com pasta zincoenólica na região dos molares após manipulação mandibular. A posição da placa articular superior foi então determinada por meio da utilização de arco facial para posterior montagem dos modelos de trabalho em articulador semi-ajustável (ASA) (Fig. 5B, C).

As linhas mediana, do sorriso forçado e dos caninos foram marcadas na região vestibular do rodete de cera superior, utilizando-se uma espátula do tipo Le Cron, como guias para a seleção dos dentes artificiais anteriores quanto ao tamanho e largura, bem como o posicionamentos dos mesmos durante a fase laboratorial a seguir. A cor foi selecionada utilizando-se a escala de cores da marca Biotone, por comparação entre pares de dentes e o modelo selecionado por meio da carta molde disponibilizada pelo fabricante, levando em consideração o julgamento do profissional e a participação do participante (Fig. 5D). 


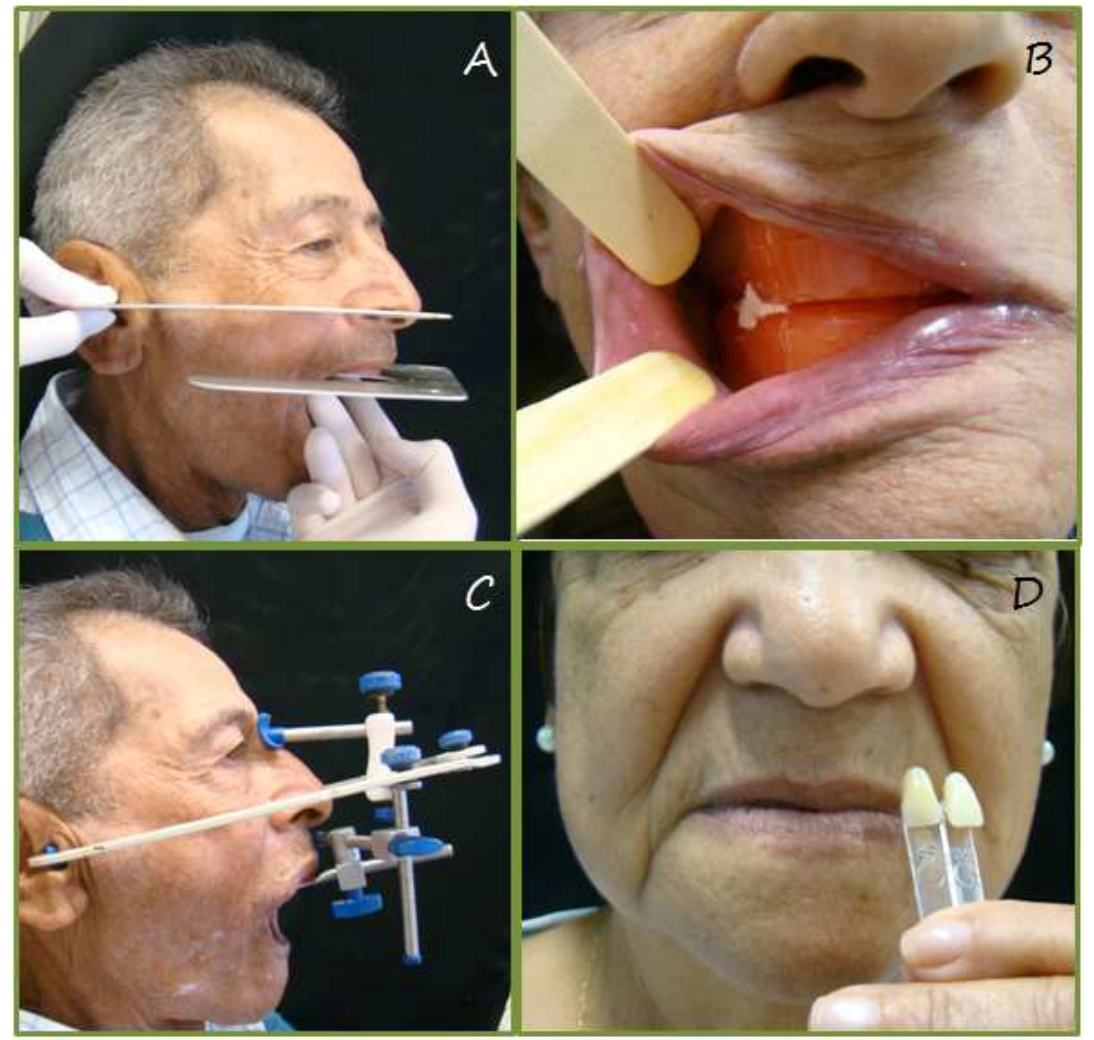

Figura 5 - (A) Ajuste das placas articulares; (B) Registro da relação cêntrica; (C) Registro com arco facial; (D) Seleção dos dentes artificiais.

\section{$\underline{3^{a} \text { etapa laboratorial }}$}

Os modelos de trabalho foram montados em ASA com medidas padronizadas de $30^{\circ} \mathrm{e}$ $15^{\circ}$ para as guias condilares sagital e lateral, respectivamente (Nascimento et al., 2004; Carlsson, 2009) (Fig. 6A). Prosseguiu-se à montagem dos seis dentes anteriores superiores e inferiores seguindo as linhas marcadas no rodete de cera superior (Fig. 6B).

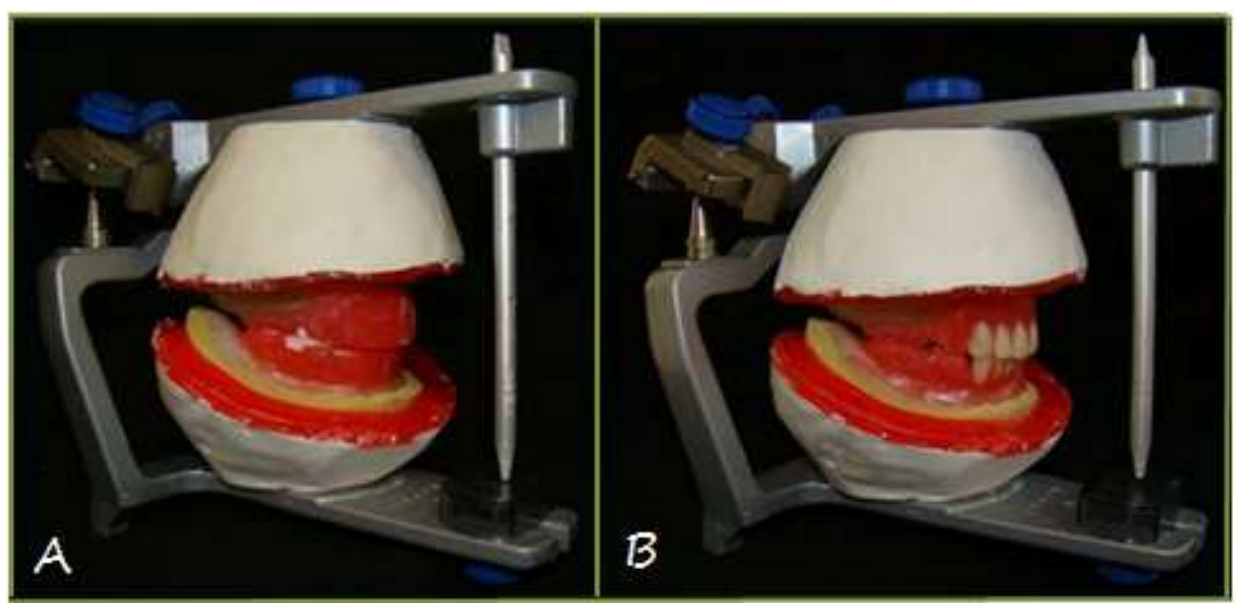

Figura 6 - (A) Modelos de trabalho montados em ASA; (B) Montagem dos seis dentes anteriores superiores e inferiores. 


\section{$\underline{4^{\mathrm{a}} \text { etapa clínica }}$}

Nesta etapa, realizou-se a prova estética dos dentes anteriores. Foi observado o arranjo, a forma, o tamanho e a cor dos dentes artificiais selecionados, a orientação e nível do plano oclusal, a posição da linha mediana e o suporte labial, bem como verificado se o registro anterior da $\mathrm{RC}$ estava correto. A estética foi discutida com os participantes e, quando necessário, foram realizadas mudanças de acordo com suas preferências (Fig. 7A) (Hickey et al., 1969).

\section{$\underline{4^{\mathrm{a}} \text { etapa laboratorial }}$}

Foram montados os dentes artificiais posteriores superiores e inferiores segundo uma oclusão balanceada bilateral (Glossary of Prosthodontic Terms, 2005), utilizando-se dentes de inclinação cuspídica 33º (Fig. 7B) (Hickey et al., 1969).

\section{$\underline{5^{a} \text { etapa clínica }}$}

Realizou-se a prova dos dentes posteriores, averiguando se o padrão oclusal obtido no articulador estava presente na boca. Também foi verificado se a DVO do participante com as placas em oclusão estava semelhante à estabelecida anteriormente (Fig. 7C).

\section{$\underline{5^{a} \text { etapa laboratorial }}$}

Após a prova clínica dos dentes posteriores, as placas articulares foram enceradas e, juntamente com os modelos de trabalho, incluídas em muflas metálicas por meio de gesso pedra tipo III. Foi seguido um protocolo de preenchimento da mufla em três camadas de gesso para diminuir o risco de movimentação dentária durante a prensagem e polimerização da prótese, bem como para facilitar a remoção da mesma. As muflas eram mantidas sob pressão em prensas manuais e, após conclusão da reação do gesso, as mesmas eram levadas a um 
recipiente com água em ebulição durante cinco minutos para a plastificação e eliminação da cera. Foram realizadas perfurações na base dos dentes artificiais para melhor fixação destes à base da prótese e, após isolamento dos modelos de trabalho com vaselina líquida, a resina acrílica termopolimerizável na fase plástica foi acomodada na contra-mufla, porção onde os dentes artificiais estavam presentes. O conjunto mufla e contra-mufla foi fechado, levado a uma prensa hidráulica de bancada e submetido a um ciclo de prensagem gradual até atingir $1,250 \mathrm{kgf}$.

Os procedimentos descritos acima para essa etapa estão de acordo com Zarb, et al. (2006b), exceto pelo ciclo de polimerização, para o qual foi empregado um patamar de $73^{\circ} \mathrm{C} \mathrm{a}$ 90 minutos, seguido de aquecimento até $100^{\circ} \mathrm{C}$, mantido por 30 minutos (Regis et al., 2011). Completado o ciclo, as muflas foram deixadas sobre bancada para serem abertas apenas após atingirem a temperatura ambiente.

Após desincluídas, as próteses receberam acabamento por meio de fresas montadas em peça reta e tiras de lixa montadas em mandril para a eliminação dos excessos de resina acrílica, de forma a tornar as superfícies da prótese arredondadas e livres de irregularidades ou aspereza (Fig. 7D). O polimento foi realizado com uma mistura de pedra pomes e água, utilizando-se discos de feltro montados em politriz de bancada.

\section{$\underline{6^{\mathrm{a}} \text { etapa clínica }}$}

Este estágio foi caracterizado pela instalação das próteses totais. A identificação de nódulos, arestas, áreas retentivas e porosidades foi feita por meio de inspeção táctil e visual da base das próteses. Caso necessário, essas imperfeições eram eliminadas com o auxílio de brocas em peça reta. Durante a instalação dos aparelhos protéticos propriamente dita, verificou-se a presença de interferências nos freios, inserções musculares e correto assentamento nos limites da área chapeável. Foram avaliadas a DVO, EFL, RC, retenção, suporte, estabilidade, estética e fonética. Ajustes oclusais foram feitos com papel carbono nas 
posições de relação cêntrica, lateralidade e protrusão por meio de desgaste seletivo buscandose a presença de contatos simultâneos dos dentes posteriores para promover uma distribuição equilibrada e harmoniosa da carga mastigatória nos rebordos residuais, conferindo estabilidade à prótese e conforto ao paciente (Corrêa, 2005). Instruções quanto à alimentação, adaptação da fala, uso noturno e higienização eram dadas ao paciente e reforçadas durante os retornos (Duncan et al., 2004; Kimoto et al., 2007; Felton et al., 2011).

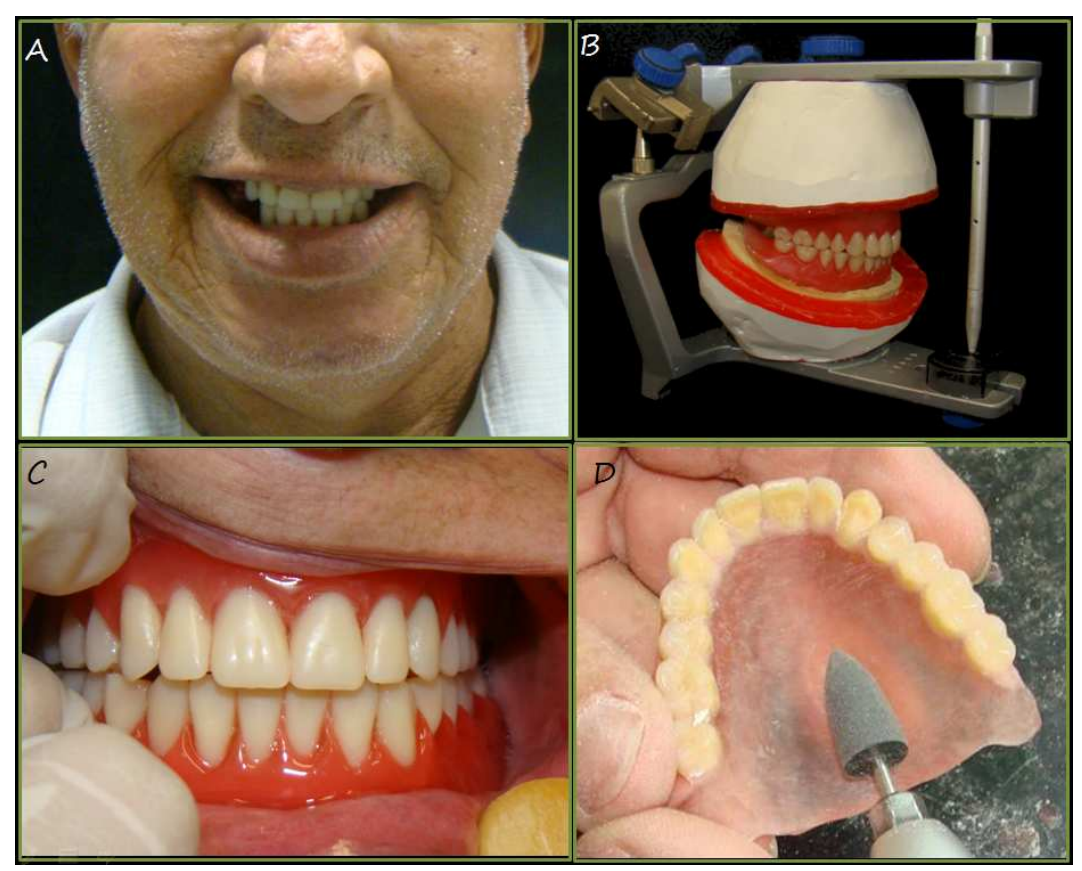

Figura 7 - (A) Prova clínica dos dentes anteriores; (B) Montagem dos dentes posteriores; (C) Prova clínica dos dentes posteriores; (D) Processamento, acabamento e polimento das próteses.

\section{$\underline{7^{a} \text { etapa clínica }}$}

Nas sessões dos ajustes agendados depois de 1, 7 e 14 dias após a instalação, foram realizados ajustes das bases das próteses, quando estas causavam alguma injúria aos tecidos de suporte utilizando-se uma pasta indicadora de pressão (Kimoto et al., 2007). O mesmo protocolo de ajuste oclusal realizado na instalação foi seguido, se necessário. Caso os participantes apresentassem qualquer queixa após o terceiro ajuste, sessões posteriores eram marcadas até que o paciente se encontrasse livre de irritações teciduais e confortáveis com suas próteses (Kimoto et al., 2007). 


\subsubsection{Técnica Simplificada}

As diferenças propostas para a técnica simplificada foram:

(A) Exclusão da etapa laboratorial de confecção de moldeira individual e da etapa clínica de moldagem funcional. Assim, as bases de registro foram obtidas diretamente sobre os modelos iniciais em gesso pedra tipo III e adaptadas segundo Duncan e Taylor (2001, 2004), nos quais a extensão posterior da prótese é marcada arbitrariamente na região das fóveas palatinas e estendida bilateralmente pelos sulcos hamulares e uma impressão do selado posterior em forma de meia-lua é escavada no modelo de estudo por meio de fresas. Assim, a espessura do selado posterior, tanto da placa articular quanto do aparelho protético final, fica maior, igualando-se ao selado posterior obtido pela técnica convencional. Outra modificação adotada, proposta pelos mesmos autores, é a localização das bordas das placas articulares obtidas sobre os modelos de estudo, a qual é determinada visualizando o ponto do fundo de sulco onde o processo alveolar (porção vertical) termina e começa a região do vestíbulo (porção horizontal) (Fig. 8).

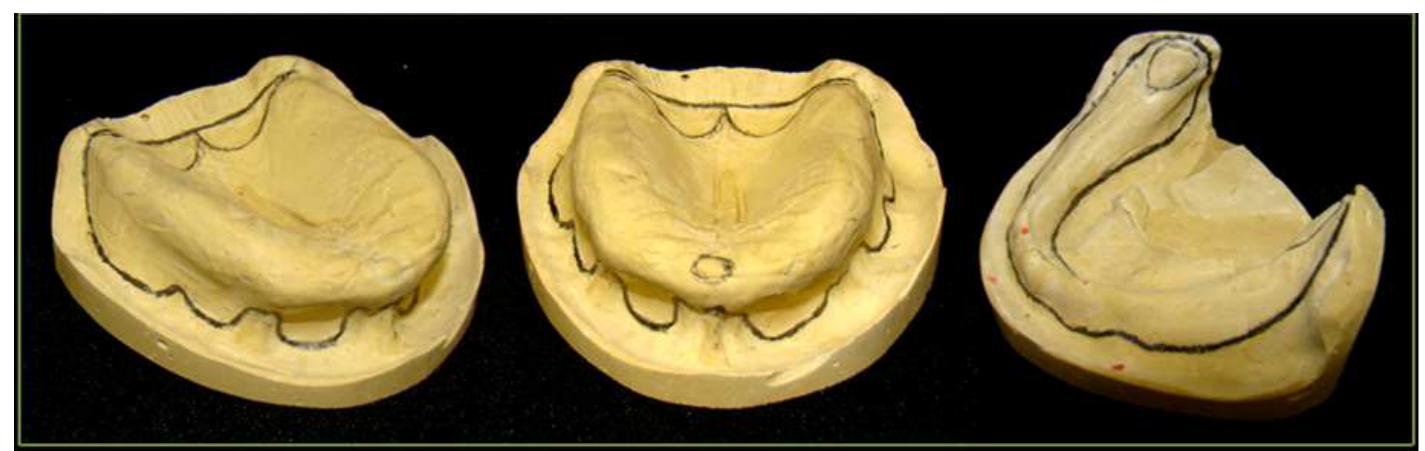

Figura 8 - Posicionamento das bordas periféricas das placas articulares e forma do selado posterior superior.

(B) Após ajuste das placas articulares, não foi utilizada nenhuma forma de registro com arco facial. O modelo superior foi montado por meio da mesa auxiliar com inclinação de $15^{\circ}$ fixada ao ramo inferior do ASA, com os rodetes de cera posicionados simetricamente em torno da linha média da mesa auxiliar (Carlsson, 2009) (Fig. 9). 


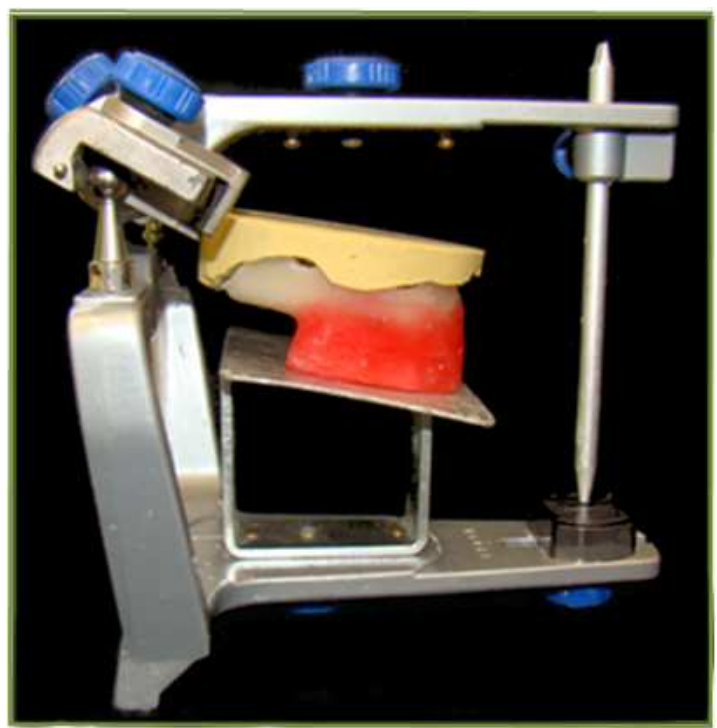

Figura 9 - Montagem do modelo de trabalho superior utilizando uma mesa auxiliar (plano de Camper).

(C) Os dentes artificiais anteriores e posteriores foram montados de forma que uma única prova clínica fosse realizada, a fim de checar estética, relações intermaxilares e oclusão (Duncan e Taylor, 2004). Portanto, essa técnica possibilita a obtenção das próteses totais após 4 etapas clínicas e 3 etapas laboratoriais.

A remontagem das próteses em ASA após processamento não foi utilizada em nenhuma das técnicas, em concordância com os procedimentos empregados no Centro de Especialidades Odontológicas (CEO). Os procedimentos clínicos foram realizados por 2 operadores e 2 auxiliares, todos cirurgiões-dentistas, os quais também foram responsáveis pelas etapas laboratoriais. Nas fases laboratoriais, houve a supervisão pelo pesquisador principal e um técnico de prótese dentária.

\subsubsection{Alocação dos participantes nos grupos}

Após a primeira etapa clínica e obtenção dos modelos maxilar e mandibular em gesso, os participantes tratados foram alocados aleatoriamente em um dos dois grupos por meio de 
envelopes opacos e selados, codificados por ' $C$ ' ou ' $S$ ', preparados por um pesquisador sem contato com os demais procedimentos, de forma que nenhum participante ou demais pesquisadores pudessem prever a alocação. A seqüência de códigos foi obtida por meio de números aleatórios gerados por computador (Microsoft Excel 2003; Microsoft Corporation, São Paulo, SP). Os envelopes foram abertos apenas após exame clínico inicial, confirmação da inclusão dos participantes e obtenção do modelo inicial. Dessa forma, foi assegurado que o conhecimento sobre a que grupo cada participante pertenceria não influenciaria no passo de moldagem inicial, apesar da qualidade dos modelos iniciais ser essencial para os dois grupos. Entretanto, para o grupo $S$ constituem-se como modelo de trabalho, sobre os quais as placas articulares seriam confeccionadas.

\subsubsection{Variáveis de desfecho}

\subsubsection{Performance Mastigatória}

A performance mastigatória foi avaliada por meio do método colorimétrico desenvolvido por Mestriner Junior (2002), Santos, et al. (2006) e aprimorado por Moreschi (2006), que utiliza como instrumento de medida um simulador de alimento teste artificial denominado "Biocápsula” (Fig. 10A).

A "biocápsula" tem um formato retangular de dimensão aproximada a 2,0 $\mathrm{cm} \times 1,3$ cm, contendo em seu interior $250 \mathrm{mg}$ de partículas/“beads” apresentando $1 \mathrm{~mm}$ de diâmetro aproximadamente. São obtidas por geleificação ionotrópica de dispersão aquosa de pectina a $2 \%$, amido a $18,65 \%$, lactose a $20,5 \%$, sacarose a $18,65 \%$, celulose microcristalina a $40,2 \%$ e 0,016\% de fucsina, com base no teor de sólidos. As dispersões são extrusadas contra uma agulha com 1,0 mm de diâmetro interno, com velocidade constante de gotejamento de 4,5 $\mathrm{mL} / \mathrm{minuto}$, controlada por bomba peristáltica, em solução de cloreto de cálcio 1,0 M, 
mantida sob agitação branda com barra magnética, à temperatura ambiente $\left(25 \pm 1^{\circ} \mathrm{C}\right)$. A distância entre a agulha e a solução de cloreto de cálcio é padronizada em 1,0 cm. Após permanecerem em solução por 10 minutos, as "beads" são secas até atingirem um peso constante, sendo revestidas posteriormente com solução de Eudragit 5\% (Eudragit® E100) em uma mistura de solventes de acetona $10 \%$ em etanol absoluto. O revestimento da cápsula é composto por polivinil acetato, medindo $0,40 \mathrm{~mm}$ de espessura das paredes, diâmetro interno de 7,6 mm e diâmetro externo de 8,95 mm. As "biocápsulas" são seladas por radiofreqüência, o que as mantém hermeticamente fechadas ao longo de toda etapa clínica caracterizando-as como inertes e biocompatíveis. A armazenagem das mesmas deve ocorrer em ambiente com umidade e temperatura controlada (Borges, 2011).

Todos os participantes foram orientados a sentar-se em uma cadeira confortável, com os pés apoiados no chão e a coluna ereta. Antes de iniciar a avaliação com as "biocápsulas", cada participante recebeu um Hiperbolóide (Fig. 10B), que é um instrumento de mastigação que apresenta textura e tamanho padronizados (Cheida, 1997), composto de silicone Silastic, de tamanho PP, com o objetivo de retirar a memória neuromuscular de repouso e aproximar ao máximo da mastigação habitual (Santos, 2002). Os participantes mastigaram o hiperbolóide por 30 segundos, cronometrados pelo pesquisador responsável pela avaliação, utilizando um cronômetro digital.

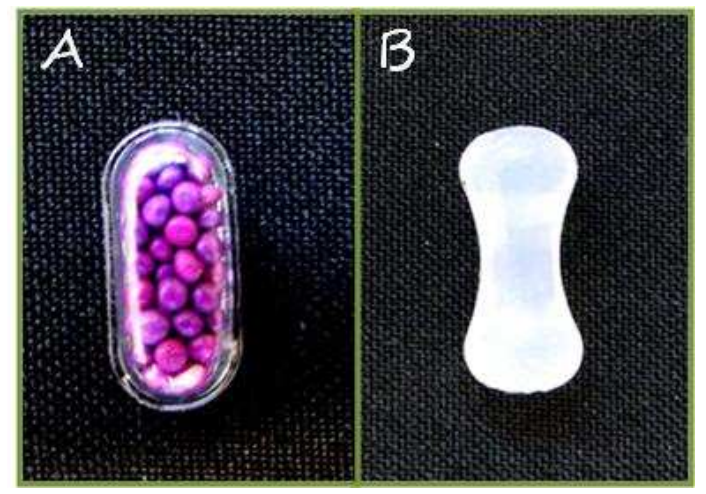

Figura 10 - (A) "Biocápsula"; (B) Hiperbolóide. 
Após um intervalo de 3 minutos, foi solicitado que cada indivíduo dos Grupos $C$ e $S$ mastigasse um total de duas "biocápsulas", uma de cada vez, durante uma quantidade determinada de ciclos mastigatórios cada uma e com um intervalo de tempo de 3 minutos entre as mesmas (Picinato-Pirola, 2010). As cápsulas foram mastigadas de modo habitual/livre, com 20 e 40 ciclos mastigatórios, sendo que a mastigação de cada uma das "biocápsulas" foi monitorada pelo examinador e interrompida com sua ordem. Essa avaliação foi realizada após três meses da instalação das próteses totais para os Grupos $C$ e $S$. Os participantes do Grupo DN realizaram esta avaliação seguindo o mesmo protocolo.

Durante a mastigação da "biocápsula", as partículas/“beads" foram quebradas (Fig. 11A) e a tintura da fucsina difundida dentro da mesma, sendo importante ressaltar que em nenhum dos casos o revestimento foi danificado permitindo escape de partículas/“beads" do seu interior. Depois da mastigação, as "biocápsulas" foram armazenadas em recipientes identificados e enviadas para análise em laboratório. As análises das "biocápsulas" foram realizadas no Laboratório de Eficiência Mastigatória do Departamento de Clínica Infantil, Odontologia Preventiva e Social da FORP-USP pelo técnico responsável pelo laboratório que não tinha conhecimento dos participantes e respectivos grupos.

No laboratório, as "biocápsulas" foram cortadas, o conteúdo então colocado em um Becker de vidro e dissolvido em $5 \mathrm{~mL}$ de água destilada sob movimento constante por 30 segundos (Fig. 11B, C, D). Em seguida, esta solução foi filtrada em papel filtro, para a remoção do envoltório (Fig. 11E) e das partículas/“beads” que não foram trituradas, e o conteúdo filtrado foi mantido em tubos de ensaios identificados. Após este processo, o corante (fucsina) da solução foi quantificado por meio do espectrofotômetro (Fig. 11F), o qual mensurou a coloração da solução em absorbância no comprimento de onda de 546 nm. 

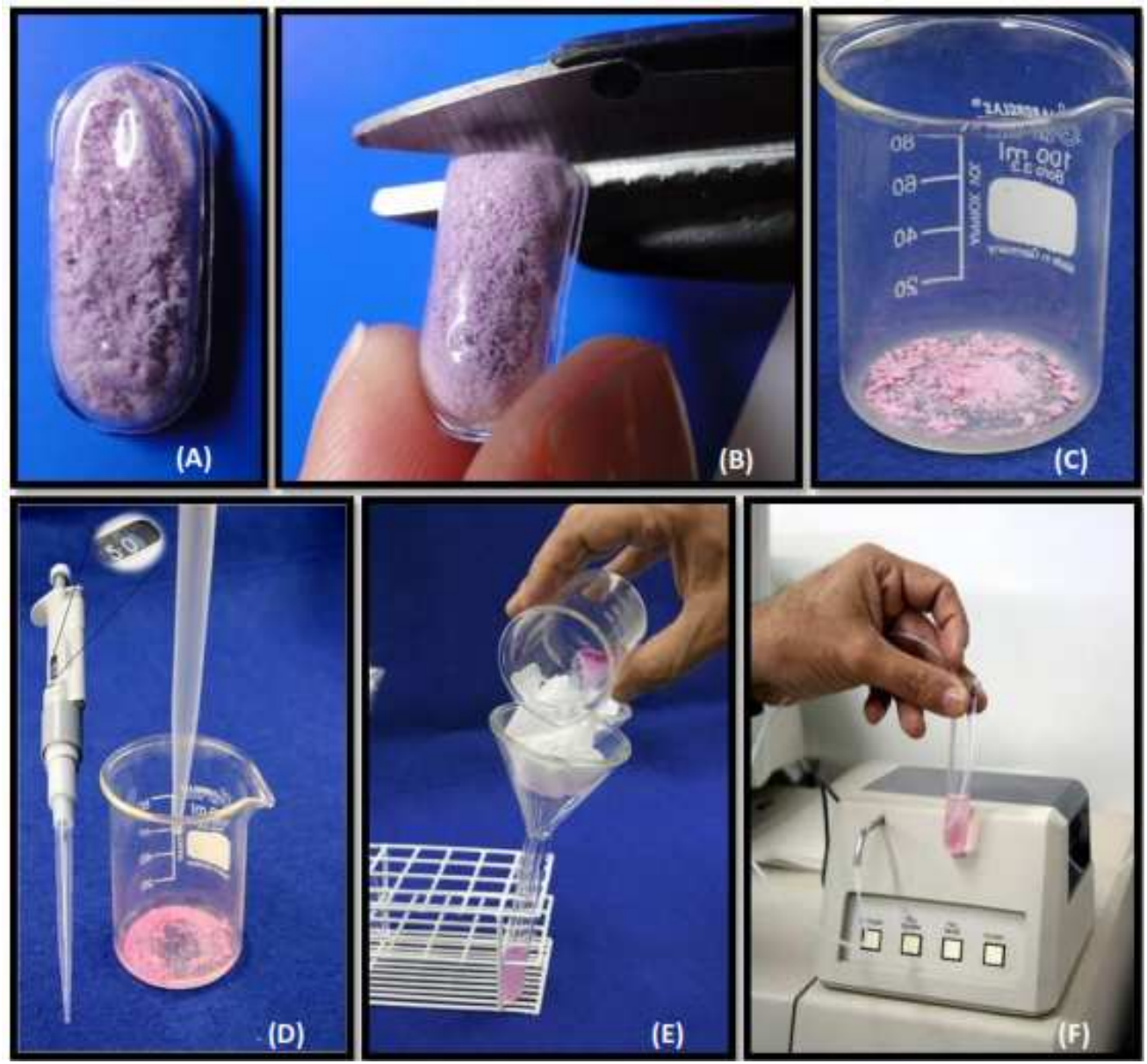

Figura 11 - Seqüência dos passos para a análise da performance mastigatória: (A) "Biocápsula" após mastigação; (B) Abertura da "Biocápsula" com auxílio de tesoura; (C) Conteúdo da "Biocápsula" despejado em Becker de vidro; (D) Dissolução do conteúdo em 5 ml de água; (E) Solução sendo filtrada após a dissolução; (F) Leitura da solução filtrada no espectrofotômetro Beckman DU-640 UV Visível.

Os valores da absorbância encontrados foram transformados em concentração do corante fucsina a partir de uma curva padrão, calculado pela equação 1 (Fig. 12).

$$
\text { Equação 1: } y=0.167 x-0.0045
$$

Figura 12 - Equação utilizada para o cálculo da concentração do corante fucsina.

Em que:

y corresponde à absorbância em 546 nm;

$\mathbf{x}$ corresponde à concentração do corante em micrograma por mililitro $(\mu \mathrm{g} / \mathrm{ml})$. 
Assim, para cada "biocápsula" mastigada, foi encontrado um valor em concentração de fucsina $(\mu \mathrm{g} / \mathrm{ml})$ que correspondeu à performance mastigatória (Picinato-Pirola, 2010; Borges, 2011).

Para a comparação da performance mastigatória dos grupos $S$ e $C$ em relação ao grupo $D N$ utilizou-se uma regra de três simples (Equações 2 e 3) considerando a média da performance mastigatória conseguida pelo grupo DN como sendo 100\% (Silveira, 2005; Prado et al., 2006) (Fig. 13A, B).

Equação 2: $\mathrm{X}=\frac{\mathrm{PM}_{\mathrm{S}} \times 100}{\mathrm{PM}_{\mathrm{DN}}}$ (B) \begin{tabular}{l} 
Equação 3: $\mathrm{Y}=\frac{\mathrm{PM}_{\mathrm{C}} \times 100}{\mathrm{PM}_{\mathrm{DN}}}$ \\
\hline (A)
\end{tabular}

Figura 13 - (A) equação 2, utilizada para o cálculo da PM do grupo $S$ em relação ao $D N$; (B) equação 3, utilizada para o cálculo da PM do grupo $C$ em relação ao $D N$.

Em que:

$\mathbf{X}$ corresponde a porcentagem da performance mastigatória do grupo $S$ em relação ao grupo $D N$

Y corresponde a porcentagem da performance mastigatória do grupo $C$ em relação ao grupo $D N$

$\mathbf{P M}_{\mathbf{S}}$ corresponde ao valor médio da performance mastigatória do grupo $S$;

$\mathbf{P M}_{\mathbf{C}}$ corresponde ao valor médio da performance mastigatória do grupo $C$;

$\mathbf{P M}_{\mathrm{DN}}$ corresponde ao valor médio da performance mastigatória do grupo $D N$; 


\subsubsection{Habilidade Mastigatória}

Duas abordagens foram utilizadas para a aferição da habilidade mastigatória percebida pelos participantes. Uma avaliação foi realizada por meio de um questionário (Questionário HM), considerando a experiência do participante no dia-a-dia quanto à possibilidade de se alimentar sem modificar seus hábitos por problemas com a prótese e a mastigar alimentos de consistência firme (Borges, 2007; Mendes, 2008). O questionário contém cinco questões com respostas de sim ou não (Apêndice E). Quando mais de 50\% das respostas foi favorável ao esperado, a habilidade mastigatória foi definida como satisfatória, e como insatisfatória quando mais de $50 \%$ das respostas foi desfavorável. Para os participantes do Grupo $D N$, nas questões (1) e (3) do questionário, a palavra prótese foi substituída por dentição e o questionário aplicado.

Uma segunda verificação da habilidade mastigatória foi feita por meio de uma questão sumária a ser respondida por meio de uma escala visual analógica (EVA) com uma questão referente à percepção de cada pessoa quanto à capacidade de triturar os alimentos. A escala é graduada de 0 a 10, sendo os extremos correspondentes aos dizeres: "totalmente insatisfeito" e "completamente satisfeito", respectivamente (Apêndice E). Foram considerados satisfeitos com a sua capacidade em triturar os alimentos os indivíduos que assinalaram acima de sete na EVA (Awad et al., 2003; Silveira, 2005; Prado et al., 2006; Borges, 2007; Mendes, 2008).

\subsubsection{Análise dos resultados}

Todos os testes estatísticos foram realizados por meio do software SPSS Statistics 17.0 (SPSS Inc. Chicago, IL, EUA), respeitando-se um nível de significância de 5\%. 


\subsubsection{Performance mastigatória}

A variável de desfecho relacionada à performance mastigatória foi a concentração de fucsina liberada nas cápsulas $(\mu \mathrm{g} / \mathrm{mL})$, que apresentou distribuição próxima à normal, conforme o teste de Shapiro-Wilk. A análise estatística foi realizada por meio do método de equações de estimação generalizadas (GEE) com uma função de ligação do tipo identidade. GEE foram utilizadas no lugar de uma ANOVA tradicional, por não haver independência entre as medidas coletadas dentro dos diferentes números de ciclos mastigatórios. Além disso, uma matriz de correlação de análise intercambiável foi assumida, além de estatística de escores generalizados no lugar de testes de Wald. Os "grupos" foram inseridos como fator de variação independente, enquanto o número de ciclos foi trabalhado como fator pareado.

Comparações múltiplas foram realizadas por meio do teste de Bonferroni. Por meio desse teste, observamos as diferenças entre pares dentro de cada fator significante, bem como a interação fatorial. Considerou-se a realização de uma análise de casos completos somente quando participantes foram perdidos por causas evidentemente externas à pesquisa (ex.: óbito ou doença sistêmica debilitante). Nas demais situações, quando houve dúvidas sobre essa falta de relação ou desistências ocorreram por motivos relacionados à pesquisa ou tratamentos fornecidos (ex.: participante insatisfeito com as próteses), decidiu-se pela análise dos dados perdidos (Lesaffre et al., 2009). Nesse caso, realizou-se a análise de sensibilidade mencionada por Jadad e Enkin (2007). Em outras palavras, foi planejado imputar o resultado mais alto observado para os participantes perdidos no grupo com os menores valores, e usar o valor mais baixo em perdidos no grupo com maiores valores. Em seguida, repetiu-se o teste estatístico e possíveis discrepâncias nos resultados seriam discutidas frente à possibilidade da perda de dados levarem a resultados enviesados que são evidenciados por diferentes conclusões conduzidas pela mesma comparação feita com casos completos. 


\subsubsection{Habilidade mastigatória}

A habilidade mastigatória resultou em uma variável dicotômica para cada uma das cinco questões, as quais foram avaliadas por meio do teste $\chi^{2}$. Dessa forma, testou-se a hipótese nula de que a distribuição das respostas entre os grupos se deu por acaso. A habilidade mastigatória também foi avaliada por meio de um escore de 0 a 5 (pior e melhor habilidade mastigatória, respectivamente), que se originou da soma das respostas satisfatórias para cada uma das questões. Nesse último caso, uma comparação entre os métodos de confecção das próteses totais foi realizada por meio do teste de Mann-Whitney. Ressalta-se que o grupo dentado não foi incluído nessas comparações devido à homogeneidade dos resultados (100\% dos participantes forneceram as mesmas respostas satisfatórias).

Uma terceira abordagem consistiu na variável quantitativa discreta originada por meio da EVA. Devido à distribuição assimétrica, a comparação entre os três grupos foi realizada por meio do teste de Kruskal-Wallis.

A fim de averiguar a influência de participantes desistentes sobre os resultados, conduzimos a mesma análise de sensibilidade realizada para a performance mastigatória. 

4. Resultados 



\subsection{Amostra}

Setenta e dois pacientes compareceram à Clínica de Prótese Total para triagem. Desses, foram excluídos sete pacientes por terem idade inferior a 45 anos, cinco por terem história recente de extração dentária, sete por possuírem elementos dentários remanescentes, dois por se recusarem a receber próteses novas, três por apresentarem sinais e sintomas de desordens temporomandibulares e, por fim, seis por apresentarem problemas cognitivos e motores, como má compreensão do português e/ou necessidade de acompanhante para responder aos questionamentos. Dos 42 pacientes restantes, uma do grupo $S$ foi perdida por falecimento antes da instalação dos aparelhos protéticos e outra por motivo de doença após a sessão de instalação; isso impossibilitou sua vinda aos retornos para ajustes e levou à exclusão dessas participantes da análise estatística. No grupo $C$, um paciente desistiu de continuar com os ajustes após instalação das próteses por ter ficado insatisfeito com o tratamento, o qual foi considerado para análise de pior cenário. Para a avaliação da performance e habilidade mastigatórias após 3 meses da instalação das próteses totais, quatro pacientes, sendo dois de cada grupo $(C$ e $S)$, não foram incluídos na análise estatística, pois o tempo de 3 meses da instalação das próteses totais ainda não havia completado. Assim, a amostra para este trabalho foi de 35 pacientes, sendo 16 homens e 19 mulheres, com idade entre 47 a 80 anos (idade média: $64,9 \pm 8,04$ anos). A figura 14 apresenta o fluxograma dos participantes deste trabalho.

O grupo de dentados $(D N)$ foi composto por 17 participantes, sendo 8 homens e 9

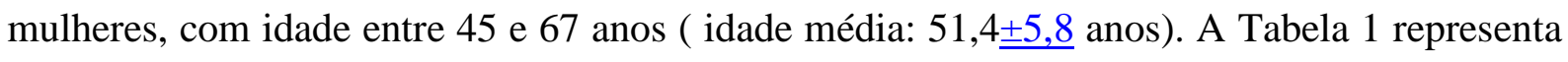
as características demográficas da amostra do estudo. 


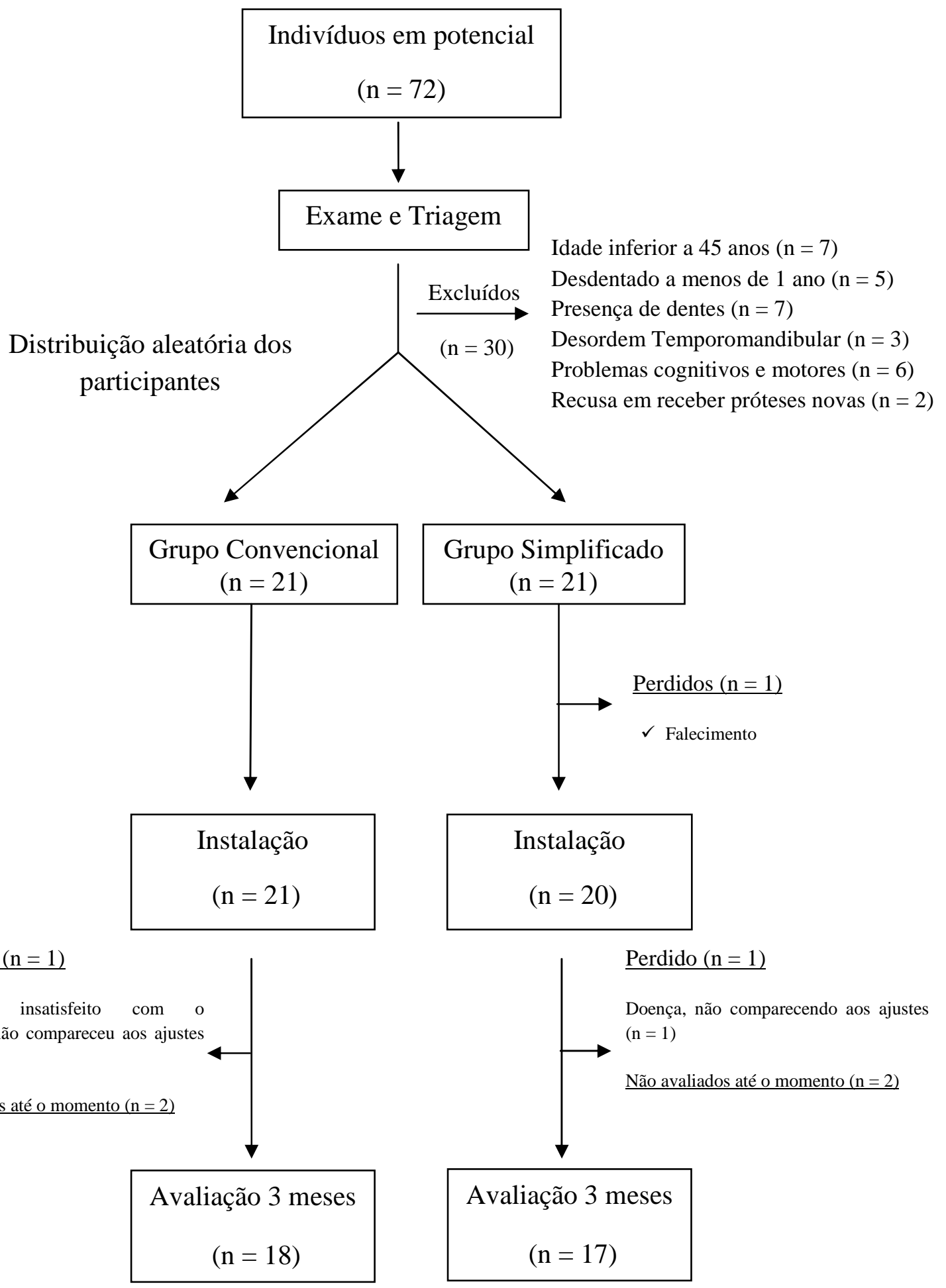

Figura 14 - Fluxograma dos participantes dos Grupos $C$ e $S$ (adaptado da Declaração CONSORT). 
Tabela 1 - Características demográficas da amostra do estudo.

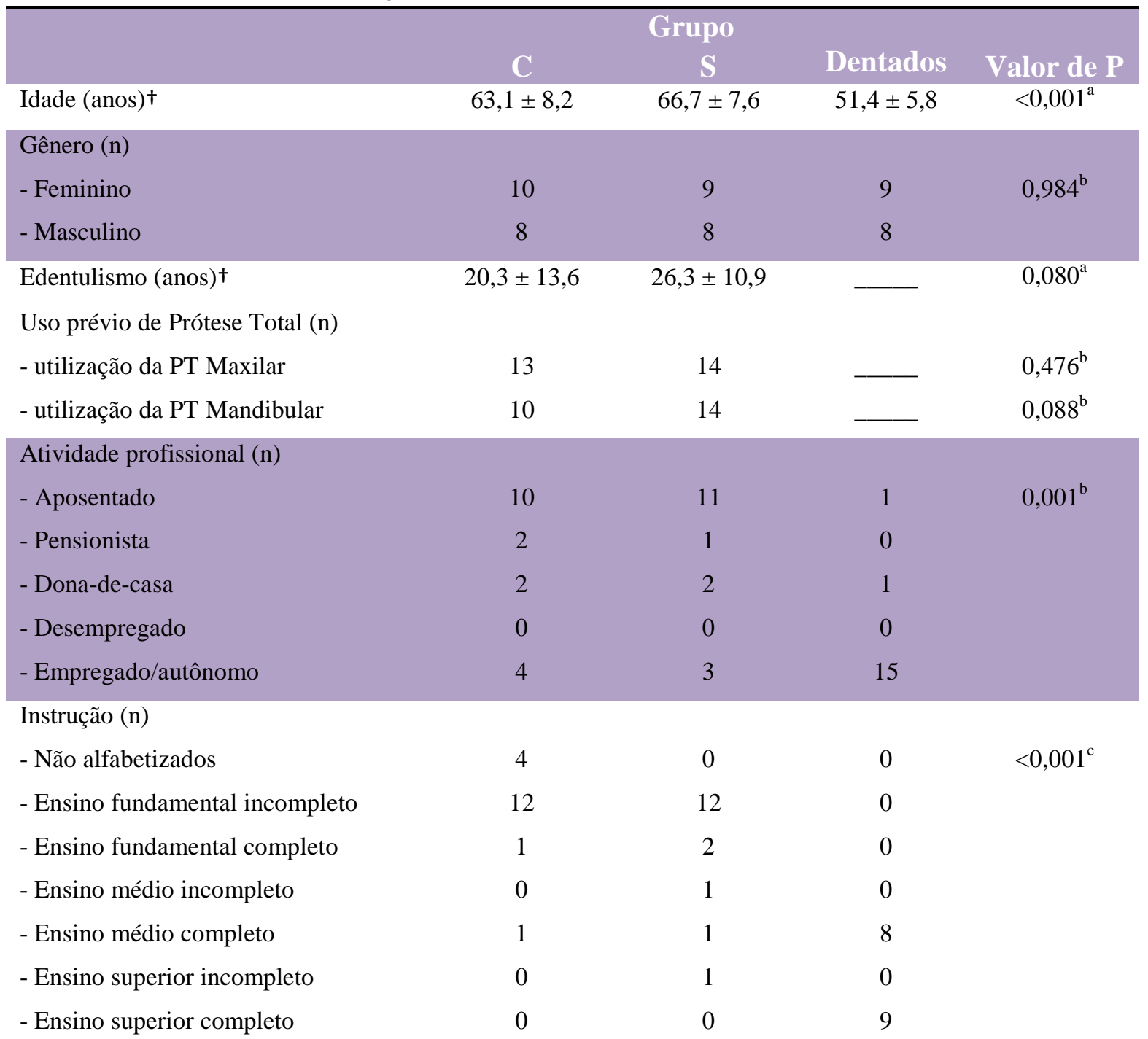

$\begin{array}{lcccc}\text { Estado civil (n) } & 7 & 10 & 17 & 0,003^{\mathrm{b}} \\ \text { - Casado } & 0 & 2 & 0 & \\ \text { - Solteiro } & 5 & 1 & 0 & \\ \text { - Divorciado } & 6 & 3 & 0 \\ \text { - Viúvo } & 0 & 1 & 0\end{array}$

Classificação da ACP

$\begin{array}{llll}\text { - I } & 1 & 1 & - \\ \text { - II } & 7 & 6 & -848^{\mathrm{d}} \\ \text { - III } & 3 & 5 & - \\ \text { - IV } & 7 & 5 & -\end{array}$

†Valores expressos em média \pm desvio-padrão. Comparações feitas pelos testes ${ }^{a}$ ANOVA; $\quad{ }^{b} \chi^{2} ;{ }^{c}$ Kruskal-Wallis; ${ }^{\mathrm{d}}$ MannWhitney. 
As médias etárias foram diferentes entre os grupos, sendo que os grupos tratados com próteses totais $(C$ e $S)$ foram semelhantes, mas foram diferentes do grupo dentado $(D N)$ (teste HSD de Tukey). No caso do uso prévio de próteses totais, os grupos tratados foram semelhantes e apresentaram predominância de usuários. Apesar de haver semelhança na proporção entre homens e mulheres, os três grupos diferiram nas demais características demográficas, devido à concentração de participantes profissionalmente ativos, universitários e casados no grupo dentado, frente a uma predominância de pacientes aposentados, com baixo grau de instrução e diversos estados civis nos demais grupos. Em relação às 4 categorias do Índice Diagnóstico do ACP, não foi encontrada diferença entre os grupos tratados com próteses totais, demonstrando que a complexidade dos casos tratados foi similar.

\subsection{Performance mastigatória}

A concentração média de fucsina $(\mu \mathrm{g} / \mathrm{ml})$ liberada após a mastigação das cápsulas, em função dos grupos $C, S$ e $D N$, e dos ciclos mastigatórios avaliados para cada grupo está ilustrada na Figura 15.

A Figura 15 mostra que o grupo $D N$ apresentou médias marcadamente superiores aos demais, independentemente do número de ciclos considerados. Os grupos tratados com próteses totais não demonstram diferenças de grande magnitude dentro de cada número de ciclos avaliados. Porém, a concentração de fucsina $(\mu \mathrm{g} / \mathrm{ml})$ parece proporcional ao número de ciclos nos três grupos, como efeito da mastigação contínua sobre as cápsulas.

A menor performance mastigatória alcançada no grupo $D N$ com 20 ciclos mastigatórios, foi maior em relação à melhor performance mastigatória alcançada nos grupos $C$ e $S$ com 40 ciclos mastigatórios. 


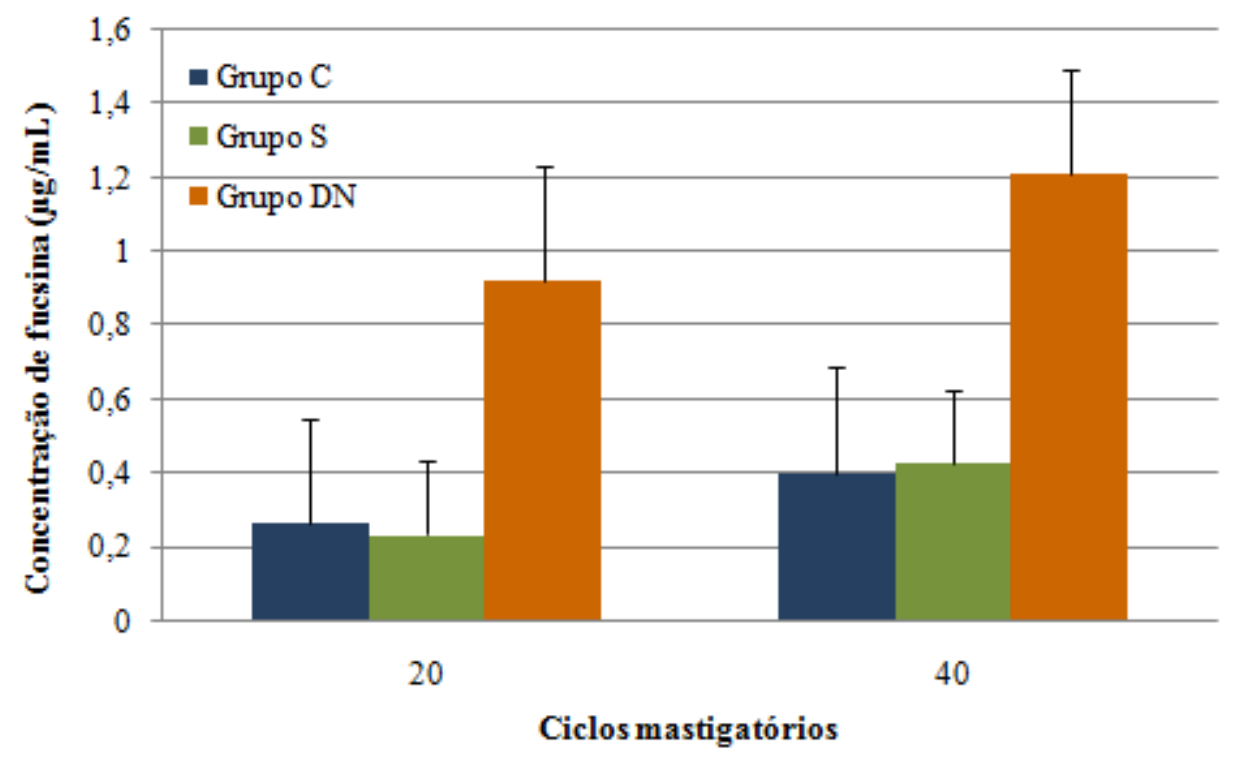

Figura 15 - Concentração média de fucsina liberada após mastigação das cápsulas, em função dos grupos e ciclos avaliados. As barras de erro representam os desviospadrão.

Por meio da análise por GEE, observou-se que a performance mastigatória sofreu influência significativa dos grupos do estudo, bem como do número de ciclos empregados no protocolo. Por outro lado, a interação entre os dois fatores não foi significante (Tabela 2), o que significa que as diferenças encontradas entre os grupos foram independentes dos ciclos, ou seja, que a diferença significante entre a concentração média de fucsina $(\mu \mathrm{g} / \mathrm{mL})$ do grupo $D N$ e os grupos $C$ e $S$, foi independente de se considerar a performance após 20 ou 40 ciclos. Bem como significa que as diferenças encontradas entre os ciclos foram independentes dos grupos, ou seja, houve diferença significante entre a concentração de fucsina $(\mu \mathrm{g} / \mathrm{mL})$ após 20 e 40 ciclos, e essa diferença teve a mesma magnitude para os grupos $C, S$ ou $D N$.

Tabela 2 - Efeito dos fatores considerados pelas GEE, para a concentração de fucsina $(\mu \mathrm{g} / \mathrm{mL})$.

\begin{tabular}{cccc}
\hline Fonte & $\chi^{2}$ & Gl & $\mathrm{P}$ \\
\hline Grupos & 25,702 & 2 & $<0,001 *$ \\
$\mathrm{~N}^{\mathrm{o}}$ de ciclos & 23,088 & 1 & $<0,001 *$ \\
Interação & 2,799 & 2 & 0,247 \\
\hline * Significante $(\mathrm{P}<0,05)$. & & &
\end{tabular}


Inserindo o único desistente na análise por meio da análise de pior cenário, os valores de $\mathrm{P}$ mantêm-se próximos, com uma mudança somente no caso da interação $(\mathrm{P}=0,205)$, e sem alteração nos resultados posteriormente descritos.

As concentrações médias de fucsina $(\mu \mathrm{g} / \mathrm{ml})$ liberada, após a mastigação das cápsulas estão ilustradas na Figura 16, em função dos grupos $C, S$ e $D N$. As médias estimadas e respectivos erros padrão para concentração de fucsina $(\mu \mathrm{g} / \mathrm{mL})$, em função dos grupos, foram: $0,34 \pm 0,06(C), 0,33 \pm 0,05(S)$ e $1,07 \pm 0,06(D N)$. Nesse caso, os valores para os dois grupos tratados com próteses totais $(C$ e $S)$ não apresentaram diferença significante $(\mathrm{P}>0,05)$, enquanto que ambos foram diferentes do grupo de participantes dentados $(\mathrm{P}<0,05)$, que apresentou maior performance mastigatória.

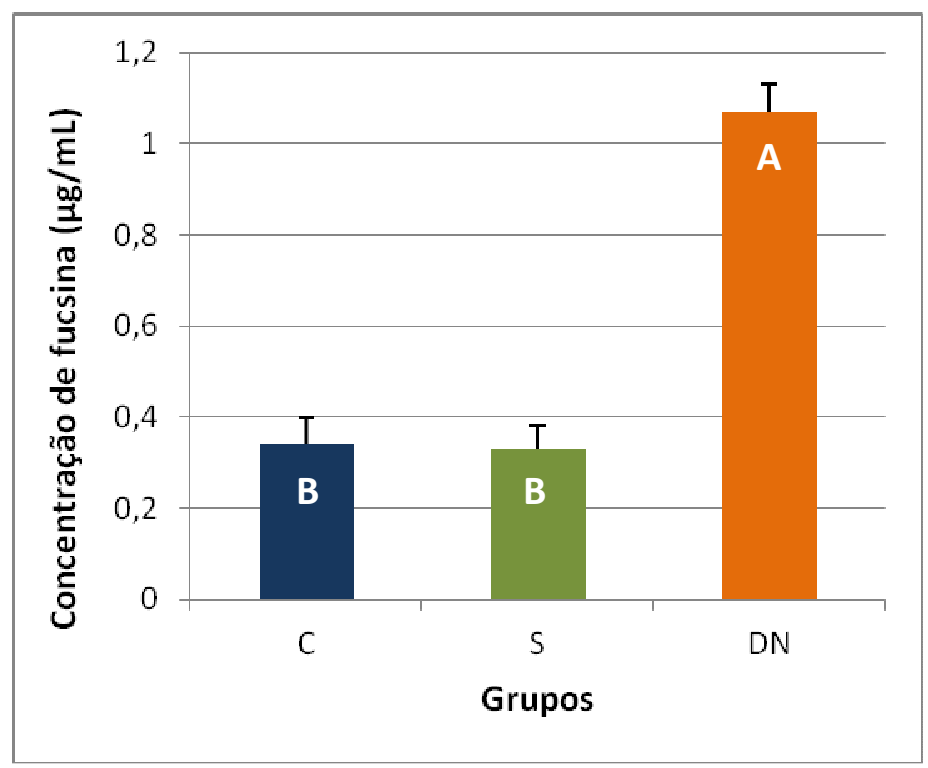

Figura 16 - Concentração média de fucsina liberada após mastigação das cápsulas, em função dos grupos. As barras de erro representam os erros-padrão. Letras iguais representam semelhança estatística conforme encontrado pelas GEE.

Para a quantificação da performance mastigatória dos três grupos estudados, a performance mastigatória do grupo $D N$ foi considerada como $100 \%$, como já explicado anteriormente, a partir das equações 2 e 3 (vide material e método, item 3.2.5.1.). Nesse caso, observou-se que a performance mastigatória dos participantes do ensaio clínico de ambos os grupos $C$ e $S$, corresponde a $31 \%$ daquela observada no grupo $D N$. 
A concentração média de fucsina $(\mu \mathrm{g} / \mathrm{ml})$ liberada, após a mastigação das cápsulas, e respectivos erros padrão estão ilustrados na Figura 17, em função dos ciclos mastigatórios 20

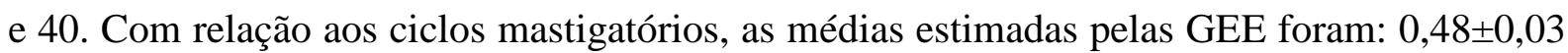
e $0,68 \pm 0,04 \mu \mathrm{g} / \mathrm{mL}$ para 20 e 40 ciclos, respectivamente. A análise considerou a média dos 40 ciclos significantemente maior que a dos 20 ciclos $(\mathrm{P}<0,05)$. Sendo assim, o número de ciclos influencia a leitura obtida, com maiores concentrações de fucsina associadas aos 40 ciclos mastigatórios, independente do grupo em questão.

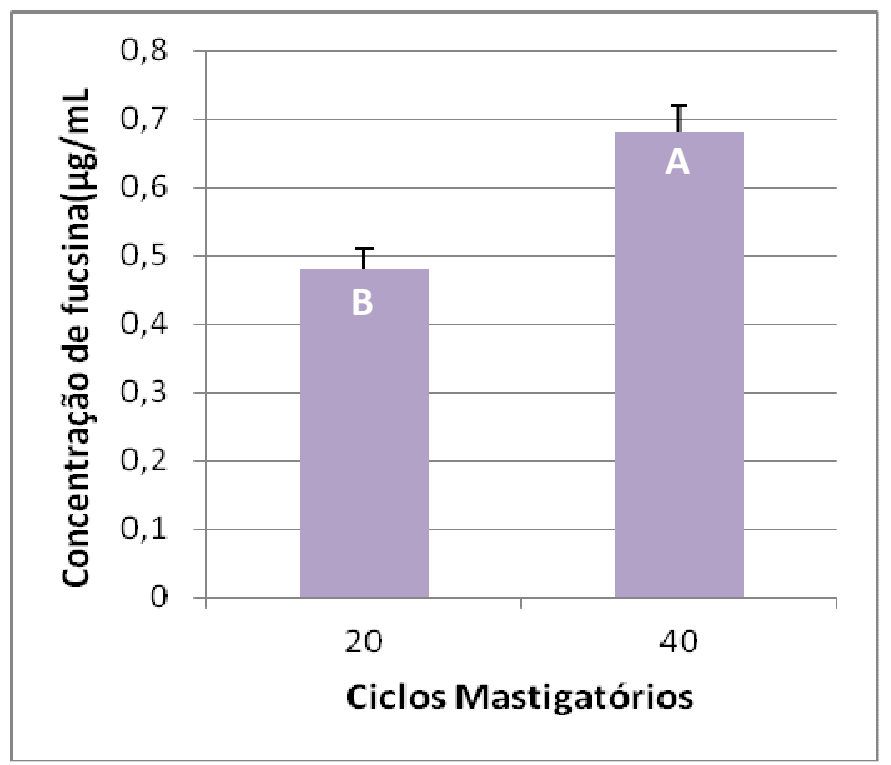

Figura 17 - Concentração média de fucsina liberada após mastigação das cápsulas, em função dos ciclos mastigatórios. As barras de erro representam os erros-padrão. Letras iguais representam semelhança estatística conforme encontrado pelas GEE.

\subsection{Habilidade mastigatória}

A Tabela 3 representa as respostas dos pacientes dos grupos $C$ e $S$ para as cinco questões do questionário HM, às quais foram atribuídos escores 1 para respostas satisfatórias e 0 para respostas insatisfatórias, e a Figura 18 representa a soma dos escores das cinco 
questões. Os dados do grupo $D N$ não foram incluídos na Tabela 3 e Figura 18 porque todos os participantes tiveram o mesmo resultado, ou seja, escore máximo para todas as questões. Por esse mesmo motivo, não foram incluídos na análise inferencial, devido à evidente diferença de comportamento com relação aos usuários de próteses totais (grupos $C$ e $S$ ).

Foram encontradas diferenças significantes para as respostas das questões 1,2 e 3 $(\mathrm{P}<0,05)$ do questionário $\mathrm{HM}$ entre os grupos $C$ e $S$, sendo que para o grupo $S$ as respostas foram significantemente mais satisfatórias para estas questões. Porém, não houve diferença significante para as respostas das questões 4 e 5 do questionário $\mathrm{HM}$ entre os grupos $C$ e $S$.

Quando o participante desistente foi considerado na análise, os resultados foram parecidos para quase todas as questões, exceto a de $n^{\circ} 3$ (se o participante tem alterado a alimentação por causa da prótese). Neste caso, a diferença passa a não ser mais significante.

Em nenhum dos grupos tratados com próteses, houve ausência de respostas desfavoráveis às questões. O paciente desdentado tende a perceber alimentação e mastigação como mais favoráveis quando tratados com próteses totais confeccionadas de acordo com o protocolo simplificado. Isso também ocorreu para a necessidade de alterar a alimentação em função de problemas com as próteses, quando da análise de casos completos. Por outro lado, é possível que a desistência relatada tenha sido importante para essa questão, o que indicaria um tamanho amostral um pouco maior a fim de respostas conclusivas. Por fim, o tipo de dieta parece não ser influenciado pelas técnicas de confecção estudadas, conforme visto nas questões $n^{\circ} 4$ e 5 . 
Tabela 3. Respostas para o questionário HM referente à habilidade mastigatória, em função dos métodos de confecção das próteses totais.

\begin{tabular}{ccccccc}
\hline \multirow{2}{*}{ Questões } & Respostas & \multicolumn{2}{c}{ Método } & & \multicolumn{2}{c}{$\mathbf{P}\left(\right.$ teste $\left.\chi^{2}\right)$} \\
\cline { 3 - 4 } & & Convencional & Simplificado & Total & $\begin{array}{c}\text { Caso } \\
\text { completo }\end{array}$ & $\begin{array}{c}\text { Pior } \\
\text { cenário } \dagger\end{array}$ \\
\hline \multirow{2}{*}{ Q1 (alimenta-se bem) } & Não (0) & 7 & 1 & 8 & & \\
& Sim (1) & 11 & 16 & 27 & $0,020^{*}$ & $0,026^{*}$ \\
& Total & 18 & 17 & 35 & & \\
\hline \multirow{2}{*}{ Q2 (mastigação) } & Não (0) & 8 & 2 & 10 & & \\
& Sim (1) & 10 & 15 & 25 & $0,032^{*}$ & $0,042^{*}$ \\
& Total & 18 & 17 & 35 & & \\
\hline \multirow{3}{*}{ Q3 (alterou alimentação) } & Sim (0) & 6 & 1 & 7 & & \\
& Não (1) & 12 & 16 & 28 & $0,042^{*}$ & 0,052 \\
& Total & 18 & 17 & 35 & & \\
\hline \multirow{3}{*}{ Q4 (alimentos firmes) } & Não (0) & 9 & 4 & 13 & & \\
& Sim (1) & 9 & 13 & 22 & 0,105 & 0,137 \\
& Total & 18 & 17 & 35 & & \\
\hline \multirow{2}{*}{ Q5 (dieta macia) } & Sim (0) & 7 & 3 & 10 & & \\
& Não (1) & 11 & 14 & 25 & 0,164 & 0,199 \\
& Total & 18 & 17 & 35 & & \\
\hline
\end{tabular}

* Diferença significante $(\mathrm{P}<0,05)$. †Obtida após a inserção de uma resposta de valor “1" por questão.

Após o uso do questionário HM, a habilidade mastigatória foi considerada satisfatória quando mais de $50 \%$ das respostas foi favorável ao esperado, e como insatisfatória quando mais de $50 \%$ das respostas foi desfavorável. Nesse contexto a habilidade mastigatória foi considerada favorável para 16 pacientes do grupo $S$ e 10 do grupo $C$, e insatisfatória para 1 paciente do grupo $S$ e 8 do grupo $C$.

Não houve diferença significante para o escore geral (teste de Mann-Whitney, $\mathrm{P}=0,088$ ). Este resultado demonstra que não houve diferença entre a habilidade mastigatória dos participantes dos dois grupos $(C$ e $S$ ), quando se considerou a soma dos escores das respostas às cinco questões do questionário HM. Com a inclusão do participante desistente na análise, inserindo-se um escore "5", a hipótese de igualdade entre os grupos continuou aceita $(\mathrm{P}=0,123)$. Isso demonstra que o método de confecção das próteses não provoca grandes alterações na forma como o paciente percebe sua própria capacidade de mastigar, a despeito de muitos possuírem queixas improváveis em portadores de dentição natural saudável. 


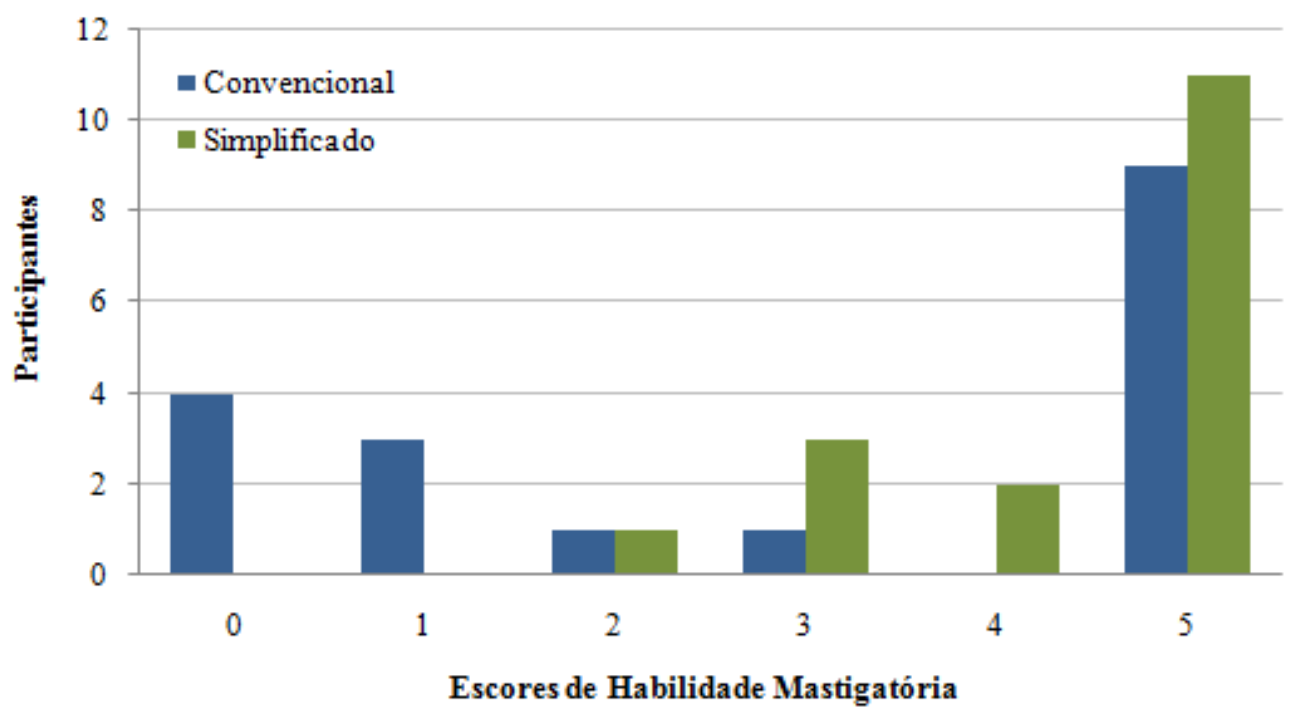

Figura 18 - Soma dos escores das cinco questões referentes à habilidade mastigatória.

A Figura 19 apresenta os valores da questão da EVA - capacidade de mastigar os alimentos - expressos pelos participantes dos grupos $C, S$ e $D N$, sendo que quanto maior o valor, melhor é a percepção dos participantes em relação à sua própria capacidade de mastigar. Foram considerados satisfeitos com a sua capacidade em triturar os alimentos os indivíduos que assinalaram acima de sete na EVA. Sendo assim, 3 pacientes do grupo $C$ e 2 do grupo $S$ foram considerados insatisfeitos, enquanto 15 pacientes do grupo $C$ e 15 do grupo $S$ foram considerados satisfeitos. Todos os participantes do grupo $D N$ assinalaram notas acima de sete, portanto todos foram considerados satisfeitos com sua capacidade de mastigar.

Não houve diferença significante para o escore geral (teste de Kruskal-Wallis, $\mathrm{P}=0,697)$. Este resultado demonstra que não houve diferença entre a habilidade mastigatória dos participantes dos três grupos após utilização da EVA, o que contrasta com o resultado do questionário e sugere que esse método possua menor capacidade de discriminar as diferenças entre os grupos avaliados.

A análise de pior cenário não mostrou um efeito da desistência de um dos participantes, resultando em valor de $\mathrm{P}$ de 0,817 para o teste de Kruskal-Wallis. 


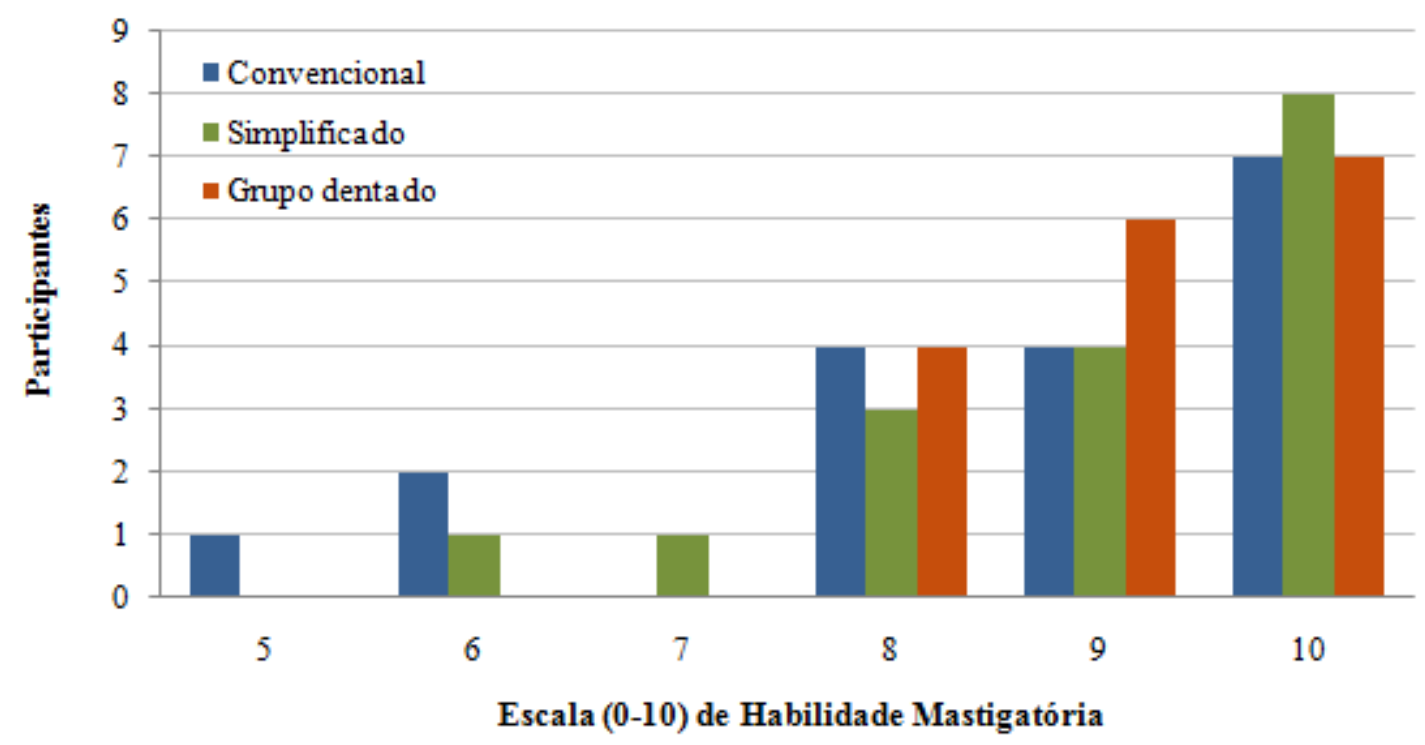

Figura 19. Valores de habilidade mastigatória, obtidos por meio da EVA. 




\subsection{Desenho do estudo}

Neste trabalho, o grupo de participantes com dentição natural $(D N)$ foi observacional, contrário aos grupos de pacientes que receberam tratamento com próteses totais convencionais, grupos $C$ e $S$, que são grupos paralelos dentro de um ensaio clínico controlado aleatorizado. A inclusão do grupo $D N$ nessa $3^{a}$ parte específica da proposta maior do estudo, após recrutamento de acordo com os critérios de inclusão e exclusão, teve o objetivo de enriquecer as comparações com os grupos $C$ e $S$, no sentido de averiguar a concordância ou não de dados de performance e habilidade mastigatórias de grupos de usuários de próteses totais convencionais em relação à indivíduos dentados, relatados na literatura.

Apesar do controle de vieses ser relativamente objetivo em um ensaio clínico, um estudo observacional apresenta características que dificultam essa conduta, como a impossibilidade de os participantes vindos de uma mesma população serem sorteados para um dos grupos. O que ocorre, em contraste, é o recrutamento dentro de dois grupos populacionais distintos - neste estudo, pacientes indicados para próteses totais e voluntários completamente dentados. Sendo assim, foram realizados testes estatísticos para avaliação das características demográficas dos participantes da pesquisa com o objetivo de descartar a influência de fatores confundidores sobre os resultados, principalmente pelo fato de ter sido incluído o grupo observacional $D N$.

Não foram encontradas diferenças significantes entre os gêneros dos participantes dos grupos $C, S$ e $D N$. Este dado tem importância fundamental, visto que assim como o número de unidades dentais funcionais, a força de mordida também é considerada um dos preditores da performance mastigatória (Hatch et al., 2001; Okiyama et al., 2003), a qual é maior nos homens (Helkimo et al., 1977; Hatch et al., 2001; Koç et al., 2011). A medida da força de mordida é vista como um método indireto na avaliação da função mastigatória, baseada na 
correlação entre ambas (Boretti et al., 1995) e tem sido considerada de 5 a 6 vezes maior em indivíduos dentados comparados com usuários de próteses totais (Haralson et al., 1979a).

As características etárias da amostra merecem comentários mais profundos, já que foram encontradas diferenças significantes entre o grupo $D N$ e os grupos $C$ e $S$, que não foram diferentes entre si. Apesar da inclusão de participantes no grupo $D N$ na faixa etária de 45 anos ou mais, que foi a mesma faixa etária de inclusão nos grupos $C$ e $S$, a idade média do grupo $D N$ foi de 51,4 anos, devido à dificuldade de recrutar indivíduos mais velhos. Indivíduos dentados com mais de 65 anos, especialmente com as demais características demográficas similares aos pacientes desdentados, se mostraram extremamente raros e seria inviável depender deles para a formação de uma amostra estatisticamente representativa. $\mathrm{O}$ contrário foi encontrado nos grupos $C$ e $S$, nos quais a idade média dos participantes foi superior que 60 anos, o que pode ser devido à prevalência do edentulismo ser maior nesta faixa etária para cima (IBGE, 2010).

Com o aumento da idade a força de mordida tende a diminuir em indivíduos adultos, principalmente entre as mulheres (Bakke et al., 1990; Miyaura et al., 1999); no entanto, essa relação tem sido considerada dependente da deterioração da dentição relacionada à idade (Helkimo et al., 1977). Porém, Akeel, et al. (1992), após encontrarem diferença na eficiência mastigatória de indivíduos dentados em diferentes faixas etárias (abaixo e acima de 40 anos), sugeriram que o mais apropriado seria avaliar a eficiência mastigatória pela dicotomização das diferentes faixas etárias.

A diminuição da força de mordida pode ser um efeito direto da idade sobre a força muscular, ou pelas mudanças causadas na seleção de alimentos pela deterioração da dentição (Van Der Bilt, 2011). Para usuários de próteses totais é esperado que a força de mordida seja menor que em indivíduos dentados, independente da idade, visto que a perda dos dentes é um fator mais significativo na diminuição da força de mordida que o envelhecimento em si (Ikebe 
et al., 2005). Além dos efeitos da perda de dentes e atrofia muscular, a força de mordida em usuários de próteses removíveis pode ser limitada porque o tecido de suporte da prótese é mais sujeito ao desconforto, compressão e deslocamento da mesma (Fontijn-Tekamp et al., 2000). Entretanto, Wayler e Chauncey (1983) não encontraram diferença na performance mastigatória de usuários de próteses totais divididos em diferentes faixas etárias (menos de 40 anos, entre 40 e 49 anos, e mais de 50 anos), assim como Gunne, et al. (1982) não encontraram diferença na eficiência mastigatória entre grupos de usuários de próteses totais divididos nas faixas etárias com mais e menos de 60 anos.

Os grupos $C$ e $S$ não diferiram entre si nas demais características demográficas pela predominância de pacientes aposentados, com baixo grau de instrução e diversos estados civis, semelhante ao que foi encontrado nos pacientes edêntulos dos trabalhos de Heydecke, et al. (2008) e Kawai, et al. (2010). Em relação a estas características, Hunt, et al. (1985) encontraram maior prevalência de pessoas idosas edêntulas, quando estas tinham menor grau de instrução, eram não casadas e não ocupavam cargos profissionais. Os grupos $C$ e $S$ foram diferentes do grupo $D N$ em relação a estas características demográficas, devido à concentração de participantes profissionalmente ativos, universitários e casados no grupo dentado. Essas diferenças entre o grupo dentado e os demais não parecem exercer influência sobre os resultados, mas tem uma provável relação com o fato dos participantes terem preservados sua dentição até idades mais avançadas. $\mathrm{O}$ edentulismo tende a ser menos freqüente em indivíduos em condições socioeconômicas favorecidas (Petersen et al., 2005).

O uso prévio de próteses totais, bem como o tempo de edentulismo, foi semelhante entre os grupos tratados. O uso prévio do par de próteses totais não foi considerado um critério de inclusão ou exclusão do trabalho, sendo considerado somente o tempo de desdentamento superior a 1 ano como critério. Apesar da experiência com a utilização das próteses totais poder ser relacionada à função mastigatória, não houve diferença estatística 
entre os grupos $C$ e $S$ em relação ao tempo de edentulismo, bem como ao uso prévio de próteses totais.

Quanto à dificuldade esperada para a resolução dos casos clínicos, não foi encontrada diferença estatística entre os grupos tratados com próteses totais de acordo Índice Diagnóstico do ACP (McGarry et al., 1999). Tem sido encontrada na literatura relação entre a altura do processo alveolar com a performance e/ou eficiência mastigatórias e força de mordida (Lassila et al., 1985; Miyaura et al., 2000), apesar dessa correlação ser considerada de baixa a moderada (Slagter et al., 1992b). Sendo assim, é importante ressaltar que os grupos tratados com próteses totais foram semelhantes em termos de complexidade, e é improvável que eventuais diferenças se devam a algum confundidor, mas sim às diferenças entre protocolos clínicos.

\subsection{Protocolo clínico}

Muitos procedimentos envolvidos na confecção de próteses totais têm sido utilizados sem uma forte evidência científica de que sejam importantes para o sucesso do tratamento (Carlsson, 2010). O que se observa é a preponderância da opinião e experiência clínica de cirurgiões dentistas como determinante da conduta clínica adotada. Por outro lado, a simplificação pela eliminação e/ou modificação de passos clínicos e laboratoriais da técnica de confecção destes aparelhos protéticos não resulta em pacientes menos satisfeitos, bem como em próteses de menor qualidade (Kawai et al., 2005; Ellis et al., 2007; Heydecke et al., 2007; Heydecke et al., 2008). Sendo assim, a técnica utilizada neste trabalho para confecção das próteses do grupo $S$ se baseou nas simplificações encontradas nos poucos ensaios clínicos controlados aleatorizados sobre o tema (Kawai et al., 2005; Heydecke et al., 2008; Kawai et al., 2010). Também foi levado em consideração que os passos clínicos e laboratoriais 
eliminados na confecção das próteses totais do grupo $S$, têm potencial de tornar esta técnica de melhor custo-efetividade e sem consequiências negativas pela economia no custo (Kawai et al., 2010), requerendo menos visitas à clínica odontológica (Duncan e Taylor, 2001).

O registro dos tecidos de suporte das próteses totais é importante para muitos aspectos, como a saúde dos tecidos, função e retenção das próteses, e o sucesso desse tratamento depende grandemente de uma adequada impressão dos tecidos durante os procedimentos de moldagem (Rao et al., 2010). Esses aspectos têm sido relacionados à utilização de técnicas de moldagens mais complexas, como a utilização de moldeiras individuais e materiais de moldagens específicos, por exemplo, para moldagens de borda e para área de suporte. Porém, Owen (2006) propôs um protocolo mínimo aceitável para construção de próteses totais que inclui na fase de tratamento a moldagem final feita com um material, suportado de variadas maneiras, que permitirão ao operador alcançar conformidade com os requisitos ideais de apropriada cobertura, íntimo contato tecidual e selamento (periférico) de borda, no qual acreditamos se encaixar o passo de moldagem do grupo $S$.

Nos últimos anos, estudos têm confirmado que a utilização do arco facial nos procedimentos de transferência e montagem do modelo maxilar em articulador não oferece vantagens clínicas significantes (Shodadai et al., 2001; Nascimento et al., 2004; Kawai et al., 2005; Carlsson, 2006; Heydecke et al., 2007, 2008). Na China, apesar do uso do arco não ter sido abandonado como ensinamento, assim como no Reino Unido (Petropoulos e Rashedi, 2005), 97\% dos protesistas chineses relatam que raramente usam o arco facial (Wang et al., 2008).

Com respeito à técnica de montagem das próteses do grupo $S$ em articulador semiajustável, com o auxílio da mesa acessória, buscou-se eliminar o arco facial para montagem do modelo maxilar, com motivação nas controvérsias referentes a seu uso. Porém, o articulador foi importante para a montagem dos dentes e verificação dos contatos oclusais nas 
excursões laterais, passo este que difere do trabalho de Kawai, et al. (2005) onde foi utilizado um articulador monoplano para montagem dos modelos no grupo simplificado. Consideramos que o baixo custo decorrente do uso de um articulador semi-ajustável associada à possibilidade de um ajuste nas excursões mandibulares não justifica o uso de um equipamento mais rudimentar.

A remontagem também foi um passo eliminado, porém para ambos os grupos tratados, para que fosse possível a avaliação das diferentes montagens em articulador semi-ajustável no padrão de ajustes necessários após instalação e que foi parte da proposta maior do estudo. Isso está em concordância com o procedimento vigente no Centro de Especialidades Odontológicas de Ribeirão Preto, que emprega um protocolo de confecção de próteses totais semelhante ao usado no grupo $\mathrm{C}$ deste estudo. $\mathrm{O}$ procedimento de remontagem no articulador também não foi utilizado no trabalho de Heydecke, et al. (2008), bem como no trabalho de Kawai, et al. (2005), o qual realizou a remontagem das próteses totais em articulador após os ajustes clínicos no grupo tradicional e por meio de novos registros das relações intermaxilares, o que não foi adotado em nenhum dos grupos do presente estudo.

\subsection{Avaliação da função mastigatória}

Para a avaliação da performance mastigatória dos grupos do estudo, a seleção do método colorimétrico associado às "biocápsulas", em detrimento do método das tamises que é o mais utilizado, se deveu ao fato de que este envolve procedimentos complexos, variações dos materiais-teste utilizados e imprecisão das metodologias empregadas (Santos et al., 2006). Por outro lado, o método utilizado neste trabalho tem sido considerado de processamento laboratorial rápido e eficaz, bem como confiável, sensível e reprodutível para avaliação da performance e/ou eficiência mastigatórias (Santos et al., 2006; Farias Neto et al., 2010). 
Porém, a condução do protocolo de teste sem que os participantes estivessem habituados à mastigação de um alimento que não sofre cominuição, como as "biocápsulas", poderia não levar a resultados confiáveis. Sendo assim, procedeu-se ao uso do hiperbolóide que, além de retirar a memória neuromuscular de repouso e aproximar a mastigação do padrão habitual (Santos, 2002), serviu de instrumento de treino antes da mastigação das "biocápsulas", visto que também não sofre cominuição.

A performance mastigatória não diferiu significantemente entre os grupos $C$ e $S$, no entanto a melhor performance mastigatória alcançada no grupo $D N$ era esperada, visto que a substituição dos dentes por próteses totais não é considerada satisfatória do ponto de vista funcional. A função mastigatória de usuários de próteses encontra-se muito aquém daquela de indivíduos dentados (Prado et al., 2006; Kapur e Soman, 2006), a ponto de serem considerados inválidos orais pela deficiência quanto à função mastigatória, ainda que próteses removíveis clinicamente satisfatórias sejam utilizadas (Haraldson et al., 1979b; Helkimo et al., 1977).

Embora a importância da qualidade dos aparelhos protéticos não possa ser negada, a correlação entre a qualidade das próteses totais e a performance e/ou eficiência mastigatórias de usuários não tem sido estabelecida (Perez, et al., 1985; Budtz-Jorgensen et al., 2000; Prado et al., 2006; De Lucena et al., 2011). Isso pode ser atribuído à acomodação de indivíduos a próteses mal adaptadas, modificando seus padrões motores para otimizar a performance mastigatória (Demers et al., 1996; Ikebe et al., 2007), o que implica que o processo mastigatório é individualmente determinado e adaptado, muitas vezes compensando más condições da prótese (Witter et al., 2011).

No presente estudo, para verificar a performance mastigatória dos indivíduos dos três grupos estudados, optou-se por vinte e quarenta ciclos já que a maioria dos trabalhos sobre a performance mastigatória utilizam os mesmos números (Manly e Braley, 1950; Edlund e 
Lamm, 1980; Akeel et al., 1992; Slagter et al., 1992a; Wilding, 1993; Kapur e Soman, 2006; Prado et al., 2006; Mendonça et al., 2009; De Lucena et al., 2011). Dessa maneira, os resultados podem ser comparáveis em termos de protocolo, a despeito dos diferentes tipos de alimentos testados.

O número de ciclos influenciou a performance mastigatória dos grupos estudados, sendo que os três grupos apresentaram os melhores resultados com 40 ciclos. No estudo de Prado, et al. (2006) também foi encontrada melhor performance mastigatória com o aumento de ciclos. Portanto, todos os indivíduos e, principalmente, os usuários de próteses totais removíveis devem ser estimulados a mastigar os alimentos por maior número de ciclos, para que obtenham melhor cominuição dos alimentos (Silveira, 2005). No entanto, de acordo com Manly e Braley (1950) e Bates, et al. (1976), a reduzida eficiência mastigatória de usuários de próteses totais não é compensada involuntariamente por meio de um maior tempo de mastigação, havendo uma tendência desses indivíduos em deglutir partículas maiores de alimento.

É consenso que indivíduos portadores de próteses totais convencionais necessitam de maior quantidade de ciclos mastigatórios para reduzir os alimentos (Borges, 2007; Mendonça et al., 2009), tendo sido considerado no estudo de Borges (2007) que 20 ciclos mastigatórios não são ideais para definir performance mastigatória desse tipo de tratamento. Ainda, Mendes (2008) considerou que a realização de 20 ciclos mastigatórios foi um treino para que usuários de próteses totais convencionais se familiarizassem com o alimento teste. Porém os valores de performance mastigatória que foram encontrados para os grupos $C$ e $S$ neste estudo, alcançaram valores maiores que $25 \%$ após 20 ciclos mastigatórios, comparando com a performance mastigatória alcançada pelos indivíduos do grupo DN (considerado 100\%) após a mesma quantidade de ciclos. Isso é importante porque demonstra um efeito detectável da mastigação sobre as cápsulas empregadas neste estudo, com somente 20 ciclos mastigatórios. 
A avaliação da performance e habilidade mastigatórias foi realizada após um período de 3 meses da instalação das próteses totais para os grupos $C$ e $S$, pelo fato deste tempo ser considerado suficiente para adaptação funcional (Müller et al., 2001). Valores maiores de performance mastigatória poderiam ser alcançados se fosse considerado um maior tempo de adaptação às próteses totais, visto que o tempo de uso das próteses totais é um fator relevante na performance mastigatória (Mendes, 2008). Prado, et al. (2006) verificaram valores maiores de performance mastigatória em usuários de próteses totais com mais de seis meses de uso das mesmas. Contrário ao encontrado por Gunne, et al. (1982) que ao avaliar a eficiência mastigatória em pacientes usuários de próteses totais, após a troca das próteses antigas, não encontrou diferença na eficiência mastigatória até 18 meses.

Os estudos anteriores variam com respeito à porcentagem da performance mastigatória alcançada por indivíduos reabilitados por próteses convencionais em relação à indivíduos com dentição natural. Enquanto Manly e Braley (1950) e Yamashita, et al. (2000) acusaram uma perfomance de $40 \%$ e $33,3 \%$, respectivamente, valores bem menores foram observados, como 16\% (Kapur e Soman, 1964) e 5\% (Ow et al., 1998). Prado, et al. (2006) e Mendonça, et al. (2009) encontraram valores de performance mastigatória em usuários de próteses totais duplas de $12 \%$ e $31 \%$ para 20 e 40 ciclos mastigatórios, o que é sugestivo de alguma interação entre o número de ciclos e as condições do participante. Provavelmente essa interação é decorrente de protocolo distinto do nosso, já que os autores empregaram um alimento à base de silicone de condensação. Naqueles estudos, é provável que a cominuição do alimento inicie após um determinado número de ciclos nos usuários de próteses totais. $\mathrm{O}$ valor da performance mastigatória encontrado neste estudo foi de $31 \%$ para os grupos $C$ e $S$ em relação ao grupo $D N$, reafirmando a pobre performance mastigatória de usuários de próteses totais convencionais e, apesar das diferenças em relação aos valores encontrados em outros trabalhos, o que se relaciona provavelmente às metodologias utilizadas, o valor encontrado neste estudo ficou próximo aos maiores valores encontrados na literatura. 
Em relação à habilidade mastigatória, que foi considerada satisfatória para os grupos $C$ e $S$ e sem diferença entre eles, avaliada por meio do questionário HM e pela EVA, os valores baixos de performance mastigatória, quando comparado aos indivíduos do grupo $D N$, demonstram que a avaliação dos pacientes de sua mastigação, em geral, foi muito otimista (Carlsson, 1984). Essa avaliação tem sido considerada mais importante que testes fisiológicos da mastigação para usuários de prótese total (Boretti et al., 1995). Não foi possível encontrar relação entre habilidade e performance mastigatória dos grupos $C$ e $S$, e ainda que a percepção dos participantes tenha resultado em habilidade mastigatória satisfatória, a performance mastigatória foi muito aquém daquela nos indivíduos dentados.

Esse achado tem sido comum em indivíduos portadores de próteses totais (Slagter et al., 1992a; Prado et al., 2006; Farias Neto et al., 2010), podendo se afirmar que a percepção do paciente da função oral não é baseada no grau de trituração dos alimentos, mas no conforto e estabilidade durante a mastigação (De Lucena et al., 2011). Entretanto, uma avaliação da função mastigatória deve compreender testes de performance e/ou eficiência mastigatória, a fim de avaliar a capacidade de redução dos alimentos pelos indivíduos, bem como considerar a percepção dos participantes de sua própria mastigação, visando à melhoria da qualidade de vida (Mendes, 2008).

Diferença estatística foi encontrada entre as questões 1,2 e 3 do questionário HM entre os grupos $C$ e $S$, como mais favoráveis quando as próteses totais foram confeccionadas de acordo com o protocolo simplificado, o que não era esperado. Um resultado como esse pode refletir a influência entre os indivíduos de fatores como a atitude frente às próteses, a personalidade e expectativa dos pacientes, a relação paciente-profissional e mesmo o julgamento da qualificação e habilidades do profissional no julgamento final do tratamento (van Waas, 1990). Como os participantes foram distribuídos entre os grupos por meio de um processo aleatório, esses fatores estão provavelmente equilibrados entre os grupos, e as 
diferenças se devem, na verdade, aos resultados obtidos com cada método de confecção. Uma observação comum no grupo $\mathrm{C}$ era de participantes queixosos da rugosidade da área moldada das próteses; porém, uma análise direcionada a esse aspecto, não planejada a princípio, poderia encontrar se esse fator é relevante para a habilidade mastigatória. Essa característica associada à técnica de moldagem estaria de acordo com o descrito por McCord (2009), ou seja, que próteses totais obtidas por meio de moldes funcionais feitos com pasta zincoenólica, em um ensaio clínico cruzado, são menos preferidas pelos pacientes que aquelas moldadas com silicona de adição ou uma mistura à base de godiva.

Não foram encontradas diferenças das questões 4 e 5 do mesmo questionário HM entre os grupos $C$ e $S$, o que indica que o tipo de dieta parece não ser influenciado pelas técnicas de confecção estudadas. Esse resultado pode ser explicado pelo fato de usuários de próteses totais, apesar de alcançarem valores baixos de performance mastigatória, normalmente adaptarem sua alimentação à sua capacidade alimentar, aumentando o número de ciclos mastigatórios antes de deglutir os alimentos, deglutindo pedaços grandes de alimento, evitando os alimentos mais difíceis de mastigar, modificando a resistência dos alimentos cozinhando-os por mais tempo, cortando-os em pedaços menores ou amolecendo-os em líquidos (Andrade e Seixas, 2006). No entanto, a compensação da baixa performance mastigatória pelo aumento do número de ciclos mastigatórios provavelmente acontece em partes e não é proporcional à perda dos dentes.

Das limitações do trabalho, o fato de alguns participantes terem recebido suas primeiras próteses totais limitou a obtenção de dados pré-tratamento, que servissem para averiguar se os grupos têm alguma diferença importante que possa ter influenciado os resultados após 3 meses. Esses participantes não conseguiriam fornecer dados relativos à mastigação, e realizar essas leituras resultaria em médias não representativas da amostra estudada, pela grande porcentagem de dados censurados. Essa limitação foi compensada por 
meio dos processos de aleatorização e alocação oculta, bem como pela confirmação de que os participantes possuíam as características demográficas e clínicas mais similares possíveis nos grupos considerados.

O efeito teto observado para o questionário de habilidade mastigatória foi uma limitação importante, já que todos os indivíduos do grupo dentado e muitos dos demais apresentaram escore máximo. Por outro lado, as propriedades desse questionário foram suficientes para determinar o que nos propomos a fazer, ou seja, comparar os diferentes grupos e, inclusive, detectar diferenças entre os métodos de confecção das próteses em algumas questões. Por outro lado, a avaliação da habilidade mastigatória pela EVA não foi capaz de discriminar diferença no resultado entre os três grupos avaliados. Como as diferenças entre usuários de próteses totais e indivíduos dentados são bem estabelecidas na literatura, esse método foi considerado inadequado para a sua função no trabalho. Essa última limitação foi compensada pelas propriedades adequadas do questionário aplicado com o mesmo intento.

Em relação à perda e desistência de participantes, como a amostra não sofreu influências deletérias nessa situação, essa não foi considerada uma limitação, já que a única ocorrência relacionada ao protocolo respondeu por um pequeno percentual da amostra e não influenciou, de maneira geral, os resultados obtidos.

Ainda em relação às limitações do trabalho, como o teste de performance mastigatória foi realizado com um único alimento teste, a "biocápsula", não pode-se considerar que o potencial que os participantes demonstraram no teste, necessariamente reflita a performance mastigatória no dia-a-dia. Sugiura, et al. (2009) sugerem que múltiplos testes mastigatórios utilizando alimentos teste com diferentes texturas podem fornecer uma visão mais ampla da função mastigatória de pacientes quando da avaliação do efeito do tratamento protético. Porém, pela consistência firme das cápsulas utilizadas, é de se esperar que as maiores 
diferenças de comportamento se dessem com essa condição que quando da mastigação de alimentos macios. Além disso, o ensaio mostrou-se eficaz na discriminação entre os grupos tratados com prótese e os voluntários dentados de forma semelhante a outros métodos.

Visto que o método simplificado de confecção de próteses totais não teve influências deletérias sobre a performance e habilidade mastigatórias do grupo estudado, sugere-se que diferentes protocolos e materiais tenham sua efetividade estudada na confecção de próteses parciais fixas ou removíveis, bem como em próteses sobre implante. A avaliação da função mastigatória nos grupos de pacientes reabilitados por esses tratamentos poderá revelar métodos com características funcionais comparáveis àqueles considerados como "padrãoouro", porém com melhor acessibilidade em termos de custo ou indicação clínica. 

6. Conclusão 

A partir da análise dos resultados, dentro das limitações deste estudo, é possível concluir que:

- Próteses totais convencionais confeccionadas pelo método simplificado proporcionaram a mesma performance mastigatória que aquelas obtidas convencionalmente. Porém, em ambos os casos a performance mastigatória foi bastante inferior àquela encontrada com a dentição natural.

- A simplificação do procedimento de confecção das próteses totais não teve influência deletéria sobre a habilidade mastigatória, em comparação ao método convencional. Queixas referentes à função mastigatória, improváveis em indivíduos dentados, podem aparecer em usuários de próteses totais convencionais e foram menos freqüentes após o uso do método simplificado.

Em sumário, métodos simplificados de confecção de próteses totais são capazes de reabilitar a função mastigatória no mínimo tão bem quanto o método convencional testado, seja de um ponto de vista fisiológico como segundo as percepções do paciente. 


Akeel R, Nilner M, Nilner K. Masticatory efficiency in individuals with natural dentition. Swed Dent J. 1992;16(5):191-8.

Anastassiadou V, Naka O, Heath MR, Kapari D. Validation of indices for functional assessment of dentures. Gerodontology. 2002;19(1):46-52.

Anderson JD. Need for evidence-based practice in prosthodontics. J Prosthet Dent. 2000;83(1):58-65.

Anderson JD. Considerações clínicas e biológicas na tomada das relações maxilomandibulares e na transferencia dos registros do paciente para o articulador. In: Zarb GA, Bolender CL, Eckert SE, Jacob RF, Fenton AH, Mericske-Stern R. Tratamento protético para os pacientes edêntulos: Próteses totais convencionais e implantossuportadas. $12^{a}$ ed. Editora Santos; 2006. p. 268-297.

Andrade BMS, Seixas ZA. Condição mastigatória de usuários de próteses totais. Int J Dent. 2006;1(2):48-51.

Ansari IH. A one-appointment impression and centric relation record technique for compromised complete denture patients. J Prosthet Dent. 1997;78(3):320-3.

Awad MA, Feine JS. Measuring patient satisfaction with mandibular prostheses. Community Dent Oral Epidemiol. 1998;26(6):400-5.

Awad MA, Lund JP, Shapiro SH, Locker D, Klemetti E, Chehade A, et al. Oral health status and treatment satisfaction with mandibular implant overdentures and conventional dentures: a randomized clinical trial in a senior population. Int J Prosthodont. 2003;16(4):390-6.

Bakke M, Holm B, Jensen BL, Michler L, Möller E. Unilateral, isometric bite force in 8-68year-old women and men related to occlusal factors. Scand J Dent Res. 1990;98(2):149-58.

Bates JF, Stafford GD, Harrison A. Masticatory function - a review of the literature. III. Masticatory performance and efficiency. J Oral Rehabil. 1976;3(1):57-67.

Boretti G, Bickel M, Geering AH. A review of masticatory ability and efficiency. J Prosthet Dent. 1995;74(4):400-3.

Borges T. Prótese Total Removível Convencional e Implanto Retida Com Carga Imediata: Função Mastigatória e Condição Nutricional. [Dissertação de Mestrado] Uberlândia: Faculdade de Odontologia da Universidade Federal de Uberlândia; 2007. 
Borges T. Eletromiografia, força de mordida, performance mastigatória e qualidade de vida em indivíduos com comprometimento periodontal. [Tese de Doutorado] Ribeirão Preto: Faculdade de Odontologia de Ribeirão Preto da Universidade de São Paulo; 2011.

Brehm TW, Abadi BJ. Patient response to variations in complete denture technique. Part IV: Residual ridge resorption--cast evaluation. J Prosthet Dent. 1980;44(5):491-4.

Brodeur JM, Laurin D, Vallee R, Lachapelle D. Nutrient intake and gastrointestinal disorders related to masticatory performance in the edentulous elderly. J Prosthet Dent. 1993;70(5):46873.

Budtz-Jørgensen E, Chung JP, Mojon P. Successful aging--the case for prosthetic therapy. J Public Health Dent. 2000;60(4):308-12.

Carlsson GE. Masticatory efficiency: the effect of age, the loss of teeth and prosthetic rehabilitation. Int Dent J. 1984;34(2):93-7.

Carlsson GE. Facts and fallacies: an evidence base for complete dentures. Dent Update. 2006;33(3):134-6, 8-40, 42.

Carlsson GE. Critical review of some dogmas in prosthodontics. J Prosthodont Res. 2009;53(1):3-10.

Carlsson GE. Some dogmas related to prosthodontics, temporomandibular disorders and occlusion. Acta Odontol Scand. 2010;68(6):313-22.

Carlsson GE, Omar R. The future of complete dentures in oral rehabilitation. A critical review. J Oral Rehabil. 2010;37(2):143-56.

Celebić A, Knezović-Zlatarić D. A comparison of patient's satisfaction between complete and partial removable denture wearers. J Dent. 2003;31(7):445-51.

Cheida AP. Hiperbolóide - instrumento de mastigação. J Bras Ortodon Ortop Maxilar. 1997;2(11):49-53.

Clark DM, Oyen OJ, Feil P. The use of specific dental school-taught restorative techniques by practicing clinicians. J Dent Educ. 2001;65(8):760-5. 
Clark RK, Radford DR, Fenlon MR. The future of teaching of complete denture construction to undergraduates in the $\mathrm{UK}$ : is a replacement denture technique the answer? $\mathrm{Br}$ Dent $\mathrm{J}$. 2004;196(9):571-5.

Cooper LF. The current and future treatment of edentulism. J Prosthodont. 2009;18(2):11622.

Corrêa GA. Remontagem e ajuste oclusal. In: Corrêa GA. Prótese Total Passo-a-Passo. Editora Santos; 2005. p. 139-160.

Critchlow SB, Ellis JS. Prognostic indicators for conventional complete denture therapy: a review of the literature. J Dent. 2010;38(1):2-9.

Davis DM, Watson RM. A retrospective study comparing duplication and conventionally made complete dentures for a group of elderly people. Br Dent J. 1993;175(2):57-60 Erratum in: Br Dent J 1993 Aug 21;175(4):129.

Davis DM. Desenvolvendo um análogo/substituto para a área de suporte da prótese total convencional da maxila. In: Zarb GA, Bolender CL, Eckert SE, Jacob RF, Fenton AH, Mericske-Stern R. Tratamento protético para os pacientes edêntulos: Próteses totais convencionais e implantossuportadas. $12^{a}$ ed. Editora Santos; 2006. p. 211-231

De Lucena SC, Gomes SG, Da Silva WJ, Del Bel Cury AA. Patients' satisfaction and functional assessment of existing complete dentures: correlation with objective masticatory function. J Oral Rehabil. 2011;38(6):440-6.

de Souza RF, Marra J, Pero AC, Compagnoni MA. Effect of denture fabrication and wear on closest speaking space and interocclusal distance during deglutition. J Prosthet Dent. 2007;97(6):381-8.

Demers M, Bourdages J, Brodeur JM, Benigeri M. Indicators of masticatory performance among elderly complete denture wearers. J Prosthet Dent. 1996;75(2):188-93.

Douglas CR. Fisiologia da mastigação. In: Douglas CR. Tratado de fisiologia aplicada às ciências da saúde. $4^{a}$ ed. São Paulo (Brasil): Rose Editorial; 2004a. p. 858-880.

Douglas CR. Sensibilidade proprioceptiva estomatognática. In: Douglas CR. Tratado de fisiologia aplicada às ciências da saúde. $4^{a}$ ed. São Paulo (Brasil): Rose Editorial; 2004b. p. 840-849. 
Douglass CW, Shih A, Ostry L. Will there be a need for complete dentures in the United States in 2020? J Prosthet Dent. 2002;87(1):5-8.

Drummond MF, Sculpher MJ, Torrance GW, O'Brien BJ, Stoddart GL. Methods for the economic evaluation of health care programmes. $3^{a}$ ed. Oxford: Oxford University Press; 2005.

Duncan JP, Taylor TD. Teaching an abbreviated impression technique for complete dentures in an undergraduate dental curriculum. J Prosthet Dent. 2001;85(2):121-5.

Duncan JP, Taylor TD. Simplified complete dentures. Dent Clin North Am. 2004;48(3):62540 .

Edlund J, Lamm CJ. Masticatory efficiency. J Oral Rehabil. 1980;7(2):123-30.

Ellinger CW, Somes GW, Nicol BR, Unger JW, Wesley RC. Patient response to variations in denture technique. Part III: Five-year subjective evaluation. J Prosthet Dent. 1979;42(2):12730 .

Ellinger CW, Wesley RC, Abadi BJ, Armentrout TM. Patient response to variations in denture technique. Part VII: Twenty-year patient status. J Prosthet Dent. 1989;62(1):45-8.

Ellis JS, Pelekis ND, Thomason JM. Conventional rehabilitation of edentulous patients: the impact on oral health-related quality of life and patient satisfaction. J Prosthodont. 2007;16(1):37-42.

Farias Neto A, Mestriner Junior W, Carreiro AFP. Masticatory efficiency in denture wearers with bilateral balanced occlusion and canine guidance. Braz Dent J. 2010;21(2):165-9.

Feine JS, Carlsson GE, Awad MA, Chehade A, Duncan WJ, Gizani S, et al. The McGill consensus statement on overdentures. Mandibular two-implant overdentures as first choice standard of care for edentulous patients. Gerodontology. 2002;19(1):3-4.

Felton D, Cooper L, Duqum I, Minsley G, Guckes A, Haug S, et al. Evidence-based guidelines for the care and maintenance of complete dentures: a publication of the American College of Prosthodontists. J Prosthodont. 2011;20 Suppl 1:S1-S12.

Felton DA. Edentulism and comorbid factors. J Prosthodont. 2009;18(2):88-96. 
Fontijn-Tekamp FA, Slagter AP, Van Der Bilt A, Van 'T Hof MA, Witter DJ, Kalk W, et al. Biting and chewing in overdentures, full dentures, and natural dentitions. J Dent Res. 2000;79(7):1519-24.

Gauthier G, Williams JE, Zwemer JD. The practice of complete denture prosthodontics by selected dental graduates. J Prosthet Dent. 1992;68(2):308-13.

Geertman ME, Slagter AP, van 't Hof MA, van Waas MA, Kalk W. Masticatory performance and chewing experience with implant-retained mandibular overdentures. J Oral Rehabil. 1999;26(1):7-13.

Giannotti LA, Costa RR, Eduardo JVP, Perasso Guariglia AC. Técnica de transferência direta do molde funcional para o articulador semiajustável. Revista de Odontologia da Universidade Cidade de São Paulo. 2007;19(1):53-60.

Goiato MC, Ribeiro PP, Garcia AR, dos Santos DM. Complete denture masticatory efficiency: a literature review. J Calif Dent Assoc. 2008;36(9):683-6.

Gunne HS, Bergman B, Enbom L, Högström J. Masticatory efficiency of complete denture patients. A clinical examination of potential changes at the transition from old to new denture. Acta Odontol Scand. 1982;40(5):289-97.

Gunne HS. Masticatory efficiency. A new method for determination of the breakdown of masticated test material. Acta Odontol Scand. 1983;41(5):271-6.

Haraldson T, Karlsson U, Carlsson GE. Bite force and oral function in complete denture wearers. J Oral Rehabil. 1979a;6(1):41-8.

Haraldson T, Carlsson GE, Ingervall B. Functional state, bite force and postural muscle activity in patients with osseointegrated oral implant bridges. Acta Odontol Scand. 1979b;37(4):195-206.

Harwood CL. The evidence base for current practices in prosthodontics. Eur J Prosthodont Restor Dent. 2008;16(1):24-34.

Hatch JP, Shinkai RS, Sakai S, Rugh JD, Paunovich ED. Determinants of masticatory performance in dentate adults. Arch Oral Biol. 2001;46(7):641-8.

Helkimo E, Carlsson GE, Helkimo M. Bite force and state of dentition. Acta Odontol Scand. 1977;35(6):297-303. 
Helkimo E, Carlsson GE, Helkimo M. Chewing efficiency and state of dentition. A methodologic study. Acta Odontol Scand. 1978;36(1):33-41.

Heydecke G, Penrod JR, Takanashi Y, Lund JP, Feine JS, Thomason JM. Cost-effectiveness of mandibular two-implant overdentures and conventional dentures in the edentulous elderly. J Dent Res. 2005;84(9):794-9.

Heydecke G, Akkad AS, Wolkewitz M, Vogeler M, Türp JC, Strub JR. Patient ratings of chewing ability from a randomised crossover trial: lingualised vs. first premolar/canineguided occlusion for complete dentures. Gerodontology. 2007;24(2):77-86.

Heydecke G, Vogeler M, Wolkewitz M, Türp JC, Strub JR. Simplified versus comprehensive fabrication of complete dentures: patient ratings of denture satisfaction from a randomized crossover trial. Quintessence Int. 2008;39(2):107-16.

Hickey JC, Henderson D, Straus R. Patient response to variations in denture technique. I. Design of a study. J Prosthet Dent. 1969;22(2):158-70.

Hirano K, Hirano S, Hayakawa I. The role of oral sensorimotor function in masticatory ability. J Oral Rehabil. 2004;31(3):199-205.

Hunt RJ, Beck JD, Lemke JH, Kohout FJ, Wallace RB. Edentulism and oral health problems among elderly rural Iowans: the Iowa 65+ rural health study. Am J Public Health. 1985;75(10):1177-81.

Hyde TP, McCord JF. Survey of prosthodontic impression procedures for complete dentures in general dental practice in the United Kingdom. J Prosthet Dent. 1999;81(3):295-9.

IBGE. Síntese de indicadores sociais. Uma análise das condições de vida da população brasileira 2010. 2009-2010. Disponível em: http://www.ibge.gov.br/home/estatistica/ populacao/condicaodevida/indicadoresminimos/sinteseindicsociais2010/SIS_2010.pdf

Ikebe K, Nokubi T, Morii K, Kashiwagi J, Furuya M. Association of bite force with ageing and occlusal support in older adults. J Dent. 2005;33(2):131-7.

Ikebe K, Matsuda K, Morii K, Furuya-Yoshinaka M, Nokubi T, Renner RP. Association of masticatory performance with age, posterior occlusal contacts, occlusal force, and salivary flow in older adults. Int J Prosthodont. 2006;19(5):475-81. 
Ikebe K, Morii K, Matsuda K, Nokubi T. Discrepancy between satisfaction with mastication, food acceptability, and masticatory performance in older adults. Int $\mathrm{J}$ Prosthodont. 2007;20(2):161-7.

Ikebe K, Matsuda K, Kagawa R, Enoki K, Yoshida M, Maeda Y, et al. Association of masticatory performance with age, gender, number of teeth, occlusal force and salivary flow in Japanese older adults: Is ageing a risk factor for masticatory dysfunction? Arch Oral Biol. 2011;56(10):991-6.

Jadad AR, Enkin MW. Randomized controlled trials: questions, answers and musings. $2^{\mathrm{a}}$ ed. London: Blackwell Publishing/BMJ Books; 2007.

Kapur KK, Soman SD. Masticatory performance and efficiency in denture wearers. 1964. J Prosthet Dent. 2006;95(6):407-11.

Kawai Y, Murakami H, Shariati B, Klemetti E, Blomfield JV, Billette L, et al. Do traditional techniques produce better conventional complete dentures than simplified techniques? J Dent. 2005;33(8):659-68.

Kawai Y, Murakami H, Takanashi Y, Lund JP, Feine JS. Efficient resource use in simplified complete denture fabrication. J Prosthodont. 2010;19(7):512-6.

Käyser AF, van der Hoeven JS. Colorimetric determination of the masticatory performance. J Oral Rehabil. 1977;4(2):145-8.

Kimoto S, Kimoto K, Tanaka K, Takeo A, Sugimura K, Imamichi Y, et al. Effect of clinicians experience on chair time and the number of denture adjustment visits required for complete denture treatment. Prosthodont Res Pract. 2007;6:166-72.

Koç D, Doğan A, Bek B. Effect of gender, facial dimensions, body mass index and type of functional occlusion on bite force. J Appl Oral Sci. 2011;19(3):274-9.

Lassila V, Holmlund I, Koivumaa KK. Bite force and its correlations in different denture types. Acta Odontol Scand. 1985;43(3):127-32.

Lesaffre E, Feine J, Leroux B, Declerck D. Statistical and methodological aspects of oral health research. Chichester: Wiley; 2009. 
Lund JP. Mastication and its control by the brain stem. Crit Rev Oral Biol Med. 1991;2(1):3364.

Macedo LD, Paranhos HFO, Lovato-Silva CH, Muglia VA. Proposição de uma técnica de moldagem de borda funcional por sucção empregada em prótese total. Revista Odontológica de Araçatuba. 2005;26(1):49-55.

MacEntee MI, Walton JN. The economics of complete dentures and implant-related services: a framework for analysis and preliminary outcomes. J Prosthet Dent. 1998;79(1):24-30.

Malachias A, Paranhos HFO, Silva-Lovato CH, Muglia VA, Moreto C. Modified functional impression technique for complete dentures. Braz Dent J. 2005;16(2):135-9.

Manly RS, Braley LC. Masticatory performance and efficiency. J Dent Res. 1950;29(4):44862.

McCord JF. Contemporary techniques for denture fabrication. J Prosthodont. 2009;18(2):10611.

McGarry TJ, Nimmo A, Skiba JF, Ahlstrom RH, Smith CR, Koumjian JH. Classification system for complete edentulism. The American College of Prosthodontics. J Prosthodont. 1999;8(1):27-39.

Mendonca DB, Prado MM, Mendes FA, Borges TeF, Mendonça G, do Prado CJ, et al. Comparison of masticatory function between subjects with three types of dentition. Int $\mathbf{J}$ Prosthodont. 2009;22(4):399-404.

Mestriner Junior W. Eficiência mastigatória: avaliação pelo uso de um método colorimétrico nas dentições decídua e permanente. [Tese de Livre Docência] Ribeirão Preto: Faculdade de Odontologia de Ribeirão Preto da Universidade de São Paulo; 2002.

Mestriner Junior W, Mazzeto M, Felício C, Freitas O, Spadaro A. Comparação da eficiência mastigatória avaliada pelo uso de um método colorimétrico nas dentições decídua e permanente. J Bras Ortodon Ortop Facial. 2005;57(10):242-8.

Ministério da Saúde (Brasil). Projeto SB Brasil 2010: Resultados principais. Brasília: Ministério da Saúde, 2011. 
Miyaura K, Matsuka Y, Morita M, Yamashita A, Watanabe T. Comparison of biting forces in different age and sex groups: a study of biting efficiency with mobile and non-mobile teeth. J Oral Rehabil. 1999;26(3):223-7.

Miyaura K, Morita M, Matsuka Y, Yamashita A, Watanabe T. Rehabilitation of biting abilities in patients with different types of dental prostheses. J Oral Rehabil. 2000;27(12):1073-6.

Moreschi P. Desenvolvimento e caracterização de micropartículas "beads" para avaliação da eficiência mastigatória. [Dissertação de Mestrado] Ribeirão Preto: Faculdade Ciências Farmacêuticas de Ribeirão Preto da Universidade de São Paulo; 2006.

Müller F, Heath MR, Ott R. Maximum bite force after the replacement of complete dentures. Gerodontology. 2001;18(1):58-62.

Müller F, Naharro M, Carlsson GE. What are the prevalence and incidence of tooth loss in the adult and elderly population in Europe? Clin Oral Implants Res. 2007;18 Suppl 3:2-14.

Nakasima A, Higashi K, Ichinose M. A new, simple and accurate method for evaluating masticatory ability. J Oral Rehabil. 1989;16(4):373-380.

Nascimento DFF, Patto RBL, Marchini L, Cunha VPP. Double-blind study for evaluation of complete dentures made by two techniques with and without face-bow. Braz J Oral Sci. 2004;3(9):439-45.

Nicol BR, Somes GW, Ellinger CW, Unger JW, Fuhrmann J. Patient response to variations in denture technique. Part II: five-year cephalometric evaluation. J Prosthet Dent. 1979;41(4):368-72.

Okiyama S, Ikebe K, Nokubi T. Association between masticatory performance and maximal occlusal force in young men. J Oral Rehabil. 2003;30(3):278-82.

Olthoff LW, van der Bilt A, Bosman F, Kleizen HH. Distribution of particle sizes in food comminuted by human mastication. Arch Oral Biol. 1984;29(11):899-903.

Ow RK, Carlsson GE, Karlsson S. Relationship of masticatory mandibular movements to masticatory performance of dentate adults: a method study. J Oral Rehabil.1998;25(11):821-9. 
Owen PC. Appropriatech: prosthodontics for the many, not just for the few. Int J Prosthodont. 2004;17(3):261-2.

Owen CP. Guidelines for a minimum acceptable protocol for the construction of complete dentures. Int J Prosthodont. 2006;19(5):467-74.

Perez P, Kapur KK, Garrett NR. Studies of biologic parameters for denture design. Part III: Effects of occlusal adjustment, base retention, and fit on masseter muscle activity and masticatory performance. J Prosthet Dent. 1985;53(1):69-73.

Petersen PE, Bourgeois D, Ogawa H, Estupinan-Day S, Ndiaye C. The global burden of oral diseases and risks to oral health. Bull World Health Organ. 2005;83(9):661-9.

Petrie CS, Walker MP, Williams K. A survey of U.S. prosthodontists and dental schools on the current materials and methods for final impressions for complete denture prosthodontics. J Prosthodont. 2005;14(4):253-62.

Petropoulos VC, Rashedi B. Current concepts and techniques in complete denture final impression procedures. J Prosthodont. 2003;12(4):280-7.

Picinato-Pirola MNC. Eficiência mastigatória na deformidade dentofacial. [Dissertação de Mestrado] Ribeirão Preto: Faculdade de Medicina de Ribeirão Preto da Universidade de São Paulo; 2010.

Prado MMS, Borges TF, Prado CJ, Gomes VL, Neves FD. Função mastigatória de indivíduos reabilitados com próteses totais mucoso suportadas. Pesquisa Brasileira em Odontopediatria e Clínica Integrada. 2006;6:259-66.

Rahn AO, Heartwell Jr CM. Textbook of complete dentures. $5^{\mathrm{a}}$ ed: Philadelphia: Lea and Febiger; 1993.

Rao S, Chowdhary R, Mahoorkar S. A systematic review of impression technique for conventional complete denture. J Indian Prosthodont Soc. 2010;10(2):105-11.

Regis RR, Zanini AP, Della Vecchia MP, Silva-Lovato CH, Oliveira Paranhos HF, de Souza RF. Physical properties of an acrylic resin after incorporation of an antimicrobial monomer. $\mathrm{J}$ Prosthodont. 2011;20(5):372-9.

Rodrigues AHC, Morgano SM. An expedited technique for remaking a single complete denture for an edentulous patient. J Prosthet Dent. 2007;98:232-4. 
Sabes WR, Ellinger CW, Tucker SR, Somes G, Unger JW, Fuhrman J. Patient response to variations in denture technique. Part V: Microscopic response of the oral mucosa. J Prosthet Dent. 1981;45(1):11-3.

Santos CE, Freitas O, Spadaro ACC, Mestriner Junior W. Development of a Colorimetric Systen for Evaluation of the Masticatory Efficiency. Brazilian Dental Journal. 2006;17:95-9.

Santos GTM. Análise eletromiográfica dos músculos temporal e masseter em portadores de maloclusão classe II de Angle durante terapia ortopédica funcional com Reabilitação Dinâmica Funcional dos Maxilares. [Dissertação de Mestrado] Ribeirão Preto: Faculdade de Odontologia de Ribeirão Preto da Universidade de São Paulo; 2002.

Shodadai SP, Türp JC, Gerds T, Strub JR. Is there a benefit of using an arbitrary facebow for the fabrication of a stabilization appliance? Int J Prosthodont. 2001;14(6):517-22.

Silveira D. Comparação da função mastigatória de pacientes desdentados reabilitados com próteses inferiores implanto-suportadas-retidas com dentição natural e próteses totais removíveis. [Dissertação de Mestrado] Uberlândia: Faculdade de Odontologia da Universidade Federal de Uberlândia; 2005.

Silverman MM. The speaking method in measuring vertical dimension. 1952. J Prosthet Dent. 2001;85(5):427-31.

Silversin JB, Shafer SM, Smales FC, Sheiham A. Time and methods used for complete denture construction in dental students and general dental practitioners in Great Britain in 1972. J Dent. 1978;6(3):196-200.

Slagter AP, Olthoff LW, Steen WH, Bosman F. Comminution of food by complete-denture wearers. J Dent Res. 1992a;71(2):380-6.

Slagter AP, Olthoff LW, Bosman F, Steen WH. Masticatory ability, denture quality, and oral conditions in edentulous subjects. J Prosthet Dent. 1992b;68(2):299-307.

Souza RF, Leles CR, Compagnoni MA. A survey of complete denture teaching in Brazilian dental schools. Pós-Grad Rev Fac Odontol Säo José dos Campos. 2002;5(1):5-11.

Sugiura T, Fueki K, Igarashi Y. Comparisons between a mixing ability test and masticatory performance tests using a brittle or an elastic test food. J Oral Rehabil. 2009;36(3):159-67. 
Sutherland SE. Evidence-based dentistry: Part IV. Research design and levels of evidence. J Can Dent Assoc. 2001;67(7):375-8.

Sutton AF, Glenny AM, McCord JF. Interventions for replacing missing teeth: denture chewing surface designs in edentulous people. Cochrane Database Syst Rev. 2005(1):CD004941.

Takanashi Y, Penrod JR, Lund JP, Feine JS. A cost comparison of mandibular two-implant overdenture and conventional denture treatment. Int J Prosthodont. 2004;17(2):181-6.

The Academy of Prosthodontics. The glossary of prosthodontic terms. J Prosthet Dent. 2005;94(1):10-92.

The British Society for the Study of Prosthetic Dentistry. Guidelines in Prosthetic Dentistry and Implant Dentistry. London: Quintessence; 1996.

Thomason JM, Lund JP, Chehade A, Feine JS. Patient satisfaction with mandibular implant overdentures and conventional dentures 6 months after delivery. Int J Prosthodont. 2003;16(5):467-73.

Trulsson M. Force encoding by human periodontal mechanoreceptors during mastication. Arch Oral Biol. 2007;52(4):357-60.

Trulsson M. Sensory-motor function of human periodontal mechanoreceptors. J Oral Rehabil. 2006;33(4):262-73.

Turano JC, Turano LM. Moldagem e materiais de moldagem em prótese total. In: Turano JC, Turano LM. Fundamentos de prótese total. $7^{\mathrm{a}}$ ed. Editora Santos; 2004. p. 27-36.

U.S. Department of Health and Human Services. Oral Health in America: A Report of the Surgeon General. National Institute of Dental and Craniofacial Research, National Institutes of Health; 2000.

Ulbrich NL, Franco APGdO. Simplification of the functional molding technique for complete denture prostheses with the utilization of a low temperature self curing resine. PCL. 2004;6(34):559-64. 
van der Bilt A, van der Glas HW, Mowlana F, Heath MR. A comparison between sieving and optical scanning for the determination of particle size distributions obtained by mastication in man. Arch Oral Biol. 1993;38(2):159-62.

Van Der Bilt A. Assessment of mastication with implications for oral rehabilitation: a review. J Oral Rehabil. 2011;38(10):754-80.

van Waas MA. The influence of psychologic factors on patient satisfaction with complete dentures. J Prosthet Dent. 1990;63(5):545-8.

Wang MQ, Xue F, Chen J, Fu K, Cao Y, Raustia A. Evaluation of the use of and attitudes towards a face-bow in complete denture fabrication: a pilot questionnaire investigation in Chinese prosthodontists. J Oral Rehabil. 2008;35(9):677-81.

Wayler $\mathrm{AH}$, Chauncey $\mathrm{HH}$. Impact of complete dentures and impaired natural dentition on masticatory performance and food choice in healthy aging men. J Prosthet Dent. $1983 ; 49(3): 427-33$.

Wesley RC, Ellinger CW, Somes GW. Patient response to variations in denture techniques. Part VI: Mastication of peanuts and carrots. J Prosthet Dent. 1984;51(4):467-9.

Wilding RJ. The association between chewing efficiency and occlusal contact area in man. Arch Oral Biol. 1993;38(7):589-96.

Williams A. Health and Economics. London: Macmillan; 1987.

Witter DJ, Anneke Tekamp F, Slagter AP, Kreulen CM, Creugers NHJ. Swallowing threshold parameters of subjects with complete dentures and overdentures. Open Journal of Stomatology. 2011;1:69-74.

Yamashita S, Sakai S, Hatch JP, Rugh JD. Relationship between oral function and occlusal support in denture wearers. J Oral Rehabil. 2000;27(10):881-6.

Zarb GA, Bolender CL, Eckert SE, Jacob RF, Fenton AH, Mericske-Stern R. Tratamento protético para os pacientes edêntulos: Próteses totais convencionais e implantossuportadas. $12^{a}$ ed. Editora Santos; 2006a.

Zarb GA, Bolender CL, Jacob RF. Encerando e processando as próteses, sua instalação e controle. In: Zarb GA, Bolender CL, Eckert SE, Jacob RF, Fenton AH, Mericske-Stern R. 
Tratamento protético para os pacientes edêntulos: Próteses totais convencionais e implantossuportadas. 12a ed. Editora Santos; 2006b. p. 389-426. 
Anexos 

Anexo A - Aprovação pelo Comitê de Ética em Pesquisa da FORP - USP.

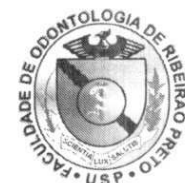

Of. CEP / 365 / FORP

\section{UNIVERSIDADE DE SÃO PAULO}

Faculdade de Odontologia de Ribeirão Preto

Comitê de Ética em Pesquisa

Ribeirão Preto, 25 de agosto de 2010

Ref. processo n. $^{\circ}$ 2010.1.971.58.0

CAAE n. ${ }^{\circ} 0061.0 .138 .000-10$

Senhor Pesquisador,

Informamos que o Comitê de Ética em Pesquisa, em sua $111^{\text {a }}$ sessão, realizada em 19/08/2010, aprovou o desenvolvimento do projeto de pesquisa envolvendo seres humanos, intitulado "Método simplificado versus convencional de confecção de próteses totais para aplicação na saúde pública".

$\mathrm{Na}$ oportunidade, lembramos da necessidade de serem entregues, na secretaria do CEP, os Relatórios Parciais em 19/05/2011 e 19/02/2012 e o Relatório Final em 19/12/2012, com os respectivos formulários preenchidos pelo pesquisador responsável.

Lembramos ainda que, quando da submissão dos relatórios a este Comitê, quaisquer inclusões ou modificações no projeto original deverão ser comunicadas e justificadas ao CEP, através do formulário supracitado.

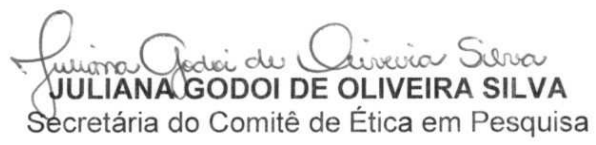

IImo. Sr.

Prof. Dr. RAPHAEL FREITAS DE SOUZA

Departamento de Materiais Dentários e Prótese desta Faculdade 


\section{UNIVERSIDADE DE SÃO PAULO}

Faculdade de Odontologia de Ribeirão Preto Comitê de Ética em Pesquisa

Of.ATAC.CEP/34511/FORP-USP/23.08.2011

CHLS/geadd

Ref. processo $n .^{\circ} \underline{2010.1 .971 .58 .0}$

CAAE n. ${ }^{\circ} 0061.0 .138 .000-10$

Senhor Pesquisador:

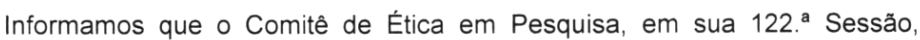
realizada em 18 de agosto de 2011, aprovou o Relatório Parcial, bem como a alteração da metodologia e a inclusão dos pesquisadores Prof. Dr. Valdir Antônio Muglia e PG. Tatiana Ramirez Cunha no projeto de pesquisa envolvendo seres humanos de "Método simplificado versus convencional de confecção de próteses totais para aplicação na saúde pública".

$\mathrm{Na}$ oportunidade, lembramos da necessidade de entregar na Secretaria do Comitê, com os formulários preenchidos pelo pesquisador responsável, o Relatório Parcial no dia 19 de fevereiro de 2012 e o Relatório Final no dia 19 de dezembro de 2012.

$$
\text { Eachetr }
$$

GISELE ELLENE DE ANDRADE DA DALTI

Secretária do Comitê de Ética em Pesquisa

IImo. Sr.

Prof. Dr. RAPHAEL FREITAS DE SOUZA

Departamento de Materiais Dentários e Prótese

desta Faculdade 
Anexo B - Ficha clínica adotada pela disciplina de Prótese Total e Materiais Aplicados da FORP-USP para anamnese e exame intra-oral.

\section{Universidade de São Paulo Faculdade de Odontologia de Ribeirão Preto SUPERVISÃO DE CLÍNICAS}

\section{AnAmnese}

INFORMAÇÃO: ESTE FORMULÁRIO É INDISPENSÁVEL AO ATENDIMENTO DO PACIENTE

\begin{tabular}{|c|c|c|c|}
\hline & & SIM & NÃO \\
\hline \multirow[t]{2}{*}{01} & Está atualmente sob tratamento médico? .................................. & & \\
\hline & Qual? & & \\
\hline \multirow[t]{2}{*}{02} & Está tomando alguma medicação? . & & \\
\hline & Qual? & & \\
\hline 03 & Tem hipertensão arterial? & & \\
\hline \multirow[t]{2}{*}{04} & Tem (teve) algum prob & & \\
\hline & Qual? & & \\
\hline 05 & Tem (teve) febre reumática & & \\
\hline 06 & Tem dores articulares? ....................................... & & \\
\hline \multirow[t]{2}{*}{07} & Tem (teve) dor opressiva no peito que irradia para o braço, pescoço ou & & \\
\hline & 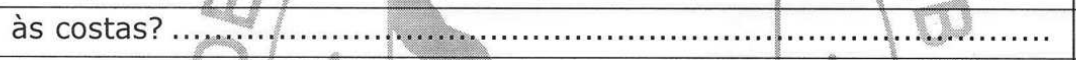 & & \\
\hline 08 & Sente cansaço quando faz esforço qualquer ou sobe uma escada? ..... & & \\
\hline 09 & Tem edema nös tornozelos ou pernas no período vespertino? .............. & & \\
\hline 10 & Tem perdido peso ultimamente? .................... & & \\
\hline 11 & 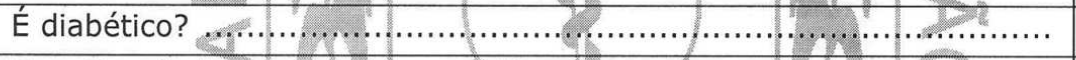 & & \\
\hline \multirow[t]{2}{*}{12} & Tem (teve) algum problema renal? .................. & & \\
\hline & Qual? & & \\
\hline 13 & 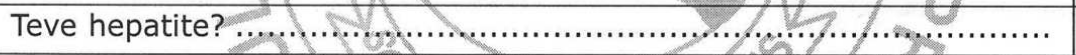 & & \\
\hline \multirow[t]{2}{*}{14} & Tem (teve) algum problema gástrico? ................ & & \\
\hline & Qual? $\quad$ MAILUX LAY SA & & \\
\hline 15 & Tem tonturas e/ou desfalecimentos rotineiramente? ....................... & & \\
\hline 16 & 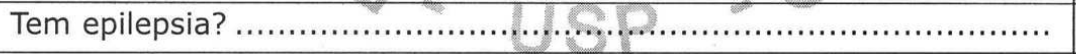 & & \\
\hline \multirow[t]{2}{*}{17} & 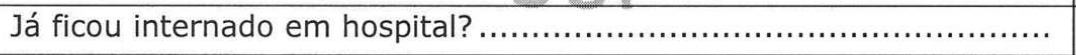 & & \\
\hline & Por que? & & \\
\hline 18 & 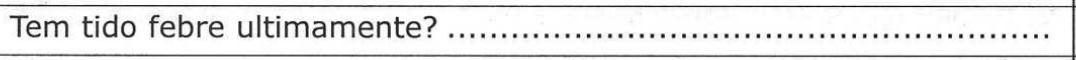 & & \\
\hline 19 & Tem tosse constante ou persistente há mais de 15 dias? .................. & & \\
\hline 20 & 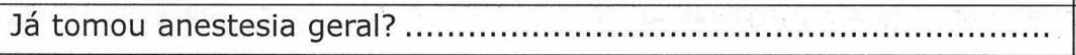 & & \\
\hline 21 & Já tomou anestesia local para tratamento dental? ........................ & & \\
\hline \multirow[t]{2}{*}{22} & Foi observada alguma reação com anestesia? .............................. & & \\
\hline & Qual? & & \\
\hline \multirow[t]{2}{*}{23} & Costuma sangrar excessivamente quando extrai dente ou se machuca? .... & & \\
\hline & Qual foi a conduta tomada para controlar esse sangramento? & & \\
\hline 24 & Já tomou penicilina (Benzetacil, Binotal, Amoxil)? ........................ & & \\
\hline 25 & Já tomou corticóide nos últimos 12 meses? (Cortizona, Decadron) ..... & & \\
\hline
\end{tabular}




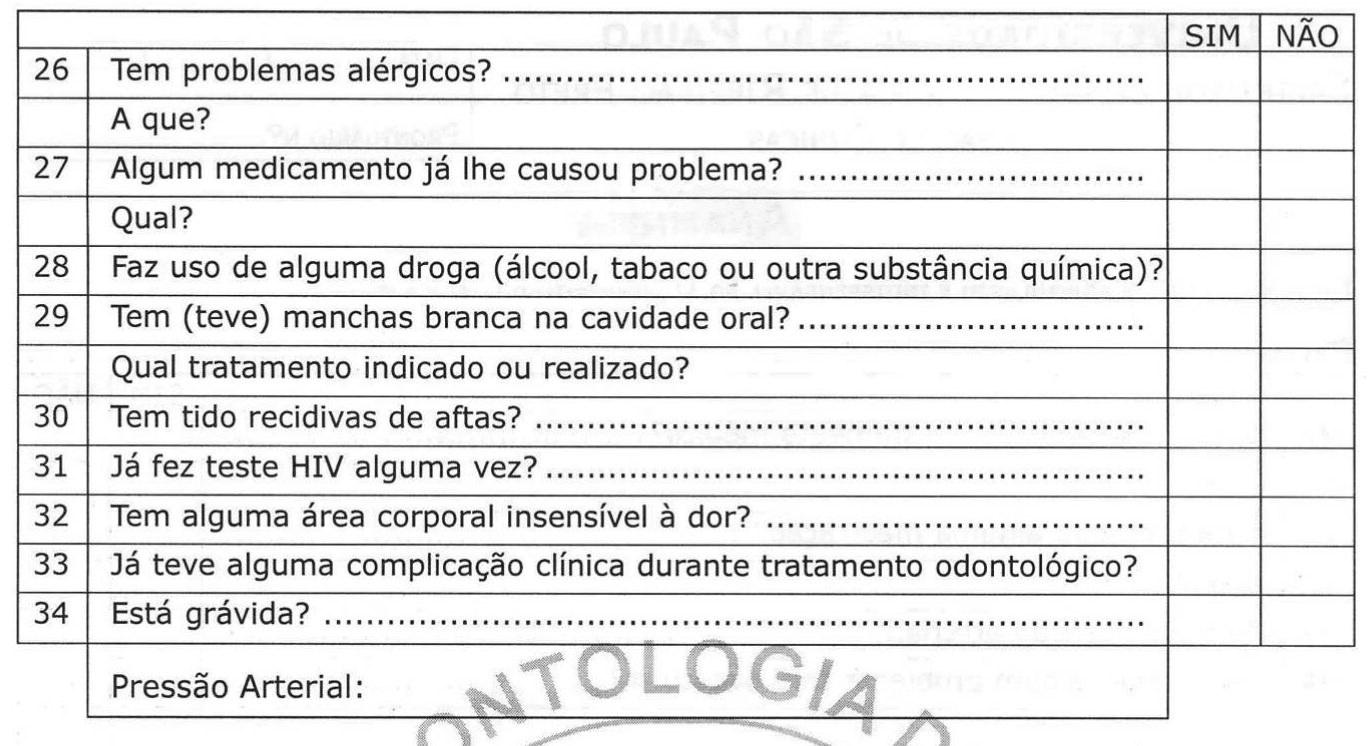

Atenção: Anamnese deVerÁ SER Refeita em CADA Disciplina, OU, No máximo, a CADA 6 MESES.

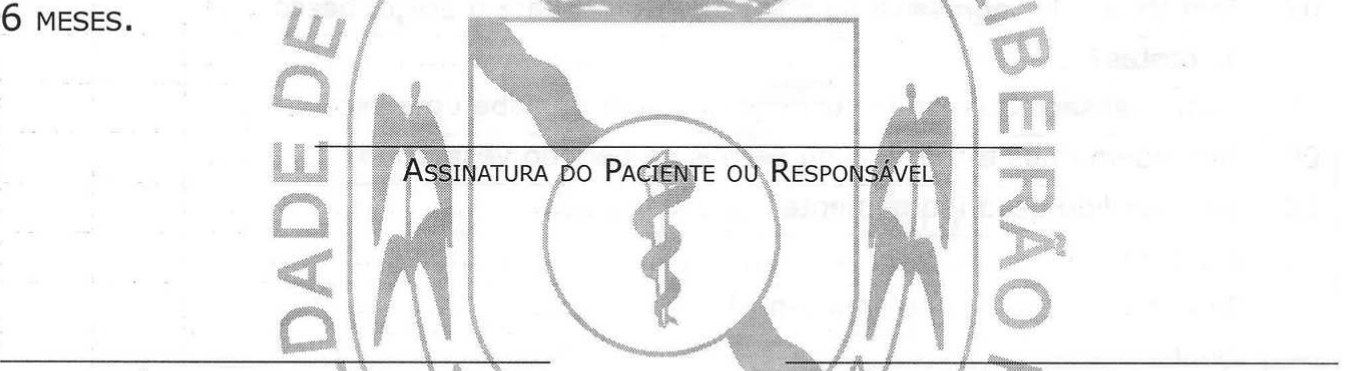

AsSinAtura do Aluno

Visto do Docente Responsável

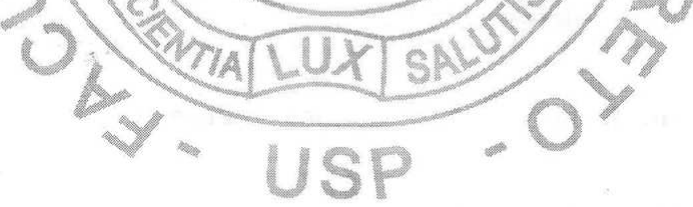

DECLARO QUE RESPONDI TODAS AS QUESTÕES ACIMA DE LIVRE E ESPONTÂNEA VONTADE, SABENDO QUE AS INFORMAÇÕES SÃO INDISPENSÁVEIS PARA MINHA SAÚDE E SEGURANÇA. GARANTO A VERACIDADE DESSAS INFORMAÇÕES, SEM OMISSÕES.

COMPROMETO-ME AINDA A INFORMAR AO PROFISSIONAL QUALQUER OCORRÊNCIA RELACIONADA À MINHA SAÚDE.

Assinatura do Paciente ou Responsável 
FICHA DA DISCIPLINA DE PRÓTESE TOTAL

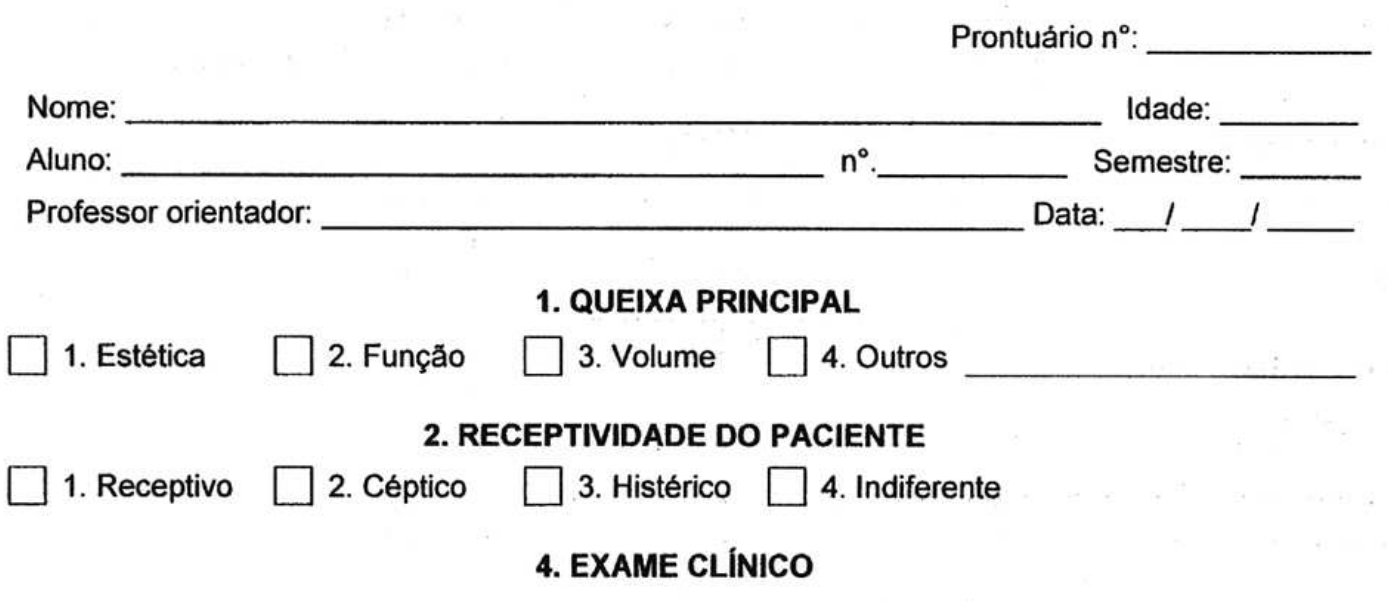

4.1 EXAME Físico

1. Aspecto geral do paciente:

\subsection{EXAME LOCO-REGIONAL.}

4.2.1. Extra-bucal:

$\begin{array}{lllll}\text { Cor da pele } & \square \text { Branca } & \square \text { Parda } & \square \text { Negra } & \square \text { Amarela } \\ \text { Cor dos cabelos } & \square \text { Pretos } & \square \text { Grisalhos } & \square \text { Castanhos } \\ \text { Cor dos olhos } & \square \text { Verdes } & \square \text { Azuis } & \square \text { Castanhos } & \square \text { Pretos } \\ \text { Forma do rosto } & \square \text { Ovóide } & \square \text { Quadrada } & \square \text { Triangular } \\ \text { Perfil } & \begin{array}{l}\text { Reto } \\ \text { Linha mediana }\end{array} & \square \text { Côncavo } & \square \text { Convexo }\end{array}$

- Alterações faciais:

4.2.2. Intra-bucal:

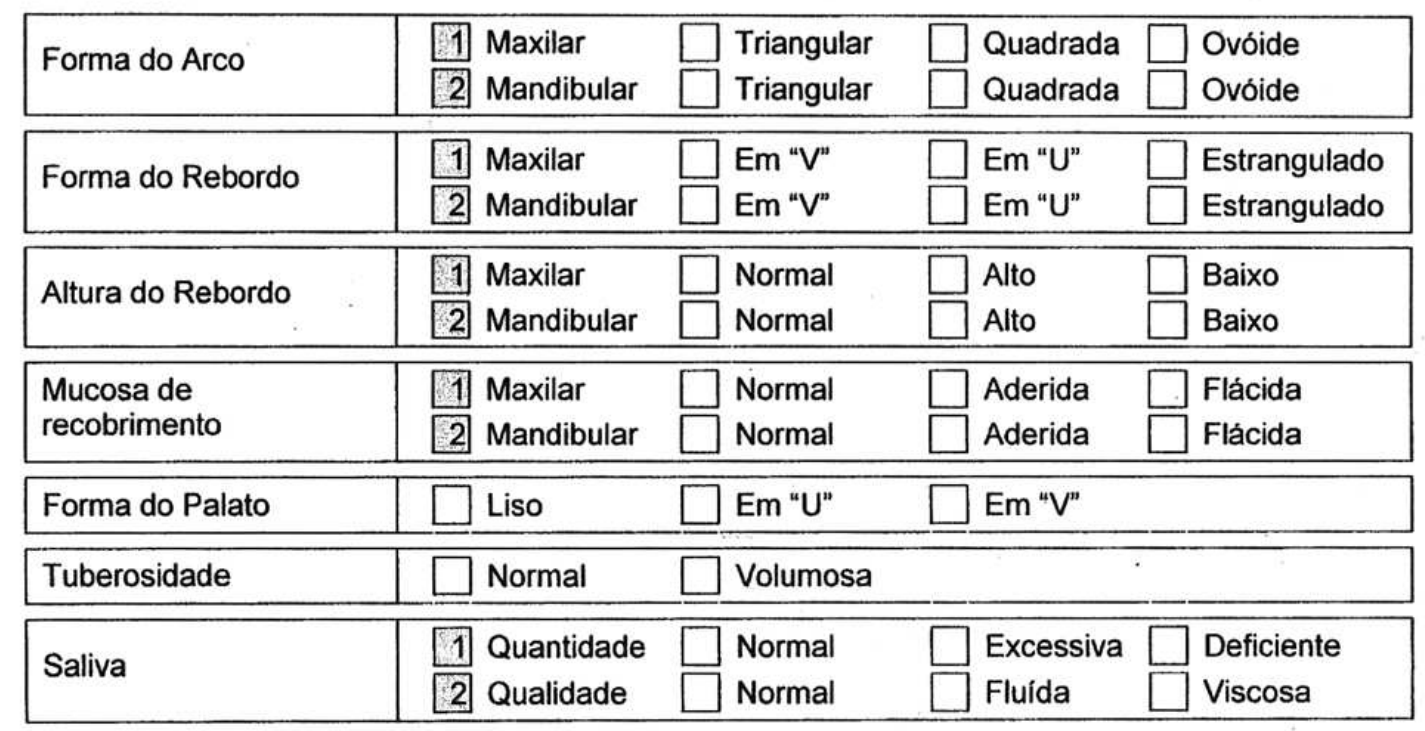




\begin{tabular}{|c|c|c|c|c|}
\hline \multirow{3}{*}{ Lingua } & (1) Integridade & Sim & Não & \multirow[b]{3}{*}{ Pequena } \\
\hline & 2 Mobilidade & Normal & Reduzida & \\
\hline & 3 Tamanho & Grande & Normal & \\
\hline Linha milohiodea & Normal & \multicolumn{3}{|l|}{ Afilada } \\
\hline Palato mole & Classe I & Classe II & \multicolumn{2}{|l|}{ Classe III } \\
\hline Torus & Palatino & \multicolumn{3}{|c|}{ Mandibular } \\
\hline
\end{tabular}

\subsection{Exame Radiográfico}

\section{EXAMES COMPLEMENTARES}
$\square$ 1. Panoråmico
$\square$ 2. Oclusal
$\square$ 3. Periapical

5.2 Exame dos modelos de estudo montados em articulador:

\begin{tabular}{|l|ll|l|}
\hline Relação intermaxilar & $\square$ Classe I $\square$ Classe II $\square$ Classe III \\
\hline Espaço Intermaxilar & $\square$ Região anterior & $\square$ Favorável \\
& $\square$ Regiăo posterior & $\square$ Favorável & $\square$ Desfavorável \\
& $\square$ Desfavorável \\
\hline
\end{tabular}

5.3 Exame das próteses

\begin{tabular}{|c|c|c|c|c|c|}
\hline \multirow{4}{*}{$\begin{array}{l}\text { Dentro da } \\
\text { cavidade oral }\end{array}$} & 1 & Oclusão & Bom & Regular & Ruim \\
\hline & 2 & Estética & Bom & Regular & Ruim \\
\hline & 3 & Retenção, suporte e estabilidade & Bom & Regular & Ruim \\
\hline & 4 & Higienização & Boa & Regular & Ruim \\
\hline
\end{tabular}

Diagnóstico
Bom
$\square$ Duvidoso
Ruim

Obs:

Prognóstico
$\square$ Favorável
$\square$ Desfavorável

PLANO DE TRATAMENTO 


\section{Apêndices}



APÊNDICE A - Registrado do estudo na base ClinicalTrials.gov

Simplified vs. Conventional Methods for Complete Denture Fabrica... $\quad$ http://clinicaltrials.gov/ct2/show/NCT01230320?term=NCT01230...

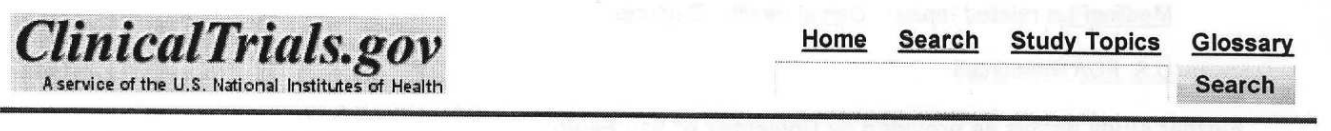

\begin{tabular}{|c|c|c|}
\hline \multicolumn{2}{c|}{$\begin{array}{c}\text { Study } 1 \text { of } 1 \text { for search of: NCT01230320 } \\
\text { Previous Study }\end{array}$} \\
\begin{tabular}{|l|l|l|l|}
\hline Tabular View & No Study Results Posted & Related Studies \\
\hline
\end{tabular}
\end{tabular}

\section{Simplified vs. Conventional Methods for Complete Denture Fabrication}

This study is currently recruiting participants.

Verified on October 2010 by University of Sao Paulo

First Received on October 27, 2010. Last Updated on June 6, 2011 History of Changes

\begin{tabular}{|r|l|}
\hline Sponsor: & University of Sao Paulo \\
\hline Collaborator: & Fundação de Amparo à Pesquisa do Estado de São Paulo \\
\hline Information provided by: & University of Sao Paulo \\
\hline ClinicalTrials.gov Identifier: & NCT01230320 \\
\hline
\end{tabular}

\section{Purpose}

BACKGROUND: The fabrication of complete dentures traditionally involves a series of complex technical procedures. Those procedures include two impressions for each jaw, the registration of the relationship between the upper teeth and the patient's head and usually two appointments for tooth try-in. However, recent studies have questioned the real need for such complex procedures. Simplified methods could have similar results if compared with conventional ones, and dentures would be delivered faster and with lower costs.

OBJECTIVES: This study aims to compare the effectiveness complete dentures fabricated with a simplified or conventional method

METHODS: Eighty edentulous patients who requested treatment by maxillary and mandibular complete denture in a public dental clinic inside the University of Sao Paulo - Ribeirão Preto Dental School will be randomly divided into two groups. Group $S$ will receive new dentures fabricated by a simplified method, whereas Group $\mathrm{C}$ will received new dentures according to a conventional method. Participants will complete a questionnaire for denture satisfaction and the oral health-related quality of life, 3 and 6 months after treatment. At the same time, a specialist in dental prostheses will evaluate the quality of new dentures. Panoramic radiographs will be taken after 24 months in order to detect changes in the jaws' height.

\begin{tabular}{|l|l|}
\hline Condition & Intervention \\
\hline $\begin{array}{l}\text { Edentulous Mouth } \\
\text { Edentulous Jaw }\end{array}$ & Procedure: Denture fabrication technique \\
\hline
\end{tabular}

Study Type: Interventional

Study Design: Allocation: Randomized

Intervention Model: Parallel Assignment

Masking: Single Blind (Outcomes Assessor)

Primary Purpose: Health Services Research

Official Title: Simplified vs. Conventional Methods for the Fabrication of Complete Dentures in a Public Health Setting

Resource links provided by NLM: 
Simplified vs. Conventional Methods for Complete Denture Fabrica... $\quad$ http://clinicaltrials.gov/ct2/show/NCT01230320?term=NCT01230...

\section{MedlinePlus related topics: Dental Health Dentures}

\section{U.S. FDA Resources}

Further study detalls as provided by University of Sao Paulo:

Primary Outcome Measures:

- Oral health-related quality of life [ Time Frame: 6 months ]

[Designated as safety issue: No]

To be assessed by means of the Brazilian version of the OHIP-EDENT.

Secondary Outcome Measures:

- Denture satisfaction [ Time Frame: 6 months ] [ Designated as safety issue: No ]

To be assessed by specific questionnaires.

- Denture quality [ Time Frame: 3 months ] [ Designated as safety issue: No ]

To be assessed by means of clinical exam following a specific form.

- Post-insertion adjustments [ Time Frame: 14 days ] [ Designated as safety issue: No ]

Necessary post-insertion, as done routinely for conventional denture patients.

- Treatment costs [ Time Frame: 6 months ] [ Designated as safety issue: No]

This outcome will be measured by means of specific forms, according to 2 components:

- Direct costs: cost of labor, materials, radiographs and medications;

- Indirect costs: patient's time and transportation expenses.

- Residual ridge resorption (change from baseline) [ Time Frame: 24 months ] [ Designated as safety issue: No]

This measure will be obtained according to 2 methods:

- Ratios between the area of the posterior residual ridge and a quadrilateral area projected over the edentulous mandible.

- Ratios between ridge height (both maxillary and mandibular) and reference lines from the lower orbital ridge to the zygomatic processes.

\section{Estimated Enrollment:}

$\begin{array}{ll}\text { Study Start Date: } & \text { October } 2010 \\ \text { Estimated Study Completion Date: } & \text { December } 2013\end{array}$

Estimated Primary Completion Date: December 2011 (Final data collection date for primary outcome measure)

\begin{tabular}{|c|c|}
\hline Arms & Assigned Interventions \\
\hline $\begin{array}{l}\text { Simplified (S) technique: Experimental } \\
\text { Complete dentures fabricated according to a } \\
\text { simplified technique, divided into the following } \\
\text { four sessions: } \\
\text { 1. Maxillary and mandibular casts will be } \\
\text { obtained from irreversible hydrocolloid } \\
\text { impressions made in stock trays. } \\
\text { 2. Record bases will be adjusted } \\
\text { according to vertical dimension and } \\
\text { centric relation measurements, without } \\
\text { facebow transfer. Casts will be } \\
\text { mounted in a semi-adjustable }\end{array}$ & $\begin{array}{l}\text { Procedure: Denture fabrication } \\
\text { technique } \\
\text { Sequence of procedures } \\
\text { involved with the fabrication } \\
\text { of conventional complete } \\
\text { dentures. Examples of } \\
\text { common procedures are: } \\
\text { 1. the reproduction of } \\
\text { denture-bearing } \\
\text { tissues by means of } \\
\text { impression techniques } \\
\text { and casts; }\end{array}$ \\
\hline
\end{tabular}




\begin{tabular}{|c|c|}
\hline $\begin{array}{l}\text { articulator using standardized } \\
\text { measures and artificial teeth will be } \\
\text { selected. } \\
\text { 3. Trial dentures will be evaluated for } \\
\text { esthetics and maxillomandibular } \\
\text { relationships. } \\
\text { 4. Insertion of finished dentures. } \\
\text { Intervention: Procedure: Denture fabrication } \\
\text { technique }\end{array}$ & $\begin{array}{l}\text { 2. the registration of } \\
\text { maxillo-mandibular } \\
\text { relations; } \\
\text { 3. try-in of artificial teeth } \\
\text { and carved denture } \\
\text { bases. } \\
\text { Other Names: } \\
\text { - - Fabrication of } \\
\text { complete dentures; } \\
\text { - - Complete denture } \\
\text { fabrication technique. }\end{array}$ \\
\hline $\begin{array}{l}\text { Conventional (C) technique: Active Comparator } \\
\text { Complete dentures fabricated according to a } \\
\text { conventional technique: } \\
\text { 1. Initial impression and the obtainment of } \\
\text { custom trays; } \\
\text { 2. Final impression with border molding } \\
\text { using compound; } \\
\text { 3. Facebow transfer; } \\
\text { 4. Determination of maxillomandibular } \\
\text { relationship; } \\
\text { 5. Try-in of anterior teeth; } \\
\text { 6. Try-in of posterior teeth; } \\
\text { 7. Insertion of finished dentures. } \\
\text { Intervention: Procedure: Denture fabrication } \\
\text { technique }\end{array}$ & \begin{tabular}{|l} 
Procedure: Denture fabrication \\
technique \\
Sequence of procedures \\
involved with the fabrication \\
of conventional complete \\
dentures. Examples of \\
common procedures are: \\
1. the reproduction of \\
denture-bearing \\
tissues by means of \\
impression techniques \\
and casts; \\
2. the registration of \\
maxillo-mandibular \\
relations; \\
3. try-in of artificial teeth \\
and carved denture \\
bases. \\
Other Names: \\
- - Fabrication of \\
complete dentures; \\
- Complete denture \\
fabrication technique.
\end{tabular} \\
\hline
\end{tabular}

\section{\$ Show Detailed Description}

\section{Eligibility}

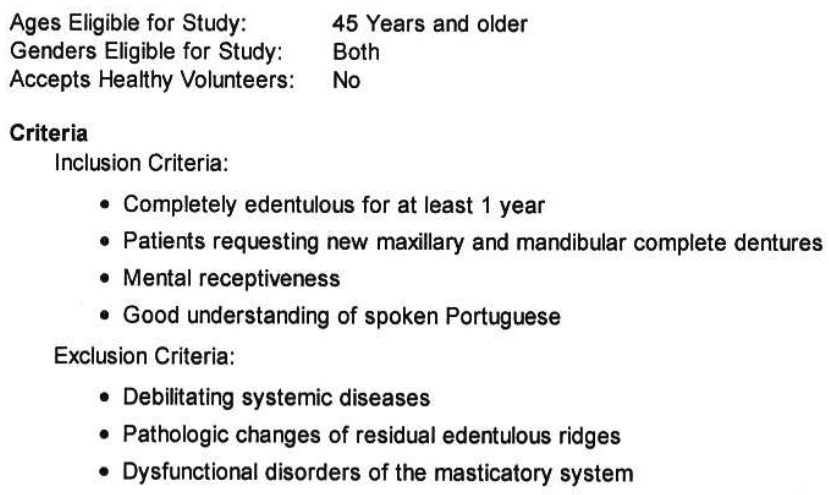

\section{Contacts and Locations}


Simplified vs. Conventional Methods for Complete Denture Fabrica... h http://clinicaltrials.gov/ct2/show/NCT01230320?term=NCT01230...

Please refer to this study by its ClinicalTrials.gov identifier: NCT01230320

Contacts

Contact: Romulo R Regis, DDS, MSc +55-16-36024800 romuloregis@hotmail.com

Contact: Viviane C Oliveira, BSc, MSc +55-16-36024800 vivianecassia@usp.br

Locations

Brazil

Ribeirão Preto Dental School Recruiting

Ribeirão Preto, São Paulo, Brazil, 14040-904

Sub-Investigator: Claudia H Silva-Lovato, DDS, PhD

Principal Investigator: Raphael F de Souza, DDS, PhD

Sub-Investigator: Helena FO Paranhos, DDS, PhD

Sponsors and Collaborators

University of Sao Paulo

Fundação de Amparo à Pesquisa do Estado de São Paulo

Investigators

Principal Investigator: Raphael F de Souza, DDS, PhD University of Sao Paulo

\section{More Information}

Additional Information

Institutional page of the Ribeirão Preto Dental School (research site) Em

Principal Investigator's CV Esit

No publications provided

Responsible Party:

Raphael Freitas de Souza, University of Sao Paulo

ClinicalTrials.gov Identifier: NCT01230320 History of Changes

Other Study ID Numbers: FORP-PT-001, 2010.1.971.58.0, 2010/09381-9

Study First Received: $\quad$ October 27, 2010

Last Updated: June 6, 2011

Health Authority: Brazil: Ministry of Health

Keywords provided by University of Sao Paulo:

Cost estimates

Complete Denture

Dental Economics

Dental Impression Technique

Denture Retention

Edentulous

Edentulism

Oral Health-Related Quality of Life

Patient Acceptance of Health Care

Patient Satisfaction

Quality of Health Care

Quality of Life

Additional relevant $\mathrm{MeSH}$ terms:

Jaw, Edentulous

Mouth, Edentulous

Stomatognathic Diseases

Jaw Diseases

Mouth Disease

Musculoskeletal Diseases

Tooth Diseases

ClinicalTrials.gov processed this record on October 26, 2011

Lister Hill National Center for Biomedical Communications, U.S. National Library of Medicine

U.S. National Institutes of Health, U.S. Department of Health \& Human Services,

USA gov, Copyright, Privacy, Accessibility, Freedom of Information ACt 


\section{APÊNDICE B - Termo de consentimento livre e esclarecido (Grupo $C$ e $S$ ).}

Convido você. RG. a participar como voluntário da pesquisa "Método simplificado versus convencional de confecção de próteses totais para aplicação na saúde publica" desenvolvida sob a responsabilidade do Prof. Dr. Raphael Freitas de Souza. Após receber todas as explicações necessárias para a participação da pesquisa, cabe a você decidir, de livre e espontânea vontade, se quer participar e assinar este Termo de Consentimento Livre e Esclarecido com a finalidade de autorizar a sua participação na referida pesquisa. Os pesquisadores responsáveis por lhe apresentar esse documento e obter seu consentimento serão Maria Paula Della Vecchia e Rômulo Rocha Regis. A Prof ${ }^{a}$ Dr $^{a}$ Cláudia Helena Lovato da Silva será responsável em avaliar a qualidade das próteses totais terminadas.

1. O estudo tem por objetivo comparar a qualidade de próteses totais confeccionadas por meio de dois métodos diferentes, o preço de cada uma delas e a sua satisfação com essas próteses. Você receberá um par de dentaduras, confeccionadas por uma das duas técnicas.

2. Você deverá comparecer à Faculdade de Odontologia de Ribeirão Preto nos dias e horários marcados para confecção das próteses, ou seja, deverá vir cerca de 10 vezes, com duração aproximada de 4 horas por vez.

3. Após o dia em que você receber as próteses, você deverá retornar à Faculdade para os ajustes necessários nos locais em que as próteses machucar e, também, depois de 3 e 6 meses, para avaliação das mesmas e de sua mastigação.

4. Para isso vamos pedir que você mastigue por algum tempo, sem engolir, três cápsulas de um simulador de alimento teste, que não apresenta nenhum risco previsível de utilização.

5. Para sabermos se você ficou satisfeito com as próteses, será pedido que você responda um questionário com perguntas sobre a qualidade das próteses, aparência e habilidade de comer com elas.

6. Você receberá as próteses sem ter que pagar nenhum valor, ou seja, o tratamento será gratuito;

7. Não há previsão de pagamento de passagens de ônibus ou qualquer outro meio de transporte para você vir até a Faculdade, por parte dos pesquisadores.

8. Os pesquisadores participantes se comprometem a prestar toda assistência necessária no decorrer da pesquisa, garantindo que o tratamento seja concluído e que o acompanhamento após o recebimento das próteses seja realizado.

9. Caso ocorra algum dano à sua saúde, em razão da participação na pesquisa, os pesquisadores serão responsáveis por quaisquer despesas. Entretanto, essa pesquisa não apresenta risco previsível algum para você.

10. Os pesquisadores manterão sigilo sobre sua participação na pesquisa.

11. Como sua participação é voluntária, você tem o direito de parar de vir em qualquer momento, sem que seja penalizado por essa decisão.

12. Qualquer dúvida que você tiver, antes, durante ou após a realização da pesquisa, poderá ser esclarecida por um dos pesquisadores envolvidos durante o desenvolvimento desta pesquisa. Caso necessitar, você poderá entrar em contato com o Prof. Dr. Raphael Freitas de Souza pelo telefone (16)3602-4006.

13. Você receberá uma cópia desse termo de consentimento.

Após estes esclarecimentos, se você, nominado acima, concordar em participar desta pesquisa, solicito que assine abaixo.

Ribeirão Preto, de de 2010.

Prof. Dr. Raphael Freitas de Souza

CPF: 26993231875

Profa. Dra. Cláudia Helena Lovato Silva

CPF: 16645699800

Tatiana Ramirez Cunha
Maria Paula Della Vecchia

CPF: 31511051817

Rômulo Rocha Regis

CPF: 88287696372

CPF: 35155992826

Para esclarecimento de dúvidas ou reclamações, entre em contato com: Comitê de Ética em Pesquisa da Faculdade de Odontologia de Ribeirão Preto da USP. Avenida do Café, S/N Monte Alegre Ribeirão Preto SP CEP 14040-904 Telefone: (16) 3602-3963 
APÊNDICE B - Termo de consentimento livre e esclarecido (Grupo DN).

Convido você. ,RG. a participar como voluntário da pesquisa "Método simplificado versus convencional de confecção de próteses totais para aplicação na saúde publica" desenvolvida sob a responsabilidade do Prof. Dr. Raphael Freitas de Souza. Após receber todas as explicações necessárias para a participação da pesquisa, cabe a você decidir, de livre e espontânea vontade, se quer participar e assinar este Termo de Consentimento Livre e Esclarecido com a finalidade de autorizar a sua participação na referida pesquisa. Os pesquisadores responsáveis por the apresentar esse documento e obter seu consentimento serão Maria Paula Della Vecchia, Rômulo Rocha Regis e Tatiana Ramirez Cunha.

1. O estudo tem por objetivo comparar a qualidade de próteses totais confeccionadas por meio de dois métodos diferentes, o preço de cada uma delas e a satisfação dos pacientes com essas próteses. Sendo assim, o convite é feito para você participar de um grupo controle, formado por voluntários que possuam dentição natural.

2. Você irá participar de uma parte específica do estudo para avaliar sua mastigação.

3. Para isso vamos pedir que você mastigue por algum tempo, sem engolir, três cápsulas de um simulador de alimento teste, que não apresenta nenhum risco previsível de utilização.

4. Essa parte do estudo é observacional, ou seja, você não receberá nenhum tratamento odontológico e a avaliação da sua mastigação será importante para comparação com a mastigação dos pacientes que receberão as próteses totais.

5. Os pesquisadores manterão sigilo sobre sua participação na pesquisa.

6. Como sua participação é voluntária, você tem o direito de parar de vir em qualquer momento, sem que seja penalizado por essa decisão.

7. Qualquer dúvida que você tiver, antes, durante ou após a realização da pesquisa, poderá ser esclarecida por um dos pesquisadores envolvidos durante o desenvolvimento desta pesquisa. Caso necessitar, você poderá entrar em contato com o Prof. Dr. Raphael Freitas de Souza pelo telefone (16)3602-4006.

8. Você receberá uma cópia desse termo de consentimento.

Após estes esclarecimentos, se você, nominado acima, concordar em participar desta pesquisa, solicito que assine abaixo.

Ribeirão Preto, de de 2010 .

Prof. Dr. Raphael Freitas de Souza

CPF: 26993231875

Rômulo Rocha Regis

CPF: 88287696372
Maria Paula Della Vecchia

CPF: 31511051817

Tatiana Ramirez Cunha

CPF: 35155992826

\section{Paciente}

Para esclarecimento de dúvidas ou reclamações, entre em contato com: Comitê de Ética em Pesquisa da Faculdade de Odontologia de Ribeirão Preto da USP. Avenida do Café, S/N Monte Alegre Ribeirão Preto SP CEP 14040-904 Telefone: (16) 3602-3963 
APÊEDICE C - Formulário utilizado para coleta de dados demográficos dos participantes.

Faculdade de Odontologia de Ribeirão Preto - USP Protocolo de Pesquisa: MÉTOdo SIMPLIFICADO VERSUS CONVENCIONAL Formulário de Coleta - Participante
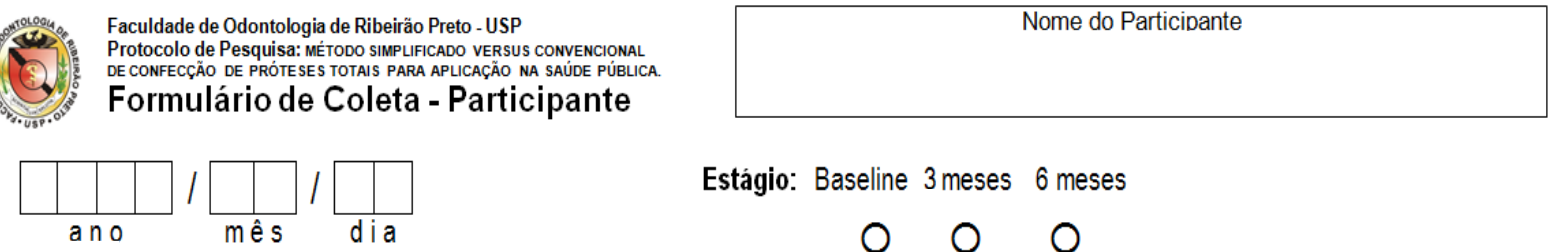

Estágio: Baseline 3 meses 6 meses

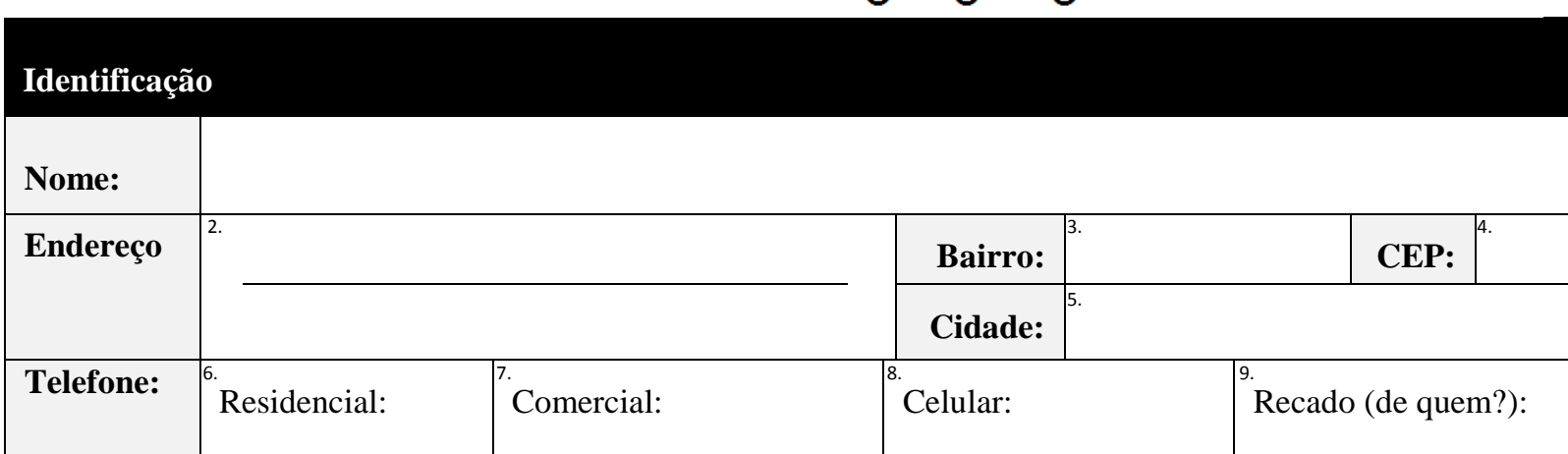

Dados demográficos

\begin{tabular}{l|l} 
10. Gênero: $\square$ Masculino $\square$ Feminino & \begin{tabular}{l} 
11. Idade (em anos): \\
\hline $\begin{array}{l}\text { 12. Tempo que não tem mais os dentes naturais: } \\
\text { anos }\end{array}$
\end{tabular} \\
\hline & $\begin{array}{l}\text { 13. Tempo de uso prévio de próteses totais bimaxilares: } \\
\text { anos }\end{array}$ \\
\hline 14. Ocupação:
\end{tabular}

15. Escolaridade:
$\square$ Analfabeto
$\square 1^{\mathrm{o}}$ grau incompleto
$\square 1^{\circ}$ grau completo
$\square 2^{\circ}$ grau incompleto

$\square 2^{\circ}$ grau completo $\quad \square$ Superior incompleto $\square$ Superior completo.

16. Estado civil:
$\square$ Casado
$\square$ Solteiro
$\square$ Divorciado
$\square$ Viúvo

$\square$ Outro (especificar):

Renda:

17. Rendimento mensal: $\mathrm{R} \$$

18. Quantas pessoas dependem dessa renda:

19. Quem recebe? $\square \mathrm{O}$ (a) próprio participante $\square$ Cônjuge $\quad \square$ Filhos $\quad \square$ Outro (especificar):

PREENCHIDO POR: 
APÊNDICE D - Ficha utilizada para classificação dos participantes tratados, segundo Índice Diagnóstico do American College of Prosthodontists (ACP).

PARTICIPANTE:

DATA:

CLASSIFICAÇÃO SEGUNDO A AMERICÁN ACADEMY OF PROSTHODONTICS

Table 1. Chacklist for Classification of Complete lidentulism

\begin{tabular}{|c|c|c|c|c|c|c|c|}
\hline$T$ & & & & Class I & Class II & Class III & Class $\mathrm{N}$ \\
\hline \multicolumn{8}{|c|}{ Bone Height-Mandibular } \\
\hline \multicolumn{8}{|c|}{$21 \mathrm{~mm}$ or greater } \\
\hline \multirow{2}{*}{\multicolumn{8}{|c|}{$16-20 \mathrm{~mm}$}} \\
\hline \multicolumn{2}{|c|}{$11-15 \mathrm{~mm}$} & & & & & & \\
\hline \multicolumn{8}{|c|}{$10 \mathrm{~mm}$ or less } \\
\hline \multicolumn{8}{|c|}{ Residyal Ridge Morphology-Maxilla } \\
\hline Type A- & \multicolumn{2}{|c|}{ resists vertical \& horlzonal, hamular } & hotch, no tori & & & & \\
\hline Type 8. & \multirow{2}{*}{\multicolumn{2}{|c|}{ ha buccal vest. poor hamular notch, }} & notori & & & 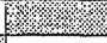 & \\
\hline Type c- & \multirow{2}{*}{\multicolumn{2}{|c|}{ no ant vest, min support, mobile ant. }} & ridge & & & & \\
\hline Type D. & & & & & & & \\
\hline \multicolumn{8}{|c|}{ Muscle Attachments-Mandibular } \\
\hline Type A. & \multirow{2}{*}{\multicolumn{3}{|c|}{$\begin{array}{l}\text { adequate attached mucosa } \\
\text { ho b attach mucosa }(22-27) \text {, +mentalis m }\end{array}$}} & & & & \\
\hline Type B- & & & & & & 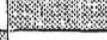 & \\
\hline Type C. & \multicolumn{3}{|c|}{ ho ant b\&: vest $(22-27),+$ genio \& mentalis $m$} & & & & \\
\hline Type 0 . & \multicolumn{3}{|c|}{\begin{tabular}{|l|l} 
att mucosa only in post & \\
\end{tabular}} & & & & \\
\hline Type E- & \multicolumn{3}{|c|}{ ho att mucosa, cheeklip moves tongue } & & & & \\
\hline \multicolumn{8}{|c|}{ Maxlliomandlbular Relationships } \\
\hline \multicolumn{8}{|c|}{\begin{tabular}{|l|l|} 
Class I & \\
\end{tabular}} \\
\hline \multicolumn{8}{|l|}{ Class II } \\
\hline \multicolumn{8}{|c|}{\begin{tabular}{|l|l|l|} 
Class III & \\
\end{tabular}} \\
\hline \multicolumn{8}{|c|}{ Conditions requirrng Preprosthet c Surgery } \\
\hline \multicolumn{8}{|c|}{ Minor soff tissue procedures } \\
\hline \multicolumn{8}{|c|}{ Minor hard tissue procedures } \\
\hline Implants - s & imple $\ldots . . .+$ & & & & & & \\
\hline Implants wi & th bone graft - cd & mplex & & & & & \\
\hline Correction & of dentofacial def & ormities & & & & & \\
\hline Hard tissue & augmentation & & & & & 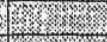 & \\
\hline Major soft t & ssue revislons & & & & & & \\
\hline Lmited Interarch & Space & & & & & & \\
\hline $18-20 \mathrm{~mm}$ & & & & & & & 8 \\
\hline Surgical co & rection needed & & & & & & \\
\hline Tongue Anatomy & & & & & & 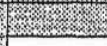 & \\
\hline Large (occl & des interdental s & space) & & & & & \\
\hline Hyperactive & - with retracted $B$ & position & & & & . & \\
\hline Modifiers & & & & & & (x) & \\
\hline Oral manife & stations of systeh & mic disease & & & & & \\
\hline & mild & & & & & (1) & \\
\hline & moderate & & & & & & $6 \%$ \\
\hline & severe & & & & 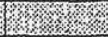 & 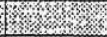 & \\
\hline Psychosoci & & & & 28 & r. & 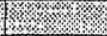 & 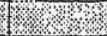 \\
\hline & moderate & & & 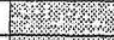 & $\sqrt{1.20}$ & & 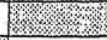 \\
\hline & major & & & & 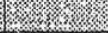 & 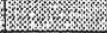 & \\
\hline TMD sympt & oms & & & & 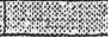 & & 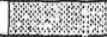 \\
\hline Hx of pares & thesia or dysesthe & esia. & & 18 & $\sqrt{3}$ & 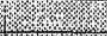 & \\
\hline Maxillofacia & defects & & & 2 & 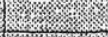 & 1. & \\
\hline Ataxia & & & & 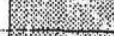 & 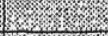 & (. . & \\
\hline Refractony & Satient & & & 18.28 & 10.3 & 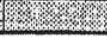 & \\
\hline
\end{tabular}

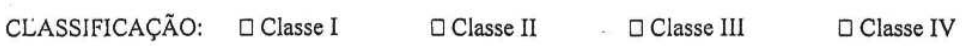

Protocolo de Pesquisa: Método simplificado versus convencional de confecção de próteses totais para aplicação na saúde pública. Responsável: Prof. Dr. Raphael Freitas de Souza 
APÊNDICE E - Questionário HM e EVA para avaliação da Habilidade Mastigatória (modelo utilizado para as avaliações).

Faculdade de Odontologia de Ribeirão Preto - USP

Protocolo de Pesquisa: MÉTODO SIMPLIFICADO VERSUS CONVENCIONAL DE CONFECÇÃO DE PRÓTESES TOTAIS PARA APLICAÇÃO NA SAÚDE PÚBLICA.
Nome do Participante

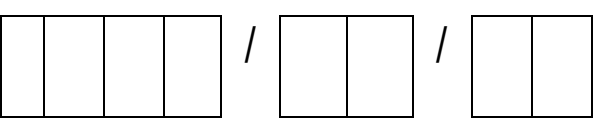

Questionário HM (Borges, 2007; Mendes 2008)

Avaliação da Habilidade Mastigatória (Questionário HM)

Questão 1 - Consegue se alimentar bem com a sua prótese? ( ) $\operatorname{Sim}($ )Não

Questão 2 - Consegue mastigar tudo o que gosta de comer? ( ) $\operatorname{Sim}($ )Não

Questão 3 - Tem alterado a alimentação por causa da prótese? ( ) $\operatorname{Sim}($ )Não

Questão 4 - Consegue comer cenoura crua, amendoim ou carne? ( ) $\operatorname{Sim}($ )Não

Questão 5 - Você tem uma dieta somente macia? ( ) Sim ( )Não

Escala Visual Analógica (EVA) (Awad et al., 2003; Silveira, 2005; Prado et al., 2006; Borges, 2007; Mendes, 2008)

Avaliação da Habilidade Mastigatória (EVA)

Questão 1 - Como você avalia sua capacidade de mastigar os alimentos?

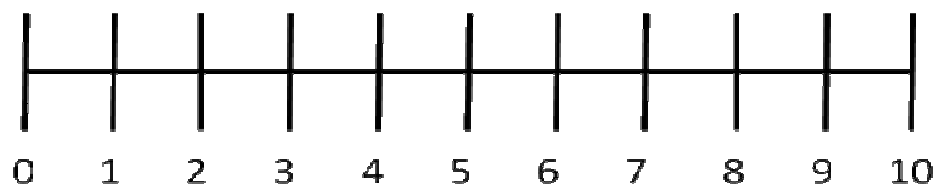

Totalmente

Completamente

Insatisfeito

Satisfeito 